NUREG/CR-6368

SEA 95-554-06-A:9

\title{
Experimental Investigation of Sedimentation of LOCA- Generated Fibrous Debris and Sludge in BWR Suppression Pools
}

Manuscript Completed: November 1995

Date Published: December 1995

Prepared by

F. J. Souto, D. V. Rao

Science and Engineering Associates, Inc.

6100 Uptown Blvd. NE

Albuquerque, NM 87110

M. L. Marshall, Jr., NRC Project Manager

A. W. Serkiz, NRC Project Manager

Prepared for

Division of Engineering Technology

Office of Nuclear Regulatory Research

U.S. Nuclear Regulatory Commission

Washington, DC 20555-0001

NRC Job Code W6459 



\section{DISCLAIMIER}

Portions of this document may be illegible in electronic image products. Images are produced from the best available original document. 


\begin{abstract}
Several tests were conducted in a 1:2.4 scale model of a Mark I suppression pool to investigate the behavior of fibrous insulation and sludge debris under LOCA conditions. NUKON ${ }^{\mathrm{TM}}$ shreds, manually cut and tore up in a leaf shredder, and iron oxide particles were used to simulate fibrous and sludge debris, respectively. The suppression pool model included four downcomers fitted with pistons to simulate the steam-water oscillations during chugging expected during a LOCA. The study was conducted to provide debris settling velocity data for the models used in the BLOCKAGE computer code, developed to estimate the ECCS pump head loss due to clogging of the strainers with LOCA generated debris. The tests showed that the debris, both fibrous and particulate, remains fully mixed during chugging; they also showed that, during chugging, the fibrous debris underwent fragmentation into smaller sizes, including individual fibers. Measured concentrations showed that fibrous debris settled slower than the sludge, and that the settling behavior of each material is independent of the presence of the other material. Finally, these tests showed that the assumption of considering uniform debris concentration during strainer calculations is reasonable. The tests did not consider the effects of the operation of the ECCS on the transport of debris in the suppression pool.
\end{abstract}



Page

Abstract $\ldots \ldots \ldots \ldots \ldots \ldots \ldots \ldots \ldots \ldots \ldots \ldots \ldots \ldots \ldots \ldots \ldots \ldots \ldots \ldots \ldots \ldots \ldots \ldots$ iii

Acknowledgements $\ldots \ldots \ldots \ldots \ldots \ldots \ldots \ldots \ldots \ldots \ldots \ldots \ldots \ldots \ldots \ldots \ldots \ldots \ldots \ldots \ldots \ldots$ viii

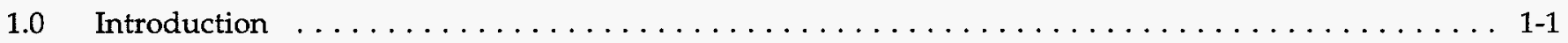

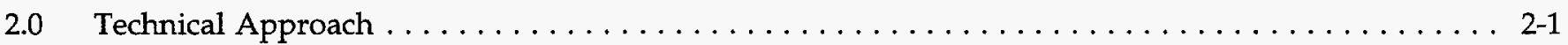

2.1 Suppression Pool Phenomena During a LOCA $\ldots \ldots \ldots \ldots \ldots \ldots \ldots \ldots \ldots \ldots \ldots \ldots . \ldots \ldots$

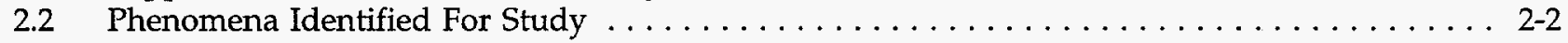

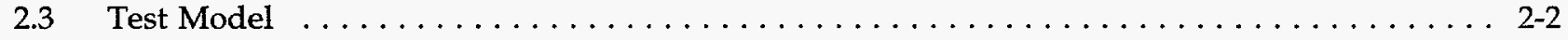

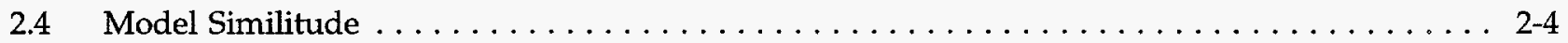

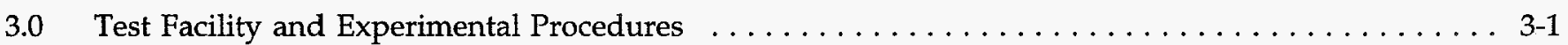

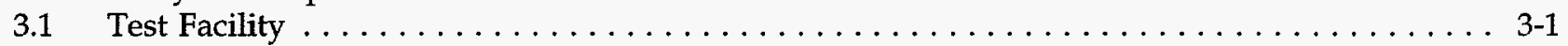

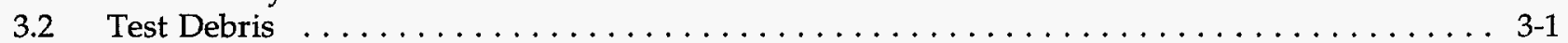

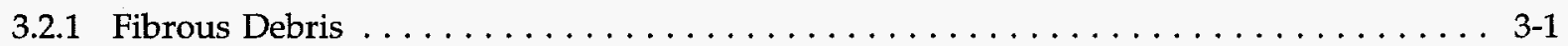

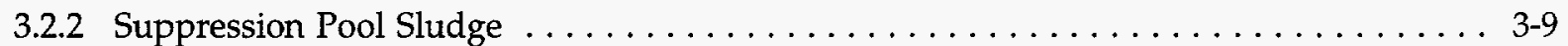

3.3 Exploratory Tests . . . . . . . . . . . . . . . . . . . . . . . . . $3-14$

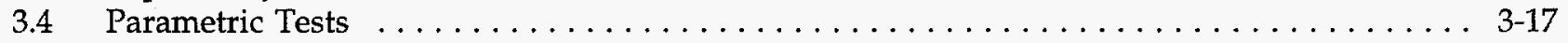

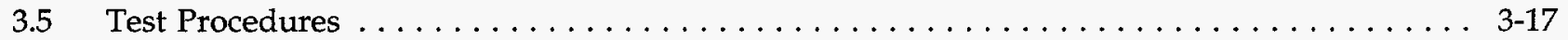

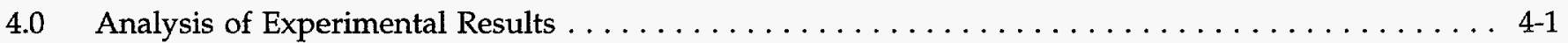

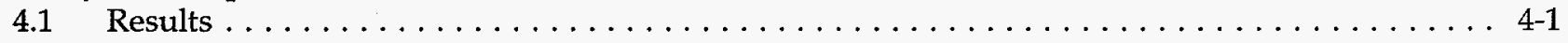

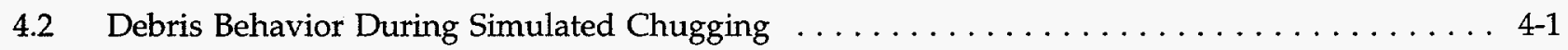

4.3 Settling After Simulated Chugging $\ldots \ldots \ldots \ldots \ldots \ldots \ldots \ldots \ldots \ldots \ldots \ldots \ldots \ldots \ldots$

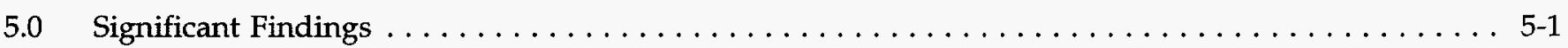

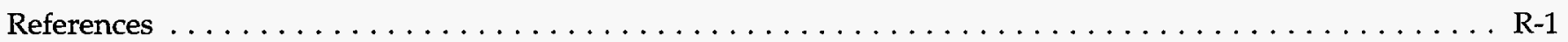

Appendix A $\quad$ BWR Pool Simulated Chugging Tests Step By Step Test Procedures $\ldots \ldots \ldots \ldots$ A-i

Appendix B $\quad$ Raw Data for the Concentration Measurements $\ldots \ldots \ldots \ldots \ldots \ldots \ldots \ldots \ldots \ldots$ B-i 



\section{List of Tables}

Page

3-1. BWROG-Provided Size Distribution of the Suppression Pool Sludge $\ldots \ldots \ldots \ldots \ldots \ldots \ldots \ldots$. . . . . .

3-2. Iron Oxide Particles Supplied by Hansen Engineering, Inc. . . . . . . . . . . . . . . . . . 3-14

3-3. Sludge A Particle Size Distribution According to Manufacturer's Specifications . . . . . . . . . . . . 3-14

3-4. Sludge A Particle Size Distribution. Sedimentation Velocity Analysis with Surfactant. . . . . . . . . 3-15

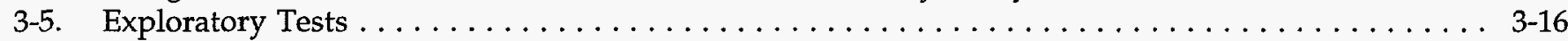

3-6. Parametric Tests . . . . . . . . . . . . . . . . . . . . . . . . . . . . . 3-18

\section{List of Figures}

2-1. Typical Downcomer Interface Oscillations Due to Chugging (Obtained from

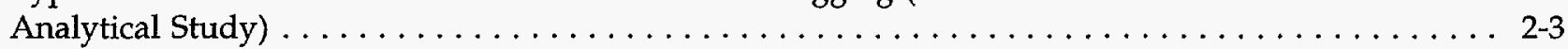

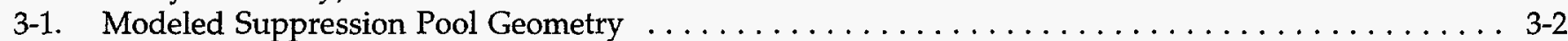

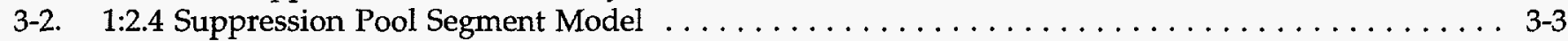

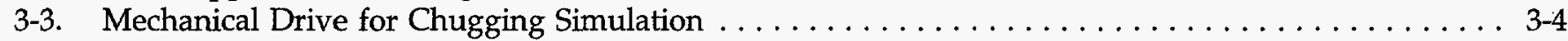

3-4. Mechanical Drive in Suppression Pool Tests $[3] \ldots \ldots \ldots \ldots \ldots \ldots \ldots \ldots \ldots \ldots \ldots \ldots \ldots \ldots . \ldots \ldots$

3-5. Scaled Downcomer Interface Oscillations for the Model Study $\ldots \ldots \ldots \ldots \ldots \ldots \ldots \ldots \ldots . . \ldots$

3-6. Comparison of Desired and Model Generated Interface Oscillations for Case 3

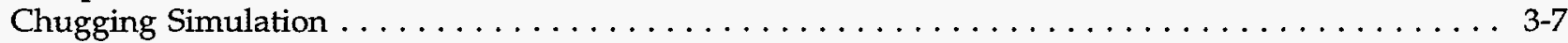

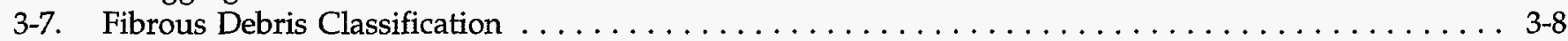

3-8. Representative Sample of Shredded NUKONTM Fibrous Debris . . . . . . . . . . . . . . . 3-10

3-9. Representative Sample of Shredded NUKON ${ }^{\mathrm{TM}}$ Fibrous Debris $\ldots \ldots \ldots \ldots \ldots \ldots \ldots \ldots \ldots \ldots$. . . . . . .

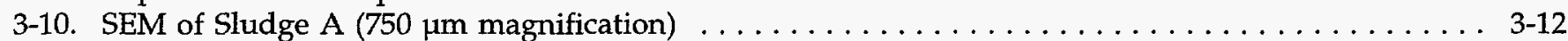

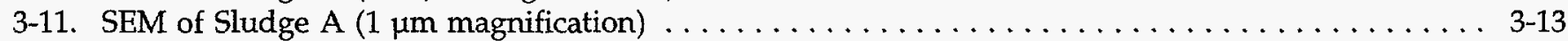

3-12. Sampling Apparatus for Debris Concentration Measurements . . . . . . . . . . . . . . . . 3-19

4-1. Debris Settling in Suppression Pool; Test A-1R1: $3.8 \mathrm{ft}$ amplitude; $1.6 \mathrm{Sec}$ Period

(Case 3) NUKONTM: $0.0032 \%$. Class $3 \& 4$. Sludge A: $0.0 \% \ldots \ldots \ldots \ldots \ldots \ldots \ldots \ldots \ldots . \ldots \ldots$

4-2. Debris Settling in Suppression Pool; Test A-2 R1: 3.8 Ft Amplitude, 1.6 Sec Period

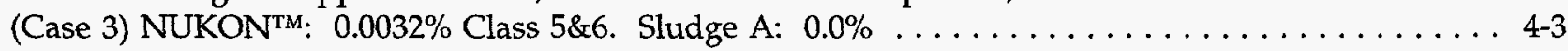

4-3. Debris Settling in Suppression Pool; Test A-3R1: $3.8 \mathrm{ft}$ amplitude; $1.6 \mathrm{Sec}$ Period

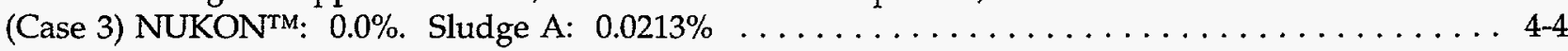

4-4. Debris Settling in Suppression Pool; Test A-4 R1: 3.8 Ft Amplitude, 1.6 Sec Period

(Case 3) NUKON ${ }^{\mathrm{TM}}$ : $0.0032 \%$ Class $5 \& 6$. Sludge A: $0.0213 \% \ldots \ldots \ldots \ldots \ldots \ldots \ldots \ldots \ldots$

4-5. Debris Settling in Suppression Pool; Test A-5: $3.8 \mathrm{ft}$ amplitude, $1.6 \mathrm{Sec}$ Périod

(Case 3) NUKON"M: $0.0032 \%$. Class $3 \& 4$. Sludge A: $0.0213 \% \ldots \ldots \ldots \ldots \ldots \ldots \ldots$

4-6. Debris Settling in Suppression Pool; Test B-6: 3.8 Ft Amplitude, 1.6 Sec Period

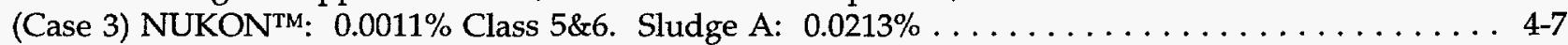

4-7. Debris Settling in Suppression Pool; Test B-7: 3.8 Ft Amplitude, 1.6 Sec Period

(Case 3) NUKON' ${ }^{\mathrm{TM}}$ : $0.0011 \%$ Class $3 \& 4$. Sludge A: $0.0213 \% \ldots \ldots \ldots \ldots \ldots \ldots \ldots$

4-8. Debris Settling in Suppression Pool; Test B-9: 3.8 Ft Amplitude, 1.6 Sec Period

(Case 3) NUKON ${ }^{\mathrm{TM}}$ : $0.0 \%$. Sludge A: $0.0638 \% \ldots \ldots \ldots \ldots \ldots \ldots \ldots \ldots \ldots \ldots \ldots$

4-9. Debris Settling in Suppression Pool; Test D-11 R1: 5.0 Ft Amplitude, 1.9 Sec Period

(Case 2) NUKON' ${ }^{\mathrm{Tm}}$ : $0.0032 \%$ Class $3 \& 4$. Sludge A: $0.0 \% \ldots \ldots \ldots \ldots \ldots \ldots \ldots \ldots \ldots$

4-10. Debris Settling in Suppression Pool; Test D-14 R1: 5.0 Ft Amplitude, 1.9 Sec Period

(Case 2) NUKONTM: $0.0032 \%$ Class $5 \& 6$. Sludge $A: 0.0213 \% \ldots \ldots \ldots \ldots \ldots \ldots \ldots \ldots \ldots$

4-11. Debris Settling in Suppression Pool; Test T-17: 3.8 Ft Amplitude, 1.6 Sec Period

(Case 3) NUKONTM: $0.0032 \%$ Class $3 \& 4$. Sludge A: $0.0032 \% \ldots \ldots \ldots \ldots \ldots \ldots \ldots \ldots \ldots$

4-12. Debris Settling in Suppression Pool; Test T-18: 3.8 Ft Amplitude, $1.6 \mathrm{Sec}$ Period

(Case 3) NUKON ${ }^{\mathrm{TM}}$ : $0.0032 \%$ Class $3 \& 4$. Sludge A: $0.0016 \% \ldots \ldots \ldots \ldots \ldots \ldots \ldots \ldots \ldots$

4-13. Settling Velocity Distribution for Classes 3\&4 and 5\&6 Shreds After Being Subjected

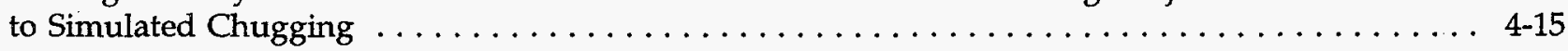

4-14. Settling Velocities for Various Sludge and Fiber Mixtures Predicting Using the

Principle of Superposition (Assumes Independent Behavior) $\ldots \ldots \ldots \ldots \ldots \ldots \ldots \ldots \ldots \ldots \ldots$

4-15. Particle Size Distribution Curve for Sludge $A \ldots \ldots \ldots \ldots \ldots \ldots \ldots \ldots \ldots \ldots \ldots \ldots \ldots \ldots \ldots$ 


\section{Acknowledgements}

Several individuals made significant contributions to this study. This study could not have been completed without the technical and management support of the U.S. Nuclear Regulatory Commission. Michael Marshall (RES) was the NRC Task Manager for this effort. He provided critical technical direction, actively participated in all of the experiments, and performed an in-depth review of the technical basis for this study. Aleck Serkiz (RES) provided significant technical insights and review of the experimental and analytical work.

Alan Johnson, Mahadevan Padmanabhan, and George Hecker of Alden Research Laboratory, Inc. (ARL) were instrumental in designing the experimental apparatus, defining the experiments, and conducting the experiments described and analyzed in this report. Their work is documented in the ARL report, "NUKON Insulation and Sludge Settling Following a LOCA in a BWR Suppression Pool," Alden Research Laboratory, Inc., May 1995.

From SEA, Gilbert Zigler was the Project Manager for this task, providing technical direction for the study. Together with Jane Brideau, he also performed a technical and editorial peer review of the report. Debbie Rettig was responsible for the typing and layout of the final document.

Other organizations whose efforts contributed to this study include the BWR Owners' Group ECCS Suction Strainer Committee and the University of New Mexico. Rocky Sgarro was the chairman of the BWROG ECCS Suction Strainer Committee, which provided estimates of the size distribution of the sludge particles present in BWR suppression pools. Toivo Kodas of the University of New Mexico performed the sludge simulant size analysis using a scanning electron microscope. 


\subsection{Introduction}

This report describes a set of experiments to investigate the transport properties of the debris materials expected to be in the suppression pool during Loss of Coolant Accidents (LOCA) in Boiling Water Reactors (BWR). The experiments were conducted at the Alden Research Laboratory, Inc. (ARL) under subcontract to Science and Engineering Associates, Inc. (SEA) on behalf of the Nuclear Regulatory Commission (NRC). These experiments are hereinafter referred to as the NRC experiments.

This study was motivated by the need to obtain experimental data to validate some of the key assumptions in the suppression pool transport models used in the BLOCKAGE computer code, developed to estimate the Emergency Core Cooling System (ECCS) pump head loss due to clogging of the suction strainers with LOCA generated debris [1]. In the development of these models, initially it was conservatively assumed that all the debris reaching the suppression pool would remain suspended and would ultimately be transported to the ECCS pump suction strainers. Subsequently, a transient model was developed considering: (1) the amount and size of the debris introduced to the suppression pool, (2) the gravitational sedimentation of the debris in the suppression pool during and after the high-energy phase of a LOCA, (3) the resuspension of the debris contained on the suppression pool floor, and (4) the ECCS flow rate. While developing this transient model, it was recognized that experimental data was required to address these issues. The underlying processes associated with the debris transport phenomena in the suppression pool following a LOCA are, however, too complex to be addressed by a single set of experiments; consequently, several scoping analyses were conducted with a previous version of BLOCKAGE to identify the most important factors influencing the model predictions. Based on these scoping calculations, the set of experiments described in this report were proposed to obtain information in the following specific areas:
- Resuspension of debris contained at the bottom of the suppression pool during the high-energy phase of a LOCA.

- $\quad$ Mixing and fragmentation of fibrous debris when subjected to high levéls of turbulence during the high-energy phase of a LOCA.

- Sedimentation characteristics of fibrous and particulate debris during and after the highenergy phase of a LOCA.

The debris generated by a LOCA in a BWR is highly plant specific, including fibrous or metallic thermal insulation of the pipes in the drywell. Similarly, the suppression pool layouts vary from small torus shaped Mark I to Mark III. Therefore, it was decided to limit the scope of the experiments to study the transport of LOCA generated debris in a reference BWR-4 with a Mark I containment, NUKONTM thermal insulation, and suppression pool sludge particles.

A 1:2.4 scale model of a Mark I suppression pool segment with NUKON ${ }^{\mathrm{TM}}$ fibrous debris and ironoxide particles was used to conduct experiments addressing the above areas; the contribution of the ECCS recirculation flow to the transport of debris materials in the suppression pool, however, was not investigated as part of this set of experiments.

This report is structured as follows. Chapter 2 presents a description of the progression of events in a LOCA, emphasizing their effects on the debris transport in the suppression pool, as well as the test model used in this study to simulate these phenomena. The description of the test facility, the debris materials, and the experimental procedures used in these tests are presented in chapter 3. Chapter 4 presents the results and the corresponding analysis; finally, chapter 5 contains the significant findings from this study. 


\subsection{Technical Approach}

In the event of a LOCA due to a pipe break within the containment of a BWR, piping thermal insulation and other materials in the vicinity of the break will be dislodged due to the jet forces caused by the mixture of steam and water ejected from the break. A fraction of this dislodged insulation and some other materials, like paint chips and concrete dust, will be transported to the suppression pool by the steam and water flow discharged from the break. Some of this debris, together with some other particulate materials that may be present in the suppression pool before the LOCA, will eventually be transported and accumulated on the suction strainers of the ECCS pumps, increasing the differential pressure, or head loss, across them. In some cases, this accumulation of debris leads to head losses that can cause the pumps to fail. In the assessment of the potential BWR ECCS strainer blockage due to LOCA generated debris, understanding of the transport phenomena in the suppression pool is a key issue. The following section provides a description of these phenomena in a BWR with a Mark-I containment system.

\subsection{Suppression Pool Phenomena During a LOCA}

Following a pipe break LOCA, the pressure and temperature of the drywell atmosphere increase rapidly. This increase in drywell pressure accelerates the water initially present in the downcomers into the suppression pool. This ventclearing process generates a water jet capable of causing turbulent mixing of the suppression pool water. Immediately after the vent-clearing process, non-condensible gases from the inert drywell atmosphere are discharged into the suppression pool through the downcomers, resulting in swelling of the suppression pool. During this initial phase of the accident, the suppression pool flow fields are dominated by large scale turbulence, leading to resuspension of the particulate materials previously contained on the suppression pool floor.

Eventually, the vent downcomer flow will consist primarily of steam and, as the flow of steam continues, pressure oscillations occur in the suppression pool. Experimental data suggest that these oscillations can be divided into two categories: "condensation oscillations", which occur at relatively high vent flow rates and are characterized by continuous oscillations, and "chugging", which occurs at lower steam flow rates and is characterized by a series of pulses, typically a second or more apart.

Chugging occurs when, as a result of reductions in the steam flow, water enters the downcomers and causes steam condensation in the downcomers. During this process, the non-condensible gases form a thin layer that prevents heat transfer between steam and water. This results in a build-up of pressure behind the condensation front, causing the front to move closer to the vent pipe exit, where the non-condensible gases could be vented from the pipe. This mechanism of steam condensation results in a situation where the condensation front (or the water front) moves upwards and downwards in the downcomers, in a cycling process that continues until the drywell and wetwell pressures equalize.

The downcomer water level oscillations during chugging result in addition of kinetic energy to the suppression pool, generating turbulent flow fields. This phase of an accident, commonly referred to as the high-energy phase, typically lasts from a few minutes to up to half an hour depending on the break size, downcomer geometry, and suppression pool temperature. The kinetic energy imparted to the pool during the high-energy phase generates turbulent flow fields which in turn may influence the suppression pool transport. In particular, the turbulence may (1) disintegrate fibrous debris into smaller classes, (2) impede settling resulting in mixed suppression pool conditions, and (3) resuspend the debris that is located at the bottom of the suppression pool.

The ECCS will inject water into the reactor vessel, flooding the core, and ultimately cascading into the drywell through the break. Since the drywell is full of steam at the time of vessel flooding, cascading water from the break causes condensation and rapid decrease in drywell pressure. At this stage, the vacuum breaker valves open to allow the noncondensible gases in the suppression pool to flow back into the drywell, leading to the equalization of drywell and wetwell pressures. Thereafter, vapor flow to the suppression pool will be reduced and the turbulence levels will decay, allowing sedimentation of debris. 
In the final stage of the accident, BWRs rely on long-term ECCS cooling for the reactor and containment sprays to control drywell pressure and temperature, and suppression pool cooling for ultimate heat removal from the containment. The actuation of the suppression pool cooling features will result in recirculation flow patterns in the suppression pool, which may affect debris sedimentation; also, if pool recirculation is sufficiently large, resuspension of a fraction of the sediment at the bottom of the suppression pool may occur.

\subsection{Phenomena Identified For Study}

The condensation oscillations in the suppression pool are expected to occur in a large LOCA during a relatively short period of time (about $30 \mathrm{~s}$ ), followed by chugging for the remainder of the blowdown phase. For a medium LOCA, condensation oscillations are very unlikely and intense to moderate chugging is more common. Depending on the break size, chugging may last up to 20 minutes in the case of a medium LOCA. The potential for debris sedimentation is minimal during condensation oscillations due to shorter duration, whereas some settling may occur during chugging. Based on these considerations, it was decided to study the behavior of debris in the suppression pool only during chugging.

The transport of debris in the suppression pool due to the operation of the ECCS after the high-energy. phase of a LOCA is an important issue that has to be addressed. However, the study of this phenomena was not considered as part of the present set of experiments.

The following section describes the test model used in this set of experiments to simulate the behavior of fibrous debris and particulate matter in the suppression pool during and after chugging.

\subsection{Test Model}

In this model it is assumed that mixing of the debris in the suppression pool during chugging is caused only by the addition of kinetic energy from the water that moves into and out of the downcomers. Pressure changes in the drywell due to the addition and sudden condensation of steam provide the only driving force for the water motion. This assumption is based on the inference that temperature gradients do not contribute significantly to internal flow or turbulence in the suppression pool.

The Mark-I full scale test facility (FSTF) tests [2] provided some information that can be used to quantify the kinetic energy of interest. In particular, these tests provided pool wall pressure data during chugging following a medium break size LOCA. Test data indicated a total chugging duration of about 4 to 5 minutes. Two types of chugging were observed: Type 1, with synchronized oscillations of neighboring downcomers; and Type 2 , with relatively unsynchronized oscillations. Since Type-1 is more representative of a medium LOCA, only this type of chugging is considered in this study.

Three cases of Type 1 chugging were identified from the FSTF data; each case represented different amounts of kinetic energy corresponding to initial, middle, and later stages of chugging. The highest kinetic energy occurred initially, when the rate of energy released from the steam pipe was the greatest.

In this study, the amount of kinetic energy imparted to the suppression pool was computed by an analytic simulation of the suppression pool coupled to the drywell. This analytic model, described in Appendix A of Reference 3, used the pool wall pressure amplitudes from the FSTF data to calculate the period and amplitude of the steam-water interface in the downcomers, and hence, the kinetic energy imparted to the pool. The resulting period and amplitude for each of the three Type 1 chugging cases are:

Case 1: $\quad 2.4$ seconds, 8.0 feet (high energy, corresponding to the initial stage of a LOCA)

Case 2: $\quad 1.9$ seconds, 5.0 feet (medium energy, corresponding to the middle stage of a LOCA)

Case 3: $\quad 1.6$ seconds, 3.8 feet (low energy, corresponding to the final stage of a LOCA)

The steam-water interface oscillations as a function of time for the three chugging cases, obtained from the analytical study, are shown in Figure 2-1. 
Technical Approach
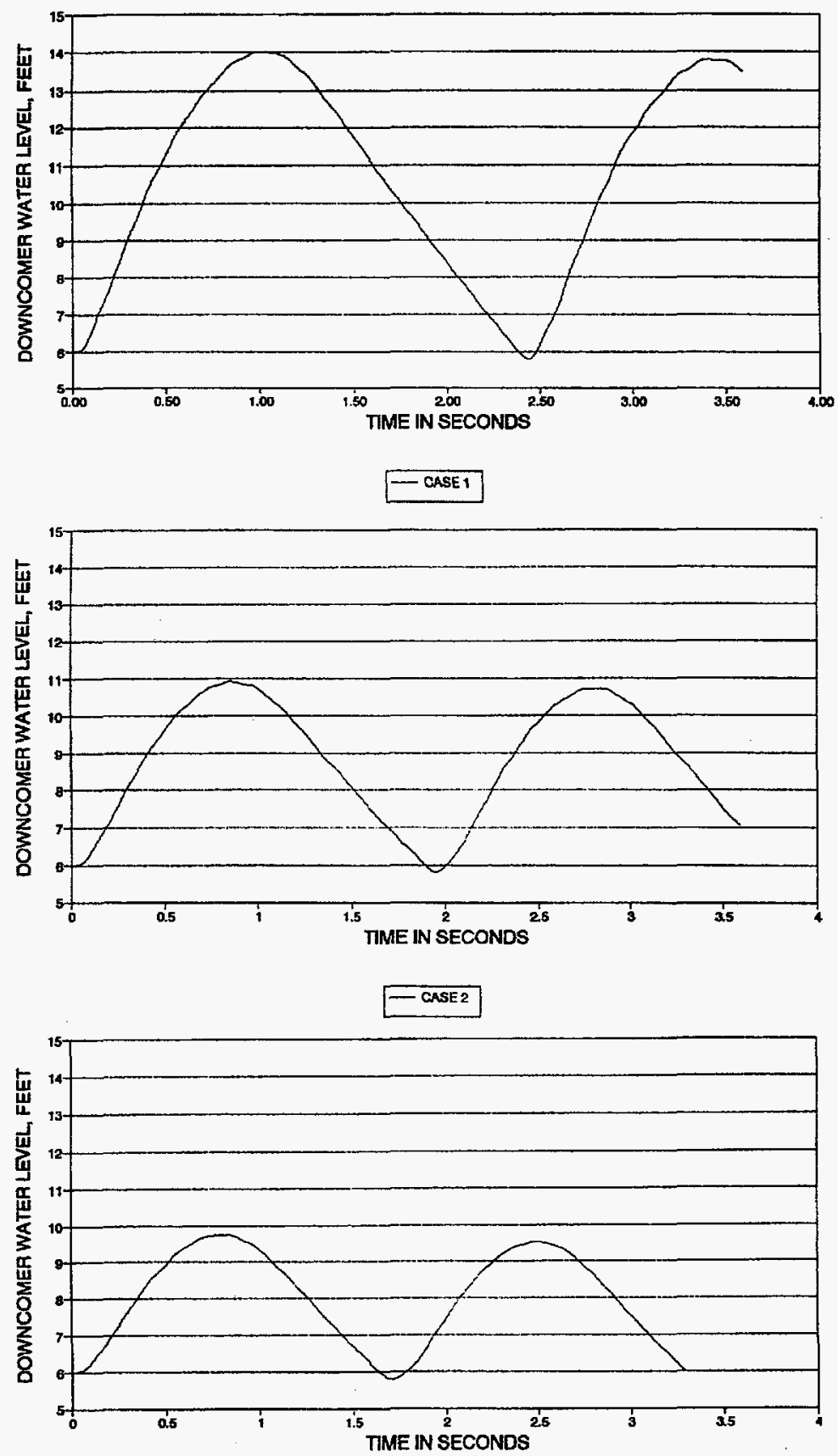

CASE3

Figure 2-1. Typical Downcomer Interface Oscillations Due to Chugging (Obtained from Analytical Study) 


\subsection{Model Similitude}

Since the experiments used the actual size debris, similitude requires that a) the kinetic energy per unit volume in the test facility be the same as in an actual BWR Mark-I suppression pool, and b) that the mode of turbulence generation in both cases be the same. Practical considerations limited the test facility geometrical scale to be 1:2.4 of the actual BWR Mark-I downcomer and suppression pool geometry. This required scaling the water surface amplitude and period in the model downcomers in such a way as to produce the same kinetic energy per unit pool volume in the test facility as in the actual case. The basis for this scaling is presented in the following discussion.

The kinetic energy per unit volume, $E$, is given by

$$
E=\rho \frac{V^{2}}{2}
$$

where $\rho$ is the density of water and $V$ is a characteristic velocity, such as the interface velocity in the downcomer.

Similitude requires equal $\mathrm{E}$ in the model and the actual case, that is

$$
\rho_{m} V_{m}^{2}=\rho_{a} V_{a}^{2}
$$

or

$$
\frac{V_{m}}{V_{a}}=\sqrt{\rho_{a} / \rho_{m}}
$$

In the above equations, the subscripts $m$ and $a$ refer to the model and actual case, respectively. Since water in the model and the actual case have about the same density (within about $1 \%$ ),

$$
V_{m}=V_{a}
$$

The time scale can be determined from the geometric scale and velocity scale. The time for a particle of water leaving the downcomer to reach the pool floor would be the distance to the pool floor divided by the average velocity. Since the distance is scaled to the geometric scale, the time scale would be equal to the geometric scale, the velocity scale being equal to 1 .

$$
\frac{T_{m}}{T_{a}}=\frac{L_{m} V_{a}}{V_{m} L_{a}}=\frac{L_{m}}{L_{a}}
$$

With the time scale and velocity scale known, and assuming a sinusoidal motion of water in the downcomer, it can be shown that the amplitudes of oscillation would scale to the geometric scale. This means that both the period and amplitude of downcomer oscillations should be scaled to the geometric scale.

Based on this model, it was concluded that the similitude criterion is met if the simulated chugging period and amplitude in the test facility are reduced by a factor of 2.4 with respect to the actual case values.

The proposed test model may introduce two types of scale effects: decay of turbulence and surface waves.

Because turbulence decay is inversely proportional to the eddy size, turbulence in the model decays somewhat quicker than in the actual case. Also, the model segment boundaries, which do not exist in the actual case, cause a quicker decay of turbulence. Although the actual case has structures inside the pool which augment turbulence decay, it was decided not to include scaled structures in the model to compensate for the otherwise quicker turbulence decay.

Surface waves generated in the model cannot be scaled, as surface waves, being gravity dominated, require Froude scaling. Their effects are considered secondary, because they do not add energy to the pool. However, if a surface wave resonant condition existed, then the mixing energy could be significant. By performing simulated chugging tests based on Froude similitude, it was confirmed that surface wave resonance does not occur in the actual case, nor did it occur during the tests described herein. 


\subsection{Test Facility and Experimental Procedures}

\subsection{Test Facility}

A 1:2.4 geometric scale simulation of a segment of a Mark I BWR suppression pool, based on the FSTF program, was constructed with a curved painted steel bottom and two plexiglas side walls for viewing. Figure 3-1 shows the model geometry, while a model photograph is included in Figure 3-2. Four downcomers, each $10^{\prime \prime}(0.25 \mathrm{~m})$ in diameter, were modeled at the appropriate locations in the tank with scaled spacing and floor clearance. The front and back walls were spaced one half the distance to the next pair of downcomers in either direction. Hence, the water volume per downcomer of the tank was scaled to the volume per downcomer of a typical BWR Mark I suppression pool. Three of the downcomers were aluminum pipes, while the fourth one was a plexiglas pipe to allow visualization of insulation debris movement inside the downcomer during chugging simulation.

The downcomer water-steam interface oscillations were simulated in the model by plungers, mechanically moved to the scaled frequency, amplitude, and position versus time. Figure 3-3 shows the mechanical drive arrangement, and Figure 3-4 is a photograph of the mechanism. All plungers oscillated in phase, which simulated Type 1 chugging as identified in the FSTF tests. The plunger movement was accomplished by a crank disc rotated at the required rpm using a $50 \mathrm{HP}$ ( 37 $\mathrm{KW}$ ) electric motor and speed controller, generating the required plunger motion versus time through a cam arrangement. The position of the cam-follower pin determined the motion and maximum amplitude, while the variable speed drive powering the motor determined the frequency. Based on model similitude relations, the downcomer water interface (plunger) amplitudes for the case selected from Figure 2-1 were scaled to the geometric scale of $1: 2.4$, and the periods or simulated chugging intervals were also scaled to 1:2.4.

Figure 3-5 shows the three cases of scaled downcomer interface oscillations obtained by scaling the corresponding three cases shown in Figure 2-1; Figure $3-6$ is a comparison of the desired interface motion and the corresponding velocities for Case 3 , determined from the analytical model, versus the actual motion from the physical mechanism. The agreement is sufficient for the purposes of this study.

\subsection{Test Debris}

These experiments considered two types of LOCA generated debris: fibrous and particulate materials. In particular, NUKON ${ }^{\mathrm{TM}}$ thermal insulation blankets were used to generate the fibrous debris, whereas iron oxides particles were used to simulate some of the particulate matter commonly found in BWR's suppression pools; these iron oxide particles are hereafter referred to as "sludge". Debris size is known to influence the sedimentation rates; hence, considerable attention was given to the following areas: 1) identification of representative size distributions of the debris likely to reach the suppression pool following a LOCA; 2) acquisition and generation of test debris that closely resemble those identified debris sizes and shapes; 3 ) implementation of proper controls on debris production for use in the experiments; and 4) characterization of the debris that were used in the tests. This debris characterization was accomplished using scanning electron microscope and sedimentation velocity (sedigraph) analysis [4].

\subsubsection{Fibrous Debris}

In the case of steel-jacketed NUKON ${ }^{\mathrm{TM}}$ thermal insulation, the LOCA generated debris is expected to vary in shape from fines to partially fragmented blankets; Figure 3-7 presents the classification of the fibrous debris that are expected during a LOCA [5]. Various analyses, however, suggested that classes 3 , 4 and 5 are more likely to be transported to the suppression pool; in addition, experiments suggest that very small quantities of fibrous debris classes 1 and 2, namely individual fibers of various lengths, would be produced in a LOCA for steel-jacketed NUKON ${ }^{\mathrm{TM}}$ insulation. Based on these considerations, it was judged that the more likely fibrous debris reaching the suppression pool in a typical BWR plant would closely resemble classes $3 \& 4$ and $5 \& 6$.

The NUKON ${ }^{\mathrm{TM}}$ thermal insulation blankets, artificially aged by heating in ovens in accordance with ASTM procedures, were provided by Performance Contracting, Inc. (PCI). The method selected to generate the desired fibrous debris 
Test Facility and Experimental Procedures

Top View

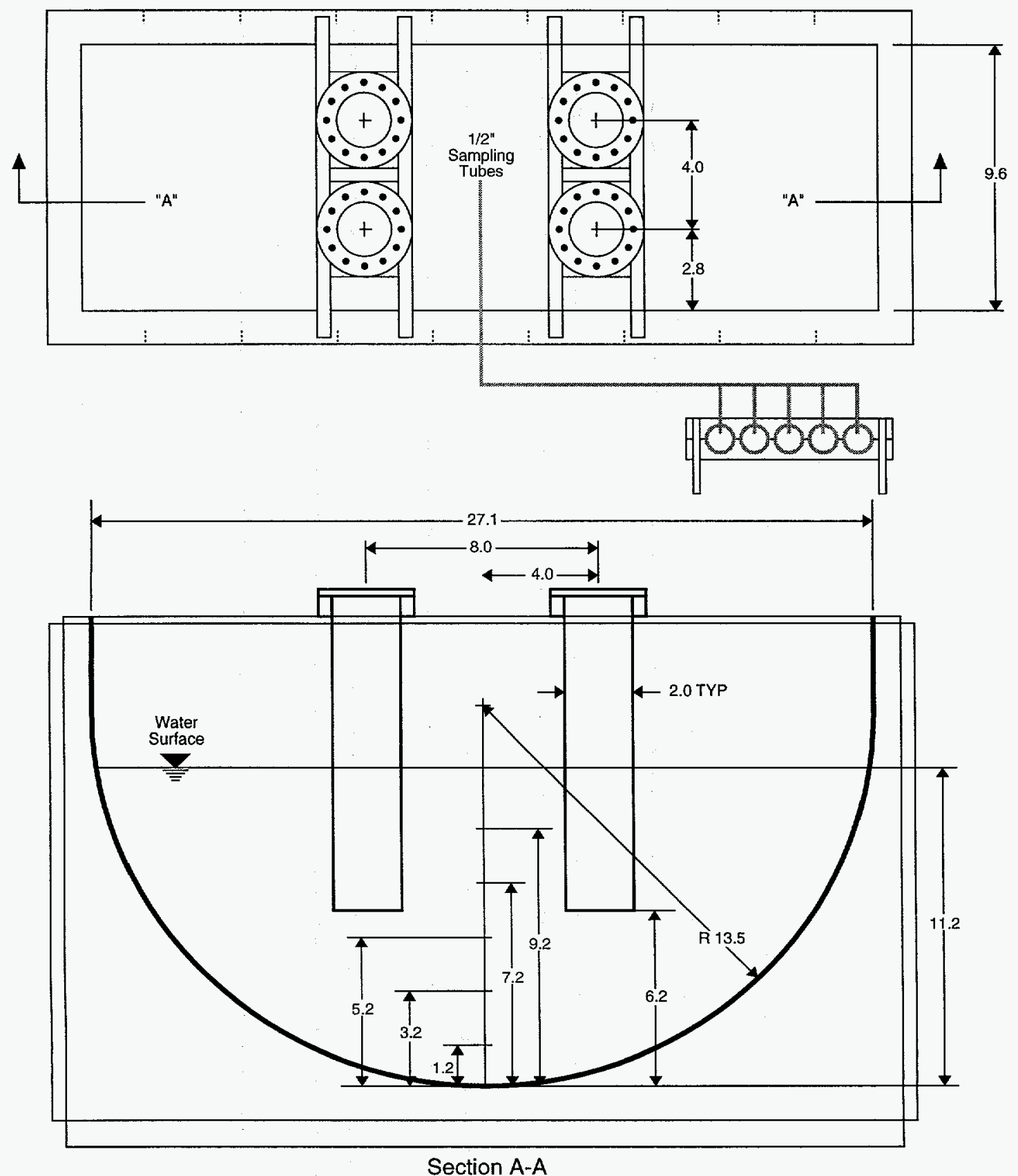

Note: All pool dimensions in feet (actual Mark / suppression pool)

Figure 3-1. Modeled Suppression Pool Geometry [3] 
Test Facility and Experimental Procedures

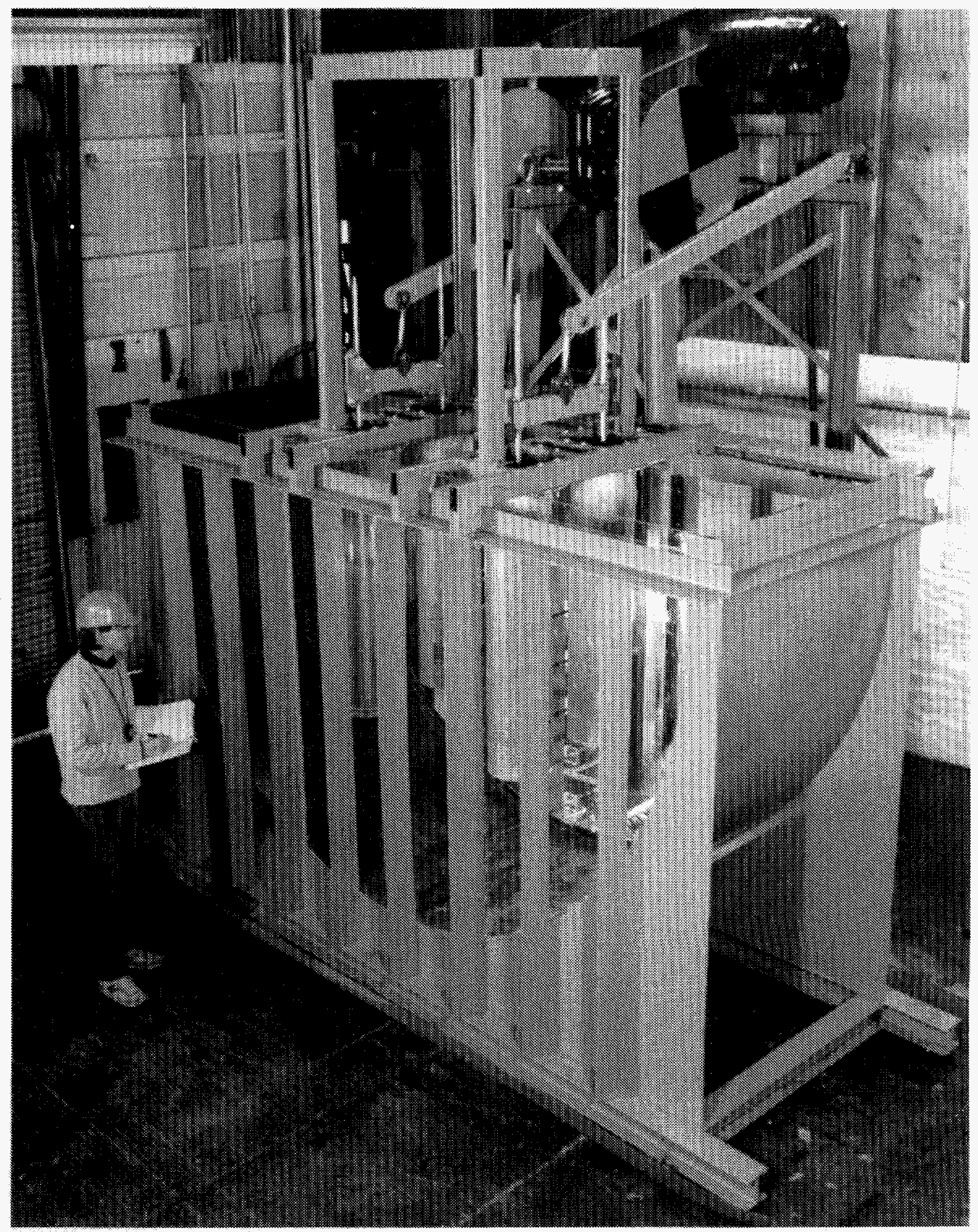

Figure 3-2. 1:2.4 Suppression Pool Segment Model [3] 
Test Facility and Experimental Procedures

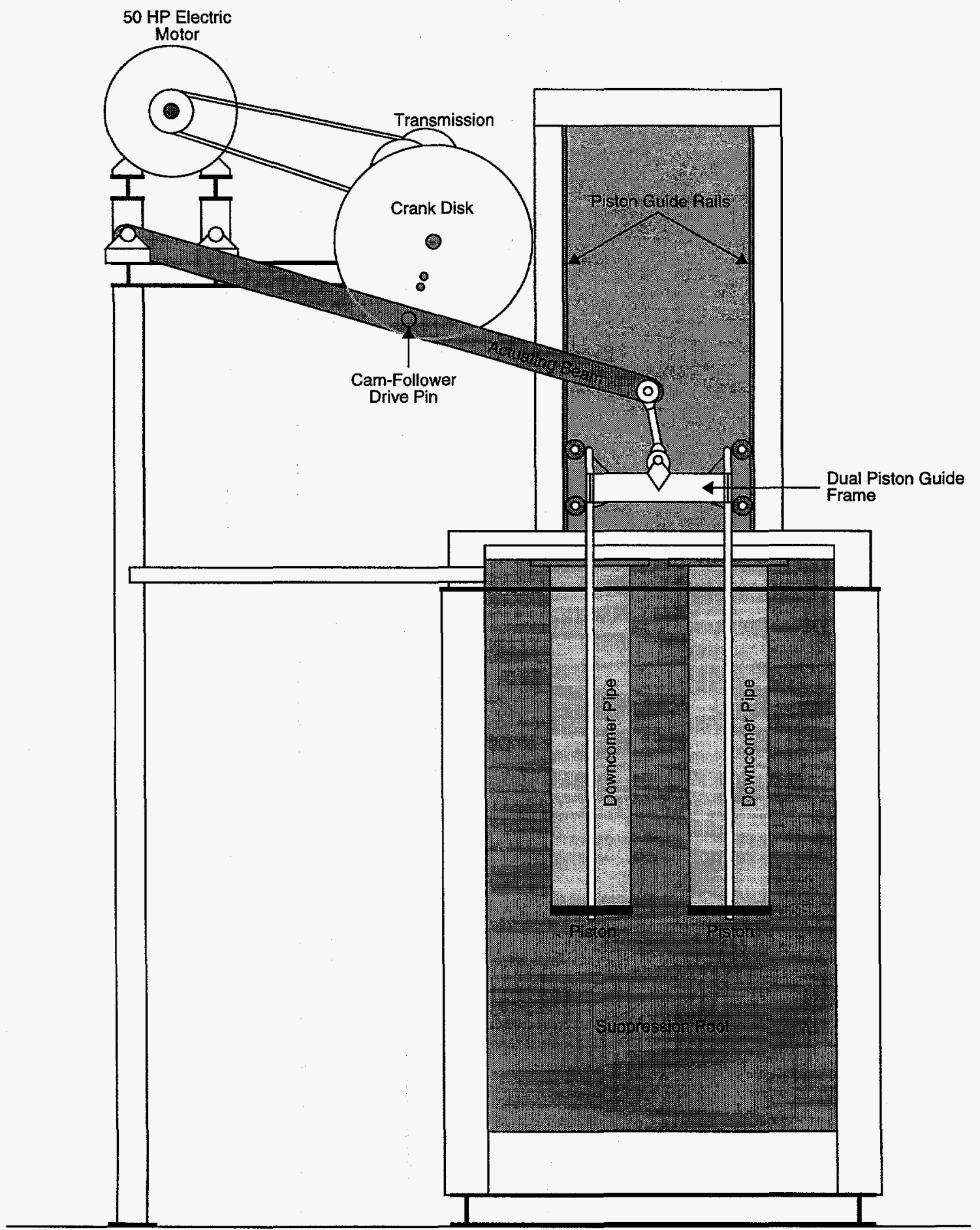

Figure 3-3. Mechanical Drive for Chugging Simulation [3] 
Test Facility and Experimental Procedures

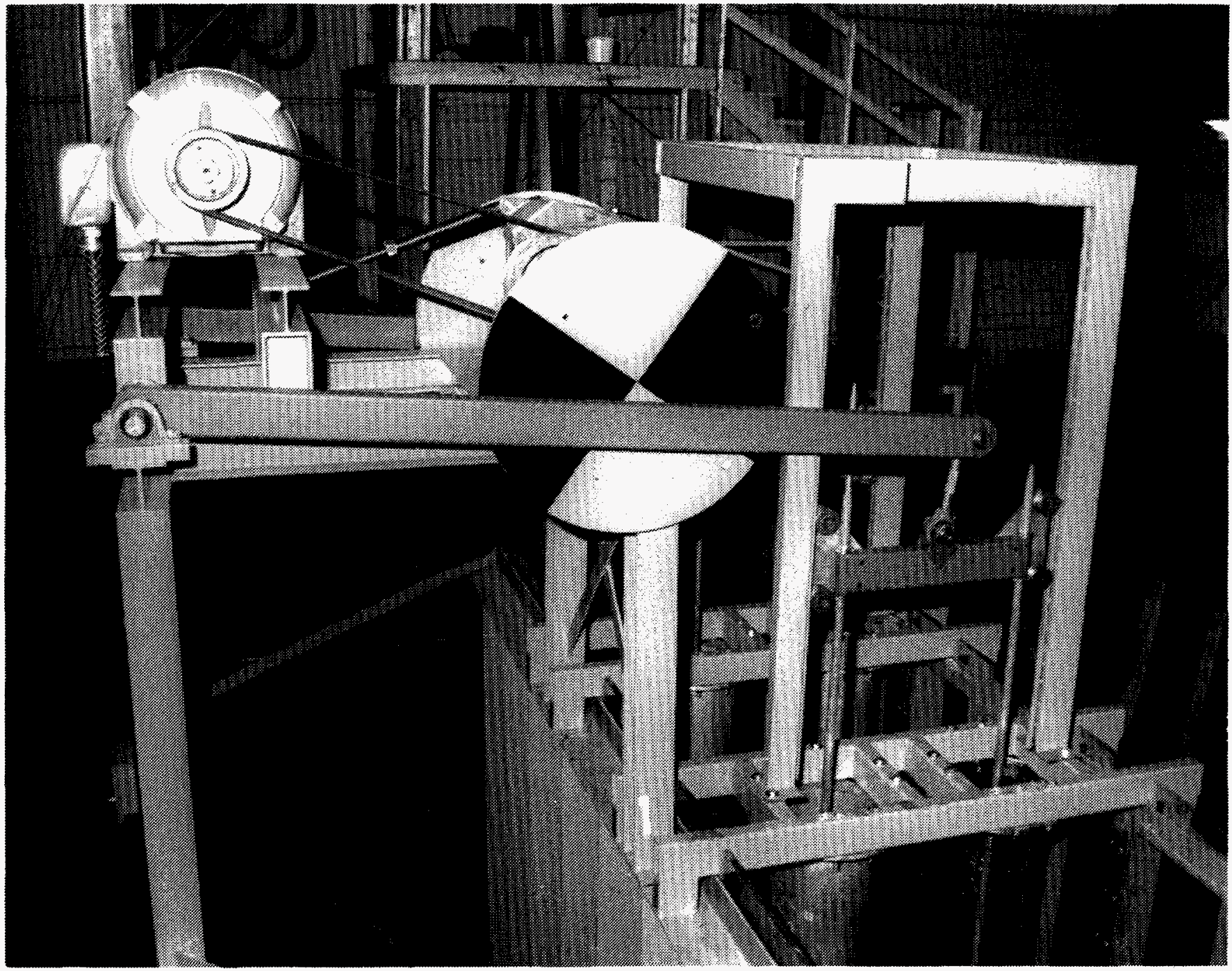

Figure 3-4. Mechanical Drive in Suppression Pool Tests [3] 
Test Facility and Experimental Procedures
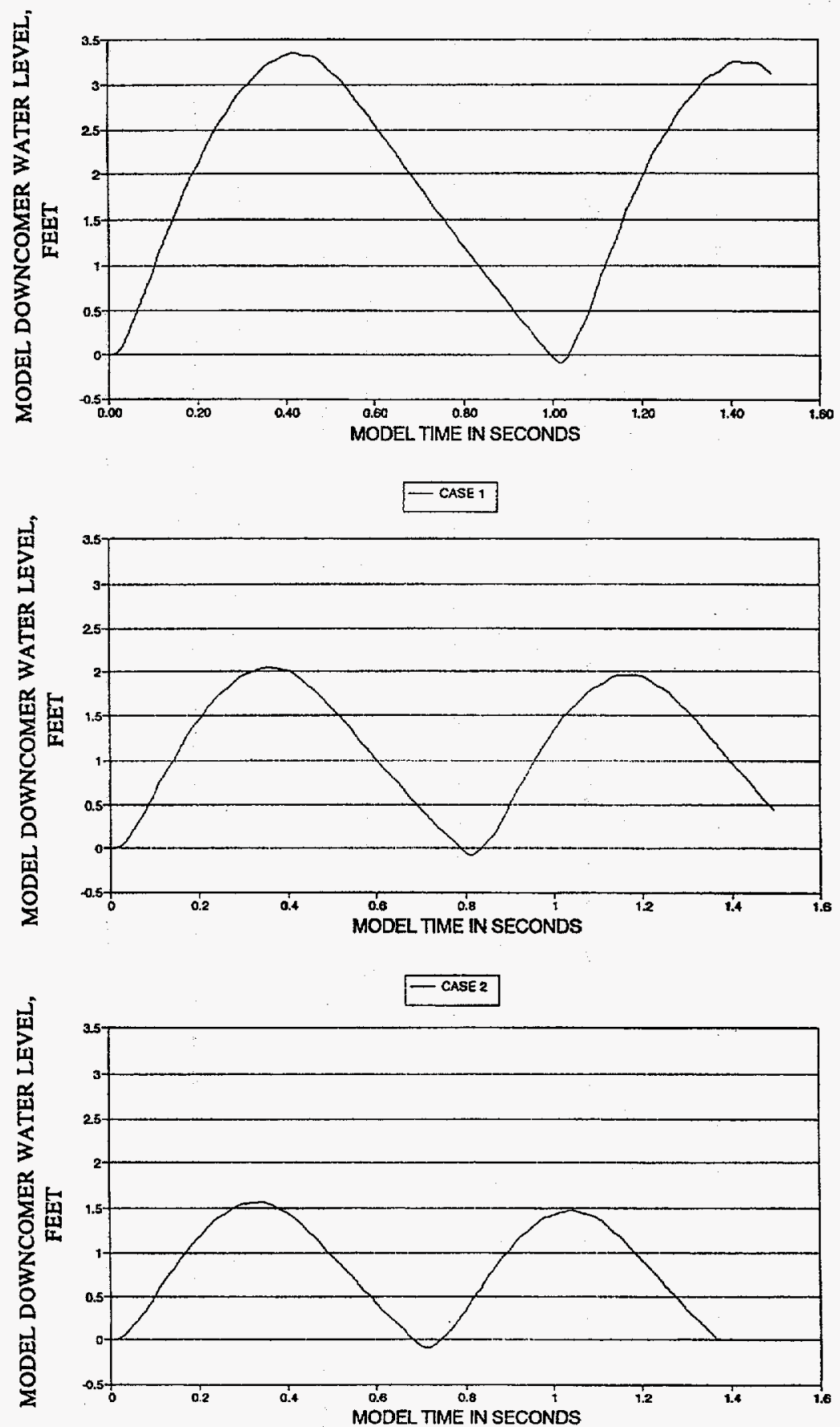

- CASE 3

Figure 3-5. Scaled Downcomer Interface Oscillations for the Model Study [3] 


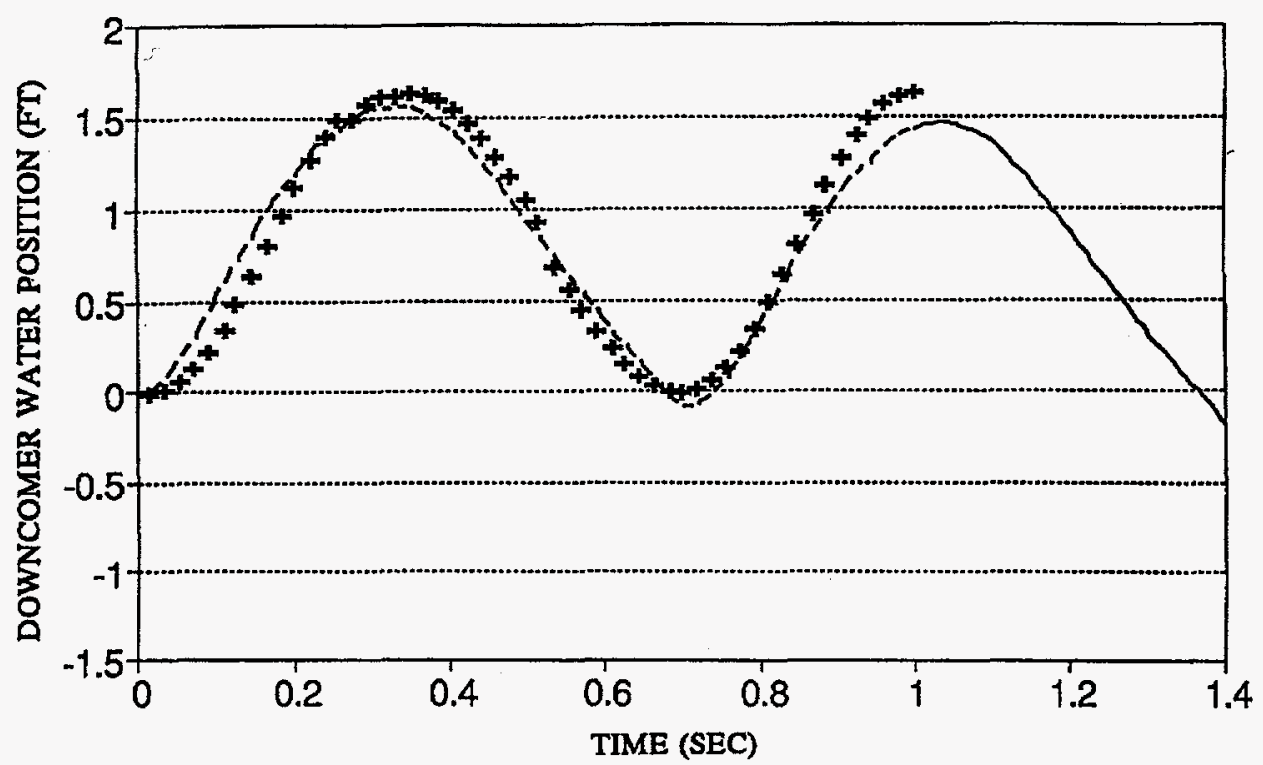

- computer analysis + model mechanism

A. DOWNCOMER INTERFACE OSCILLATIONS

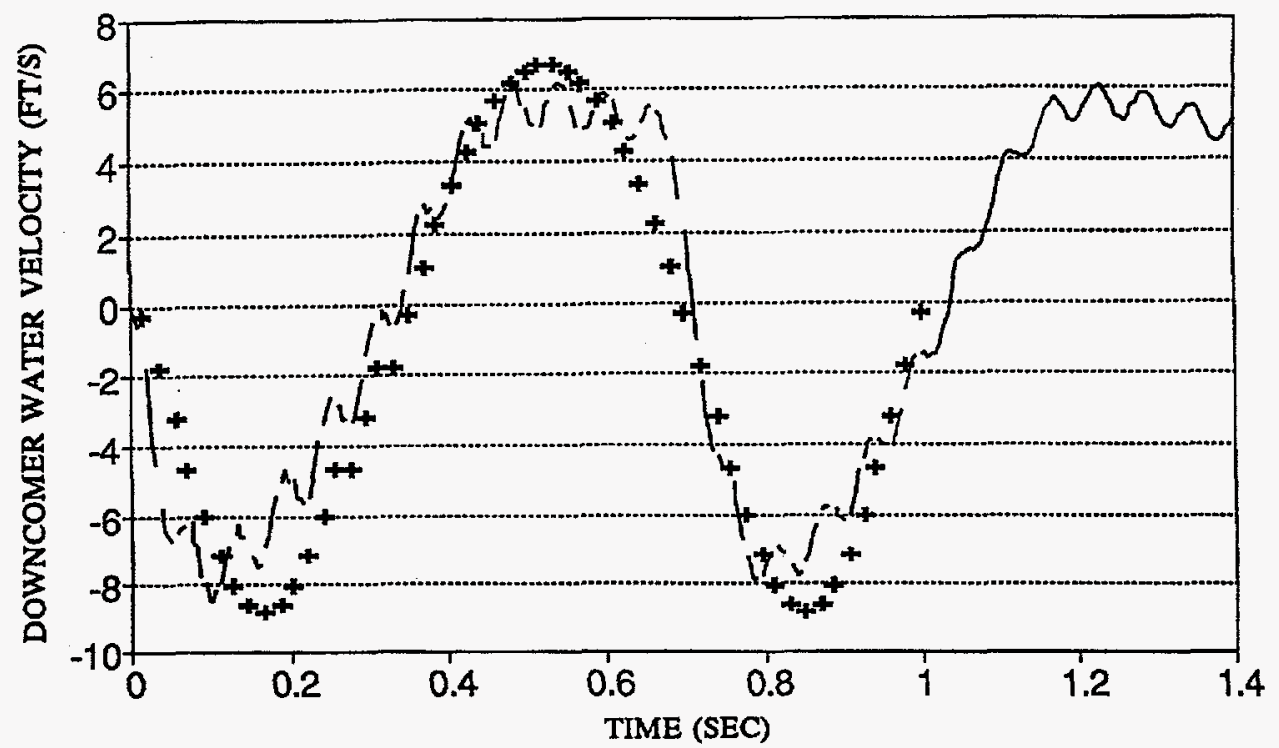

computer analysis + model mechanism

B. VELOCITY OF DOWNCOMER FLOW

Figure 3-6. Comparison of Desired and Model Generated Interface Oscillations for Case 3 Chugging Simulation [3] 
Figure 3-7. Fibrous Debris Classification

\begin{tabular}{|c|c|c|c|c|c|}
\hline $\begin{array}{l}2 \\
0 \\
0 \\
0 \\
0 \\
0 \\
\\
\end{array}$ & & Description & Settling Characteristics & $\begin{array}{l}\text { Settling Velocity in } \\
\text { Calm Pools }\end{array}$ & $\begin{array}{l}\text { Strainer } \\
\text { Filtration } \\
\text { Efficiency }\end{array}$ \\
\hline 1 & & $\begin{array}{l}\text { Very small pieces of fiberglass material, } \\
\text { "microscopic" fines which appear to be } \\
\text { cylinders of varying L/D. }\end{array}$ & $\begin{array}{l}\text { Drag equations for cylinders are well } \\
\text { known, should be able to calculate fall } \\
\text { velocity of a tumbling cylinder in still } \\
\text { water. }\end{array}$ & $\begin{array}{l}1-3.5 \mathrm{~mm} / \mathrm{s} \\
\text { Based on Cal. for } \\
0.5-2.54 \mathrm{~cm} \text { long fibers }\end{array}$ & Unknown \\
\hline 2 & & $\begin{array}{l}\text { Single flexible strand of fiberglass, } \\
\text { essentially acts as a suspended strand. }\end{array}$ & $\begin{array}{l}\text { Difficult to calculate drag forces due to } \\
\text { changing orientation of flexible strand. }\end{array}$ & Same as above & Nearly 1.0 \\
\hline 3 & & $\begin{array}{l}\text { Multiple attached or interwoven strands } \\
\text { that exhibit considerable flexibility and } \\
\text { which due to random orientations } \\
\text { induced by furbulence drag could result } \\
\text { in low fall velocities. }\end{array}$ & $\begin{array}{l}\text { This category is suggested since this } \\
\text { class of fibrous debris would likely be } \\
\text { most susceptible to re-entrainment in } \\
\text { the recirculation phase if turbulence } \\
\text { and/or wave velocity interaction } \\
\text { becomes significant. }\end{array}$ & $\begin{array}{l}0.04 \mathrm{ft} / \mathrm{s}-0.06 \mathrm{ft} / \mathrm{s} \\
\text { (measured) }\end{array}$ & 1.0 (measured) \\
\hline 4 & & $\begin{array}{l}\text { Formation of fibers into clusters which } \\
\text { have more rigidity and which react to } \\
\text { drag forces more as a semi-rigid body. }\end{array}$ & $\begin{array}{l}\text { This category might be represented by } \\
\text { the smallest debris size characterized } \\
\text { by PCls air blast experiments. }\end{array}$ & $\begin{array}{l}0.08-0.13 \mathrm{ft} / \mathrm{s} \\
\text { (measured) }\end{array}$ & 1.0 (measured) \\
\hline 5 & $S$ & $\begin{array}{l}\text { Clumps of fibrous debris which have } \\
\text { been noted to sink. Generated by } \\
\text { different methods by various } \\
\text { experimenters. }\end{array}$ & $\begin{array}{l}\text { This category was characterized by the } \\
\text { PCI air test experiments as comprising } \\
\text { the largest two sizes in a three size } \\
\text { distribution. }\end{array}$ & $\begin{array}{l}0.13-0.18 \mathrm{ft} / \mathrm{s} \\
\text { (measured) }\end{array}$ & 1.0 (measured) \\
\hline 6 & 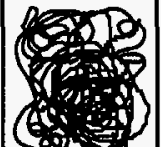 & $\begin{array}{l}\text { Larger clumps of fibers. Forms an } \\
\text { intermediate between Classes } 5 \text { and } 7 .\end{array}$ & $\begin{array}{l}\text { Few of the pieces generated in } \mathrm{PCl} \text { air } \\
\text { blast tests consisted of these debris } \\
\text { types. }\end{array}$ & $\begin{array}{l}0.16-0.19 \mathrm{ft} / \mathrm{s} \\
\text { (measured) }\end{array}$ & 1.0 (measured) \\
\hline 7 & & $\begin{array}{l}\text { Precut pieces (i.e. .25" by .25") to } \\
\text { simulate small debris. Other } \\
\text { manual/mechanical methods to } \\
\text { produce test debris. }\end{array}$ & $\begin{array}{l}\text { Dry form geometry known, will ingest } \\
\text { water, should be able to scope fall } \\
\text { velocities in still water assuming } \\
\text { various geometries. }\end{array}$ & $\begin{array}{c}0.25 \mathrm{ft} / \mathrm{s} \\
\text { (calculated) }\end{array}$ & 1.0 (estimated) \\
\hline
\end{tabular}


classes $3 \& 4$ and $5 \& 6$ was based on several exploratory studies; in this method, the NUKON ${ }^{\mathrm{TM}}$ blankets provided by PCI were first cutup manually into large pieces, typically several inches in size. These pieces were then fragmented in a leaf shredder to generate the appropriate fibrous debris classes $3 \& 4$ and $5 \& 6$. The detailed procedure to generate the fibrous debris is given in Appendix A. Figures 3-8 and 3-9 show photographs of representative fibrous debris fragments used in these experiments.

\subsubsection{Suppression Pool Sludge}

Several BWR's suppression pools contain corrosion products, primarily iron oxides, produced during routine operations; this particulate matter is commonly referred to as suppression pool sludge. In addition, other miscellaneous debris materials, such as anti-contamination coveralls, plastic bags, used tape and tools, have been found in some suppression pools [6]. In this set of experiments, only the sludge particles were simulated.

The makeup of sludge in BWR's suppression pools is plant specific, but it is generally characterized as iron oxide. By some estimates [7], the amount of sludge may vary from 70 to $5000 \mathrm{lb}$ (30 to $2300 \mathrm{~kg}$ ), depending on the plant cleanup procedures. The BWR owners' group (BWROG) characterized, using laser light scattering, the particle size distribution of the sludge samples obtained from five BWR suppression pools, including Mark I, II and III containments. Based on this characterization, the BWROG suggested the size distribution given in Table 3-1 [8].

A survey was conducted among some companies capable of providing several powders with the recommended particle size distribution. None of the surveyed companies was able to provide iron oxide powders with the required exact particle size distribution. Although it was recognized that some non-iron oxide powders could be provided with a close match to the BWROG's recommended particle size distribution, it was decided to use iron oxide powders to better simulate the sludge observed in BWR's suppression pools.

Black iron oxide, $\mathrm{Fe}_{3} \mathrm{O}_{4}$, was. supplied by Hansen Engineering, Inc. according to the size distribution specified in Table 3-2. To simulate the BWROG's suggested particle size distribution, it was decided to mix $95 \%$ (in mass) of black iron oxide \#2008 and $5 \%$ of black iron \#9109-N, resulting in the so called sludge $A$; the estimated particle size distribution for this mixture is presented in Table 3-3.

Later scanning electron microscope (SEM) analysis showed that iron oxide particles, in the dry powder state provided by the manufacturer, agglomerated extensively, leading to a broad spread of the size distribution ranging from sub-micron primary particles to about $375 \mu \mathrm{m}$ agglomerates; in most cases, the particles and agglomerates were nearly spherical; Figures 3-10 and 3-11, SEM photographs of sludge A, clearly show these observations. In addition, the sludge $A$ particle size distribution was characterized using sedimentation velocity (sedigraph) analysis, which provides an indication about the size distribution of the primary particles (i.e., before agglomeration) composing sludge $\mathrm{A}$. The results of this analysis, presented in Table 3-4, suggest a particle size distribution with a massmedian diameter of about $5 \mu \mathrm{m}$ (i.e., $50 \%$ of the sludge A particles, by mass, have an equivalent diameter less than $5 \mu \mathrm{m}$ ). This characterization study revealed that the agglomerated particles were very difficult to disperse using stirring and normal vibrators, suggesting that it is unlikely that the

Table 3-1. BWROG-Provided Size Distribution of the Suppression Pool Sludge

\begin{tabular}{ccc}
\hline $\begin{array}{c}\text { Particle Size Range } \\
(\mu \mathrm{m})\end{array}$ & $\begin{array}{c}\text { Average Size } \\
(\mu \mathrm{m})\end{array}$ & \% By Mass \\
\hline $0-5$ & 2.5 & $81 \%$ \\
$5-10$ & 7.5 & $14 \%$ \\
$10-75$ & 42.5 & $5 \%$ \\
\hline
\end{tabular}


Test Facility and Experimental Procedures

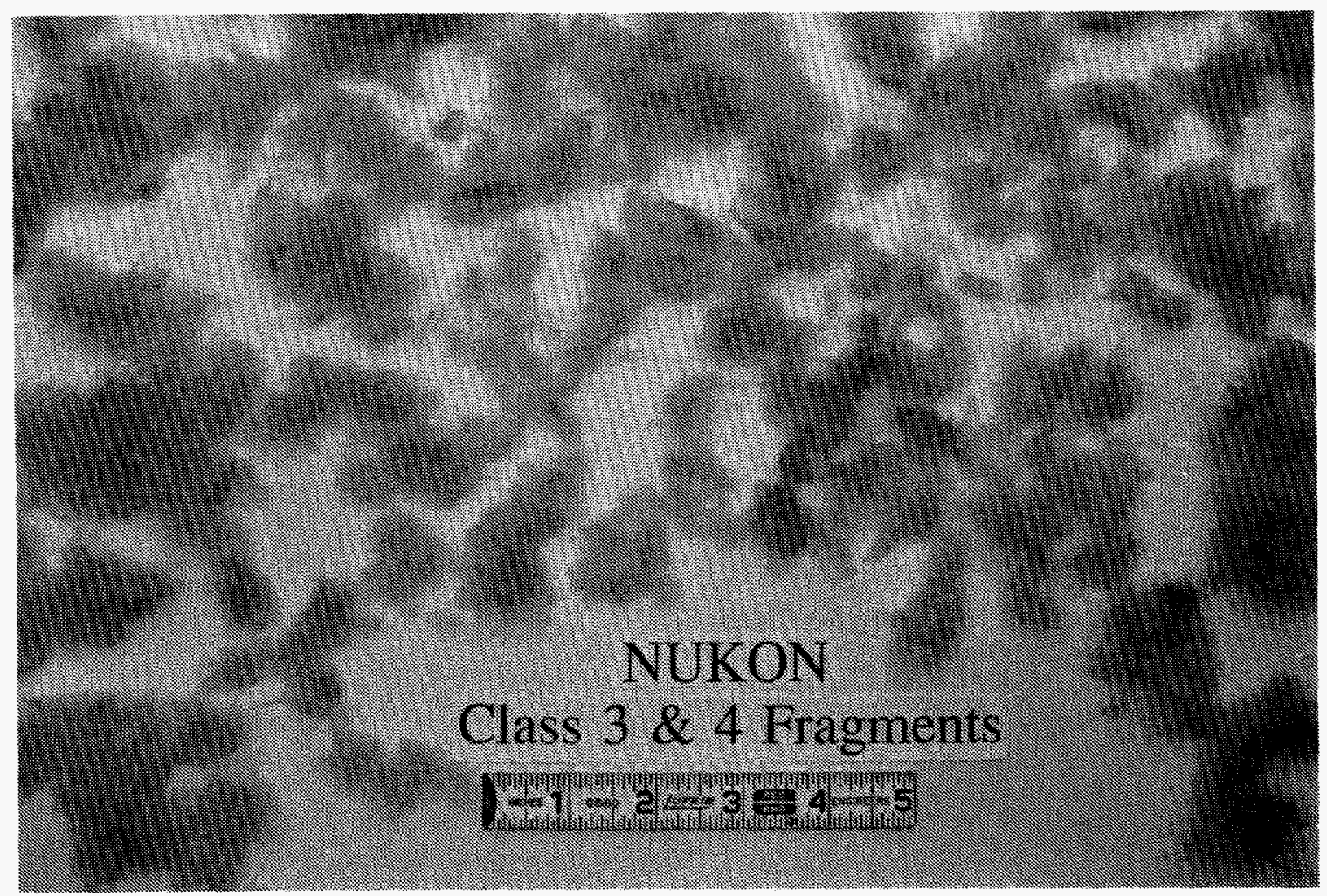

Figure 3-8. Representative Sample of Shredded NUKON ${ }^{\mathrm{TM}}$ Fibrous Debris 
Test Facility and Experimental Procedures

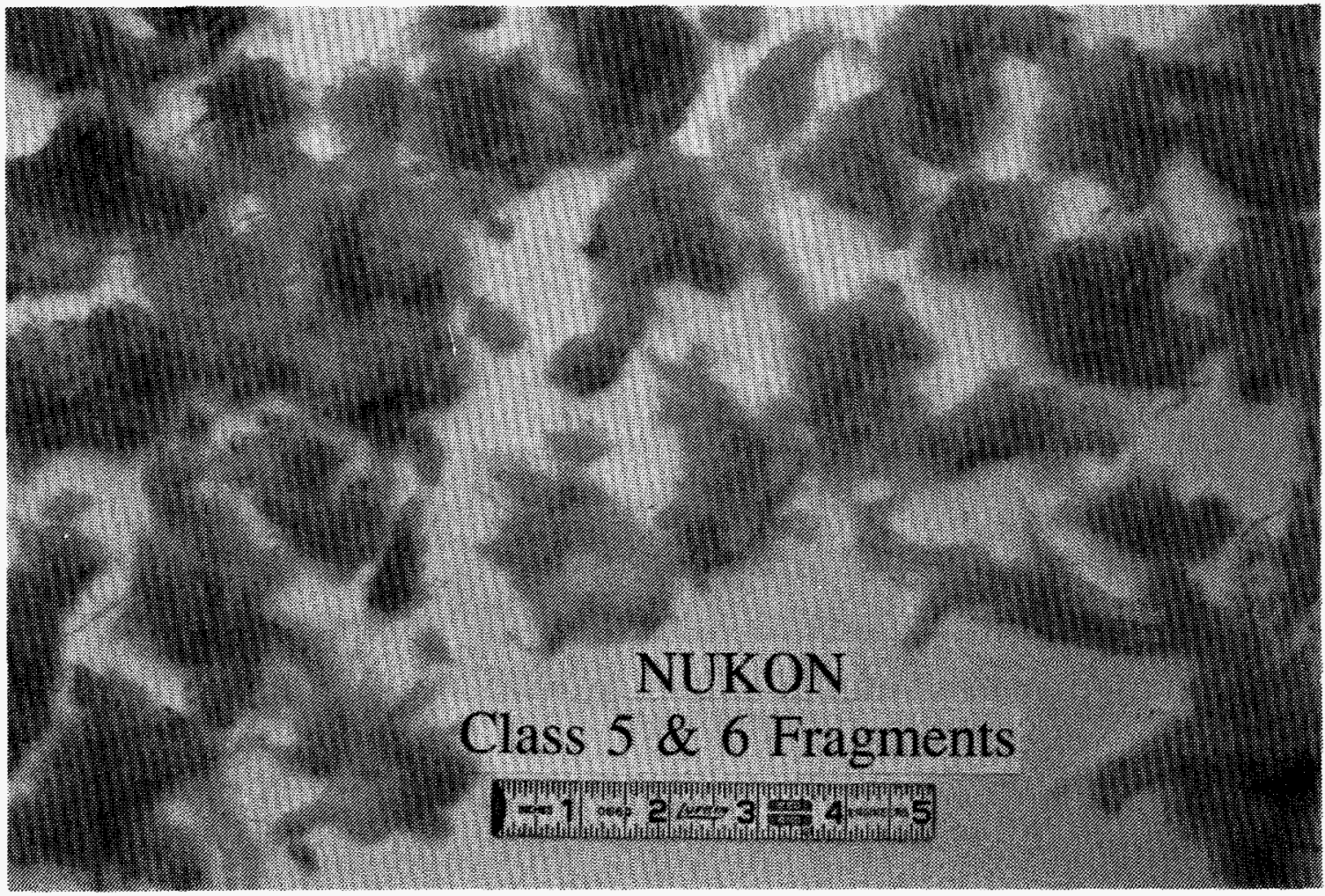

Figure 3-9. Representative Sample of Shredded NUKON ${ }^{\mathrm{TM}}$ Fibrous Debris 
Test Facility and Experimental Procedures

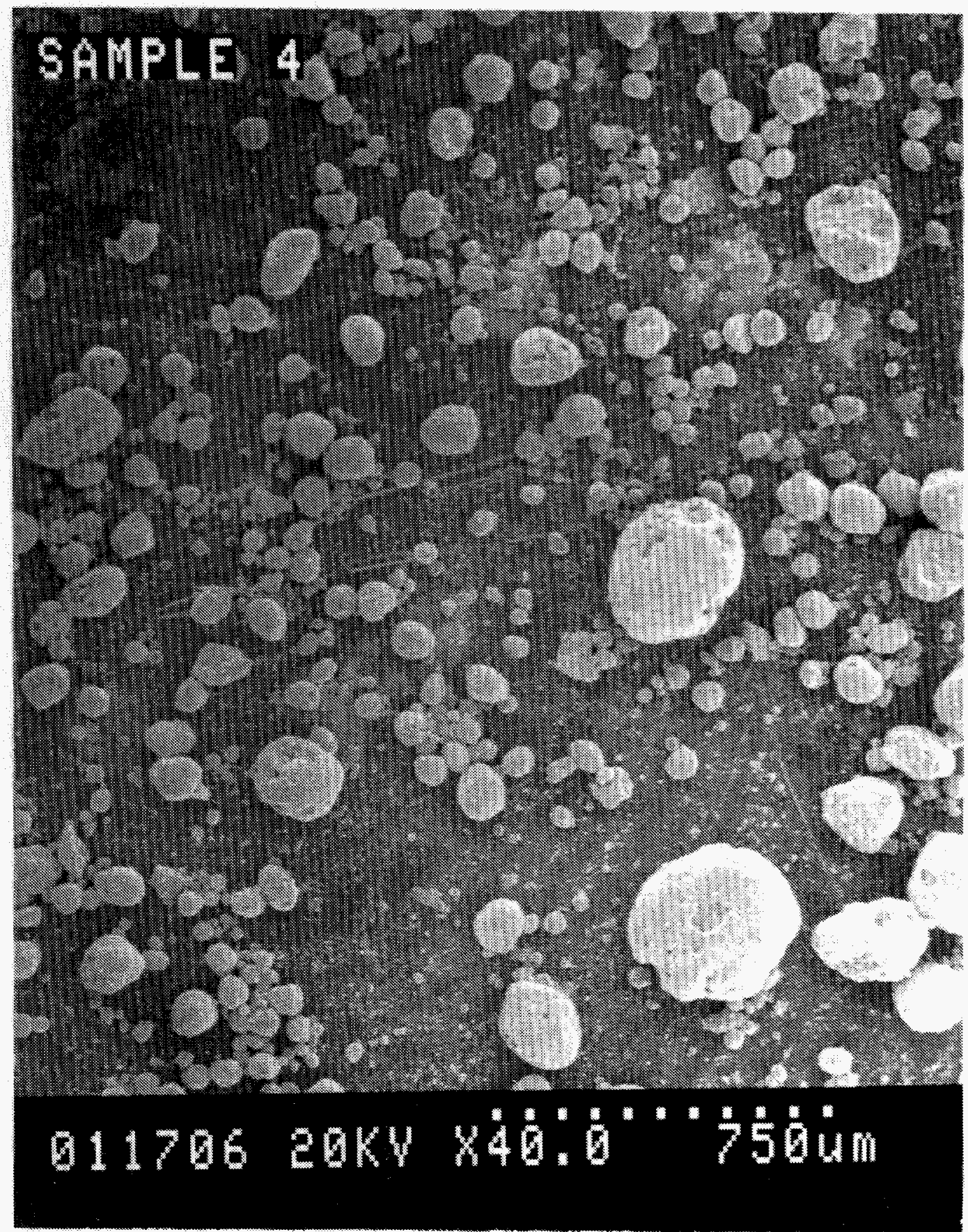

Figure 3-10. SEM of Sludge A (750 $\mu \mathrm{m}$ magnification) 


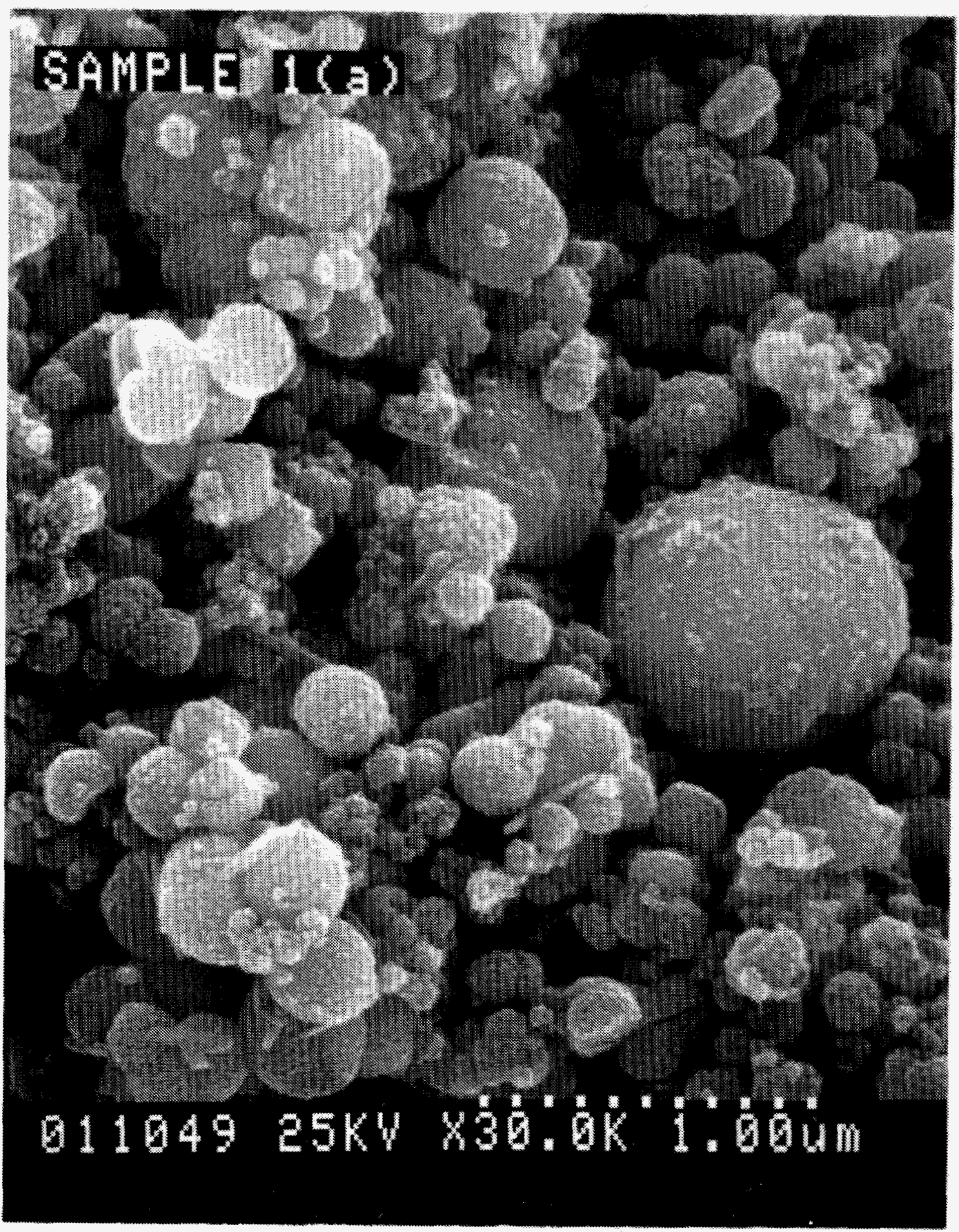

Figure 3-11. SEM of Sludge A (1 $\mu \mathrm{m}$ magnification) 
Test Facility and Experimental Procedures

Table 3-2. Iron Oxide Particles Supplied by Hansen Engineering, Inc.

\begin{tabular}{cccccc}
\hline $\mathbf{F e}_{3} \mathrm{O}_{4}$ Specification & $<\mathbf{2 \mu \mathrm { m }}$ & $\mathbf{2 - 5} \boldsymbol{\mu \mathrm { m }}$ & $\mathbf{5 - 1 0} \boldsymbol{\mu m}$ & $\mathbf{1 0 - 3 5} \boldsymbol{\mu m}$ & $>\mathbf{3 5} \boldsymbol{\mu m}$ \\
\hline$\# 2008$ & $5 \%$ & $80 \%$ & $15 \%$ & $0 \%$ & $0 \%$ \\
$\# 9101-\mathrm{N}$ & $-0 \%$ & $\sim 0 \%$ & $\sim 0 \%$ & $82 \%$ & $-18 \%$
\end{tabular}

agglomerates can be broken up by the turbulence created in the test facility.

\subsection{Exploratory Tests}

Exploratory tests were included in the test plan to optimize hardware and methods for sampling and concentration analysis; to determine if initial (additional) mixing prior to simulated chugging would be required; to determine the test duration and sample frequency (time interval), and to evaluate sample analysis accuracy. No specific matrix was formulated for the exploratory tests. However, the exploratory tests conducted are listed in Table 3-5.

There were a total of 7 exploratory tests, which were labeled Ex-1 through Ex-7. The conditions of each test are listed in Table 3-5. Information obtained from each exploratory test, used in developing a test procedure for parametric tests, is listed below:

Ex-1: The purpose was to take samples during and after simulated chugging to determine sampling rates and expected scatter in the data. Pre-soaked
Class $5 \& 6$ insulation debris was added during simulated chugging. About half of the insulation floated on the surface of the pool after simulated chugging stopped. Lessons learned were:

- Let the insulation debris settle to the bottom before simulated chugging begins.

- Take more samples over a longer time.

- Develop consistent weight analysis procedure.

- Operate model at frequencies where surface wave resonance is not present.

Ex-2: As Ex-1, but with insulation debris initially on the floor. Oscillation period adjusted to avoid resonance. Most of the insulation sank after simulated chugging stopped.

- Initially, it was believed that adding insulation during simulated chugging and/or that surface resonance were responsible for floating insulation. Later however, parametric test T-17 (see section 3.4) showed that even starting with Class $3 \& 4$ insulation debris on the floor, with no surface resonance during testing, some insulation floated to the surface after simulated chugging stopped. No

Table 3-3. Sludge A Particle Size Distribution According to Manufacturer's Specifications

Particle Size Range ( $\mathrm{mm})$

\begin{tabular}{cc}
\hline$<2$ & 4.75 \\
$2-5$ & 76 \\
$5-10$ & 14.25 \\
$10-25$ & 4.1 \\
$35-75$ & 0.9 \\
\hline
\end{tabular}


Test Facility and Experimental Procedures

Table 3-4. Sludge A Particle Size Distribution. Sedimentation Velocity Analysis with Surfactant.

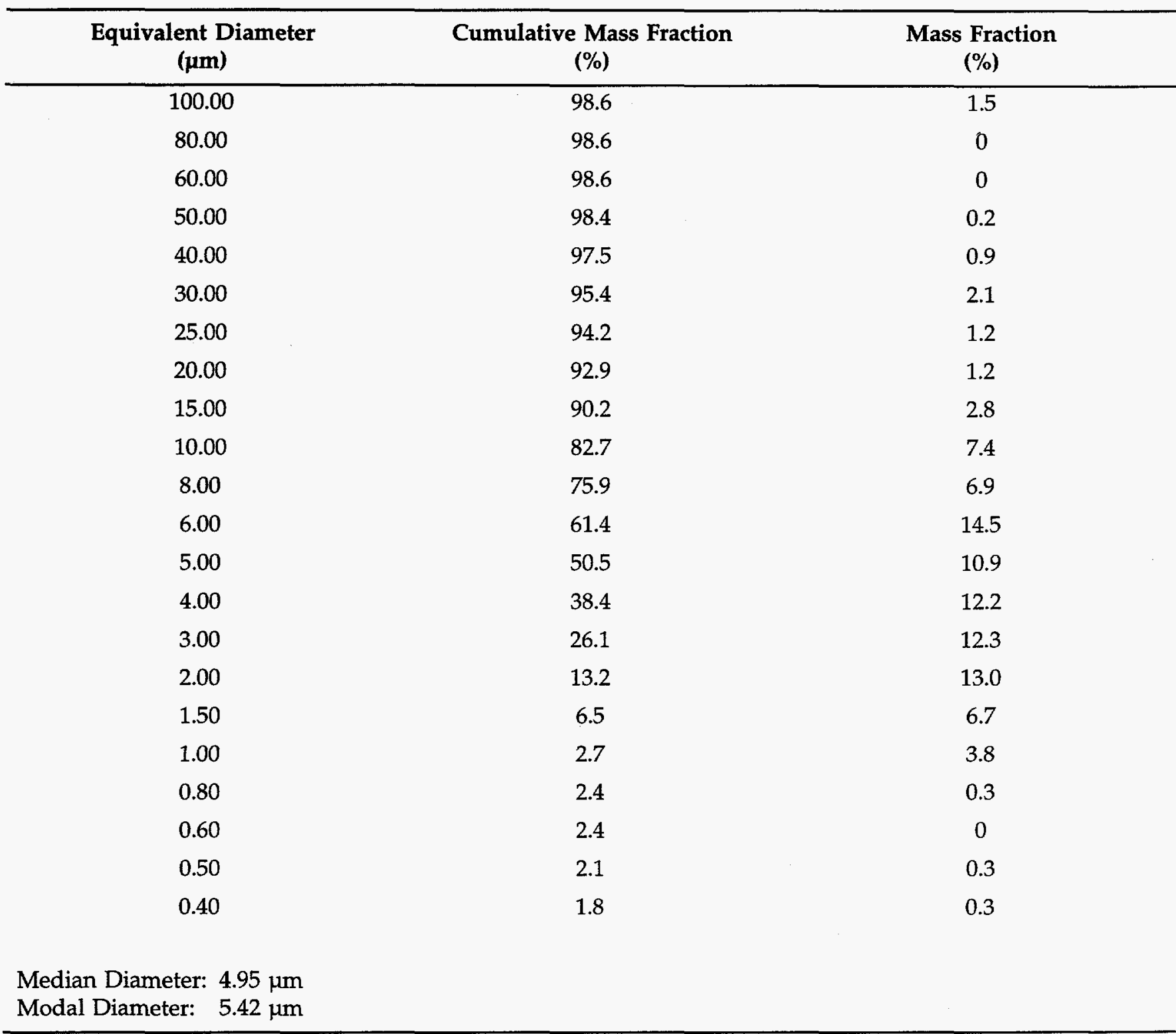

correlation was found that linked floating insulation debris with insulation size, surface wave resonance, or temperature of the water. Tests Ex-1 and T-17 were the only tests where more than a few percent of the insulation debris floated after simulated chugging stopped. The resulting settling velocities for case T-17 matched the predicted data, assuming all insulation sank; therefore, floating insulation debris was not a major concern. After test Ex-2, the extent of surface resonance was observed as a function of simulated chugging period. Froude scaled tests were conducted, and it was determined that surface wave resonance did not occur in the actual suppression pool. The Case 2 simulated chugging period was adjusted by $1 \%$ to avoid surface resonance.

Tests Ex-3 through Ex-6 extended the simulated chugging duration to about 17 minutes to measure more accurately if any settling occurred during simulated chugging and if a fully mixed condition existed. 
Table 3-5. Exploratory Tests

\begin{tabular}{|c|c|c|c|}
\hline Test \# & Debris Type & $\begin{array}{c}\text { Concentration in Water } \\
\text { (\% by Weight })\end{array}$ & $\begin{array}{c}\text { Actual Case Chugging Period; } \\
\text { Interface Amplitude in Downcomers }\end{array}$ \\
\hline \multicolumn{4}{|c|}{ Exploratory Tests } \\
\hline Ex-1 & $\begin{array}{l}\text { NUKON } \\
\text { Class } 5 \& 66\end{array}$ & $0.0032 \%$ & $1.6 \mathrm{~s} ; 3.8 \mathrm{ft}$ (Case 3) \\
\hline Ex-2 & $\begin{array}{l}\text { NUKON } \\
\text { Class } 5 \& 6\end{array}$ & $0.0032 \%$ & $1.6 \mathrm{~s} ; 3.8 \mathrm{ft}$ (Case 3) \\
\hline Ex-3 & $\begin{array}{l}\text { NUKON } \\
\text { Class } 5 \& 6\end{array}$ & $0.0032 \%$ & $1.6 \mathrm{~s} ; 3.8 \mathrm{ft}$ (Case 3) \\
\hline Ex-4 & $\begin{array}{l}\text { NUKON } \\
\text { Class } 3 \& 4\end{array}$ & $0.0032 \%$ & $1.6 \mathrm{~s} ; 3.8 \mathrm{ft}$ (Case 3) \\
\hline Ex-5 & Sludge A & $0.0213 \%$ & $1.6 \mathrm{~s} ; 3.8 \mathrm{ft}$ (Case 3$)$ \\
\hline Ex-6 & $\begin{array}{l}\text { NUKON } \\
\text { Class 5\&6 } \\
\text { Sludge A }\end{array}$ & $\begin{array}{l}0.0032 \% \\
0.0213 \%\end{array}$ & $1.6 \mathrm{~s} ; 3.8 \mathrm{ft}$ (Case 3$)$ \\
\hline Ex-7 & $\begin{array}{l}\text { NUKON } \\
\text { Class } 3 \& 4\end{array}$ & $0.0032 \%$ & $1.6 \mathrm{~s} ; 3.8 \mathrm{ft}$ (Case 3$)$ \\
\hline
\end{tabular}

Ex-3: NUKONTM insulation Class $5 \& 6$

- Samples indicate fully mixed condition (no settling) during simulated chugging.

Ex-4: NUKONTM insulation Class $3 \& 4$

- Fully mixed, no settling during simulated chugging.

Ex-5: Sludge only

- Fully mixed, no settling during simulated chugging.

Ex-6: Sludge and insulation

- Fully mixed, no settling during simulated chugging.

Ex-7: Insulation was introduced by spraying dry insulation debris with a garden hose on a plank held above the suppression pool.

- $\quad$ No difference from results with pre-soaked insulation poured in the tank and allowed to settle.

The conclusions from the exploratory tests are:
- To introduce insulation debris, samples should be pre-soaked in a bucket of water and gently squeezed to remove air bubbles. The air bubbles were removed to help achieve a consistent set of data. However, this step may not have been necessary in view of test Ex-7 where air bubbles were not removed and yet no insulation debris floated after simulated chugging stopped.

- Dry sludge should be poured into the pool. Soaking the sludge prior to introduction caused the sludge to stick to the bucket. Also, if the bucket remained dry, it could be weighed before and after the sludge was poured into the pool, verifying the weight of sludge used in the test.

- The filtering and weighing process was refined so consistent results were obtained. An analysis of sludge concentrations concluded that about $97 \% \pm 3 \%$ of a known amount could be recovered by filtering, drying, and weighing the sample.

- $\quad$ Simulated chugging, even at the lowest energy level (Case 3), provided enough energy to fully mix and re-entrain NUKON ${ }^{\mathrm{TM}}$ insulation debris (Class 3-6) and Sludge A in the suppression pool. 


\subsection{Parametric Tests}

A test matrix was developed to assess the effect of the following variables on debris mixing and potential settling during simulated chugging, settling after simulated chugging and re-entrainment of particles from the pool floor during simulated chugging:

a. Type of debris (NUKON ${ }^{\mathrm{TM}}$ insulation debris Class $3 \& 4$, Class 5\&6, and sludge);

b. Behavior of sludge only, insulation debris only, and combinations of sludge and insulation debris;

c. Varying sludge to insulation debris mass ratio; and

d. Simulated chugging energy input (different frequency and amplitude).

Table 3-6 is the test matrix developed to address the effect of these variables.

The initial condition for each test was to have the debris fully mixed in the model tank, simulating the mixing produced by the initial gas venting and pool swell immediately following a LOCA. Exploratory tests showed that about one minute of simulated chugging resulted in a fully mixed condition, even at the lowest energy level with the insulation debris and sludge initially at the bottom of the tank. Hence, the initial mixing was completed by the time the first sample was taken at 1 minute after simulated chugging started.

Using the GE FSTF test data as a guide, the total simulated chugging duration was chosen to be about 4 minutes. However, exploratory tests were conducted with a total simulated chugging duration of 7 minutes to allow more samples to be collected for a more accurate evaluation of mixing during simulated chugging.

Debris concentrations were measured in the center of the tank at five equally spaced vertical locations, starting $0.8 \mathrm{ft}(0.2 \mathrm{~m})$ below water surface. The distance between sample ports was also $0.8 \mathrm{ft}$, resulting in the sampling ports being $0.5,1.33,2.2$, 3.0 , and $3.8 \mathrm{ft}(0.15,0.41,0.76,0.91$ and $1.16 \mathrm{~m})$ off the pool floor. Scaled to an actual Mark I suppression pool, these elevations correspond to 1.2, $3.2,5.2,7.2$, and $9.2 \mathrm{ft}(0.37,0.98,1.58,2.19$, and
$2.80 \mathrm{~m}$ ) off the floor. About $2.8 \times 10^{-2} \mathrm{ft}^{3}$ or 0.8 liters $\left(8 \times 10^{-4} \mathrm{~m}^{3}\right)$ were withdrawn simultaneously from each of the five ports at selected time intervals, using the sampling apparatus shown in Figure 3-12. Prior to moving the bottles into position to collect a sample, the valves were open to flush out the sample lines. The samples were filtered, dried, and weighed (see test procedures, Appendix A), and the concentrations were expressed as the mass of debris per unit mass of water. Periodic sampling at 1 minute intervals during simulated chugging and at 2.4 minutes (and longer) intervals after simulated chugging stopped yielded concentration profiles as a function of time. The last sample set was taken about 42 minutes after simulated chugging stopped.

\subsection{Test Procedures}

A step by step test procedure for parametric tests was developed based on the experience gained in the exploratory tests; the resulting procedure, given in Appendix A, is summarized as follows:

- Fill tank to 56 inches $(1.42 \mathrm{~m}$ ) (actual case height of $11.2 \mathrm{ft}$ or $3.41 \mathrm{~m}$ ) above the floor level with clear water.

- $\quad$ Add a known quantity of pre-soaked NUKONTM insulation fragments to the tank and allow for the debris to settle to the bottom of the tank.

- $\quad$ Add a pre-determined quantity of sludge to the tank and allow the sludge to settle to the bottom of the tank.

- $\quad$ Set the variable speed pump controller frequency to the pre-determined value and adjust the cam pin position to simulate the chugging conditions on interest. Run the simulated chugging for a total of 4 minutes (or 9.6 actual case minutes).

- Draw water samples at every 60 seconds (or 2.4 actual case minutes) while simulated chugging is continuing.

- $\quad$ Terminate simulated chugging after 4 minutes (or 9.6 actual case minutes) and allow for the turbulence to decay. 
Test Facility and Experimental Procedures

- $\quad$ Draw water samples at every 2 minutes (4.8 actual case minutes) over the initial 10 minutes and every 10 minutes over the next 30 minutes.
The water samples were then used to estimate debris concentration using the filtration method described in Appendix A.

Table 3-6. Parametric Tests

\begin{tabular}{|c|c|c|c|}
\hline Test \# & Debris Type & $\begin{array}{l}\text { Concentration in Water } \\
(\% \text { by Weight })\end{array}$ & $\begin{array}{l}\text { Actual Case Chugging Period; } \\
\text { Interface Amplitude in Downcomers }\end{array}$ \\
\hline \multicolumn{4}{|c|}{ Different Fiber Classes; Sludge Type A } \\
\hline A-1 R1 & $\begin{array}{l}\text { NUKON } \\
\text { Class } 3 \& 4\end{array}$ & $0.0032 \%$ & $1.6 \mathrm{~s} ; 3.8 \mathrm{ft}$ (Case 3$)$ \\
\hline A-2 R1 & $\begin{array}{l}\text { NUKON } \\
\text { Class } 5 \& 6\end{array}$ & $0.0032 \%$ & $1.6 \mathrm{~s} ; 3.8 \mathrm{ft}$ (Case 3$)$ \\
\hline A-3 R1 & Sludge A & $0.0213 \%$ & $1.6 \mathrm{~s} ; 3.8 \mathrm{ft}$ (Case 3 ) \\
\hline A-4 R1 & $\begin{array}{l}\text { NUKON } \\
\text { Class 5\&6 } \\
\text { Sludge A }\end{array}$ & $\begin{array}{l}0.0032 \% \\
0.0213 \%\end{array}$ & $1.6 \mathrm{~s} ; 3.8 \mathrm{ft}$ (Case 3$)$ \\
\hline A-5 & $\begin{array}{l}\text { NUKON } \\
\text { Class 3\&4 } \\
\text { Sludge A }\end{array}$ & $\begin{array}{l}0.0032 \% \\
0.0213 \%\end{array}$ & $1.6 \mathrm{~s} ; 3.8 \mathrm{ft}$ (Case 3$)$ \\
\hline \multicolumn{4}{|c|}{ Different Concentrations } \\
\hline B-6 & $\begin{array}{l}\text { NUKON } \\
\text { Class 5\&6 } \\
\text { Sludge A }\end{array}$ & $\begin{array}{l}0.0011 \% \\
0.0213 \%\end{array}$ & $1.6 \mathrm{~s} ; 3.8 \mathrm{ft}$ (Case 3 ) \\
\hline B-7 & $\begin{array}{l}\text { NUKON } \\
\text { Class 3\&4 } \\
\text { Sludge A }\end{array}$ & $\begin{array}{l}0.0011 \% \\
0.0213 \%\end{array}$ & $1.6 \mathrm{~s} ; 3.8 \mathrm{ft}$ (Case 3 ) \\
\hline B-8 & Sludge A & $0.0638 \%$ & $1.6 \mathrm{~s} ; 3.8 \mathrm{ft}($ Case 3$)$ \\
\hline \multicolumn{4}{|c|}{ Different Period \& Amplitude (Tests D-12 and D-13 were deleted.) } \\
\hline D-11 R1 & $\begin{array}{l}\text { NUKON } \\
\text { Class } 3 \& 4\end{array}$ & $0.0032 \%$ & $1.9 \mathrm{~s} ; 5 \mathrm{ft}$ (Case 2$)$ \\
\hline D-14 R1 & $\begin{array}{l}\text { NUKON } \\
\text { Class 5\&6 } \\
\text { Sludge A }\end{array}$ & $\begin{array}{l}0.0032 \% \\
0.0208 \%\end{array}$ & $1.9 \mathrm{~s} ; 5 \mathrm{ft}$ (Case 2) \\
\hline \multicolumn{4}{|c|}{ Repeat Tests } \\
\hline D-11 & $\begin{array}{l}\text { NUKON } \\
\text { Class } 3 \& 4\end{array}$ & $0.0032 \%$ & $2.1 \mathrm{~s} ; 5 \mathrm{ft}$ \\
\hline D-14 & $\begin{array}{l}\text { NUKON } \\
\text { Class 5\&6 } \\
\text { Sludge A }\end{array}$ & $\begin{array}{l}0.0032 \% \\
0.0213 \%\end{array}$ & $2.1 \mathrm{~s} ; 5 \mathrm{ft}$ \\
\hline \multicolumn{4}{|c|}{ Other Concentration Ratios } \\
\hline $\mathrm{T}-17$ & $\begin{array}{l}\text { NUKON } \\
\text { Class 3\&4 } \\
\text { Sludge A }\end{array}$ & $\begin{array}{l}0.0032 \% \\
0.0032 \%\end{array}$ & $1.6 \mathrm{~s} ; 3.8 \mathrm{ft}$ (Case 3 ) \\
\hline $\mathrm{T}-18$ & $\begin{array}{l}\text { NUKON } \\
\text { Class 3\&4 } \\
\text { Sludge A }\end{array}$ & $\begin{array}{l}0.0032 \% \\
0.0016 \%\end{array}$ & $1.6 \mathrm{~s} ; 3.8 \mathrm{ft}$ (Case 3) \\
\hline
\end{tabular}




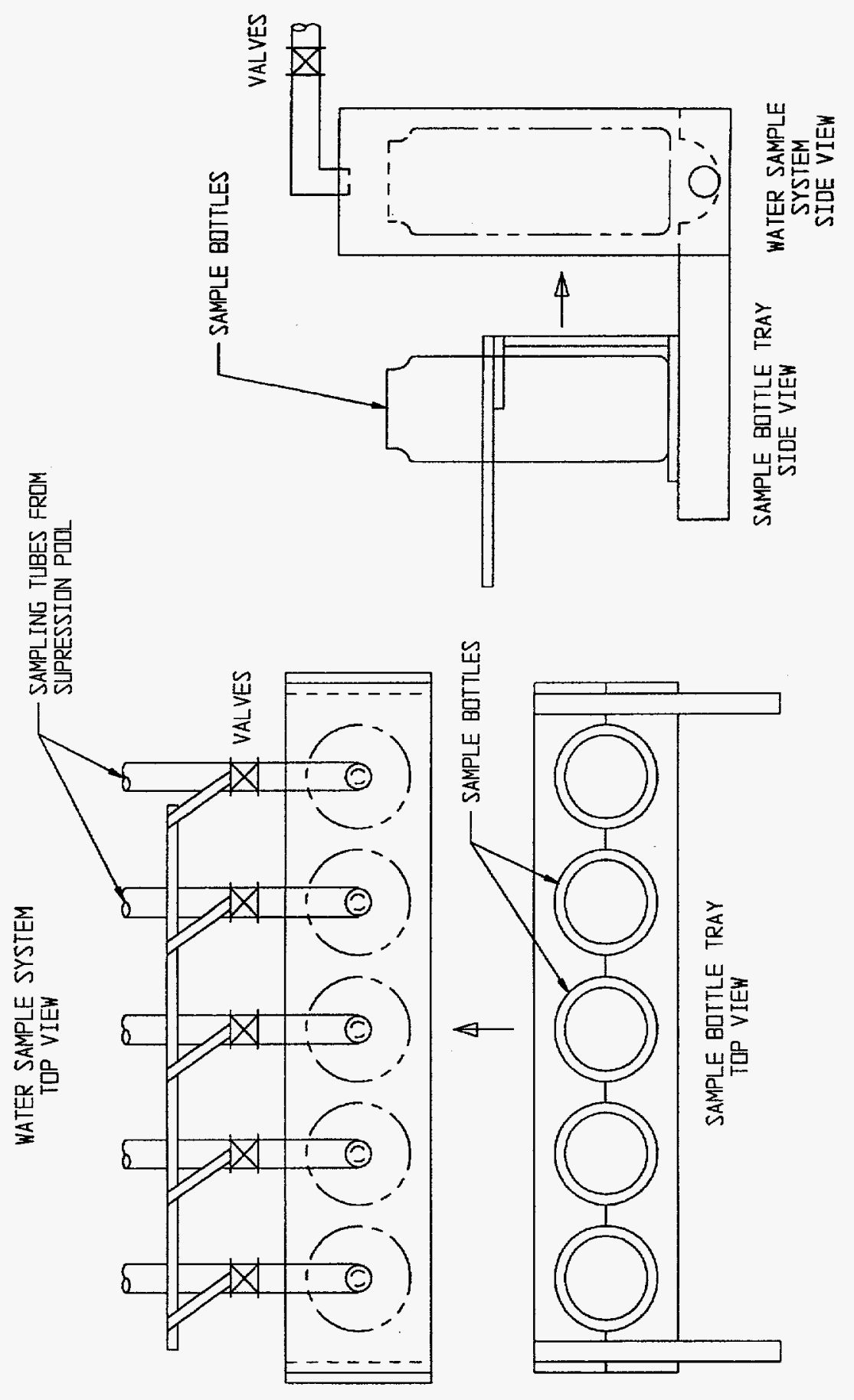




\subsection{Analysis of Experimental Results}

\subsection{Results}

Raw data of concentration measurements for the tests in the matrix (see Table 3-6) are included in Appendix B. Plots of test results are presented in Figures 4-1 through 4-12 [3] to allow ready evaluation of settling during and after simulated chugging. Actual case, i.e., full scale, values of the variables are used in all plots. Model values were converted to actual case values using the corresponding model to actual case ratios, namely 1:2.4 for depth (or height) and time, and 1:1 for concentration and velocity.

For each test, an average initial mixed concentration Cav is calculated by dividing the total mass of debris added by the mass of water in the tank. In the figures, measured concentrations $C$ for each test are expressed as a percent of the calculated average initial concentration Cav. Average concentrations during chugging versus height in the tank are plotted in caption a) of Figures 4-1 through 4-12. Individual concentration measurements are plotted as functions of height and as functions of time in captions b) and c), respectively. Settling velocities calculated from concentration measurements are shown in caption d) of Figures 4-1 through 4-12.

Average concentration during chugging, caption a) in Figures 4-1 through 4-12, show the extent of entrainment of debris from the floor of the suppression pool. The data are the average of four measurements for each sample port. To get a measured average close to the true average, seven samples were taken during the exploratory tests to obtain an average with less error. Averages near $100 \%$ would indicate that debris is entrained and fully mixed.

Vertical concentration profiles, caption b) in Figures 4-1 through 4-12, show the concentration data versus height at specific times. Random scatter of data near $100 \%$ concentration during chugging would suggest that all debris was entrained in the pool and that no settling occurred. As settling occurs after simulated chugging stops, the slope of the concentration profiles shows the concentration gradient in the pool at the time specified. Scatter in the data is expected for the larger insulation fragments, and as those settle and only the finer material remains in suspension, the data become more consistent. More samples could not be taken because the loss of more water from the suppression pool would change the test conditions.

Concentration versus time at each sample elevation, caption c) in Figures 4-1 through 4-12, show how the concentration decreases with time after chugging. The time at which simulated chugging stops is marked on each plot. The steeper the slope, the faster the debris settles.

To allow use of the data in a more general format, including in the code BLOCKAGE, it was desired to evaluate sedimentation after chugging in terms of particle settling velocities. The test data of concentration decay with time, after the end of simulated chugging, were analyzed using a settling column approach, commonly used in the settling analysis of discrete solids of varying sizes in waste water settling chambers [9]. Equating the model pool to a settling column, the measured debris concentration $C$ as a percent of Cav at some time represents the percent of debris with settling velocity less than or equal to a settling velocity $V s=$ $H / t$, where $H$ is the depth of the sampling port from the water surface, and $t$ is the time elapsed after simulated chugging stops. A plot of $(100-C)$ versus Vs relates the fraction of total debris with the minimum settling velocity for that fraction. Settling velocity data are included as caption d) in Figures 4-1 through 4-12.

\subsection{Debris Behavior During Simulated Chugging}

Debris initially on the floor became fully resuspended within the first few seconds after the simulated chugging commenced as observed by visual inspections, both for low and moderate chugging energy levels (Cases 3 and 2, respectively). The debris tested included Class $3 \& 4$ and Class $5 \& 6$ fibrous debris with and without sludge. As seen from the time averaged vertical concentration profiles, for all practical purposes the debris remained fully mixed and suspended in the pool, even for the lowest energy. Any fluctuations in the vertical concentration profiles are attributable to the randomness in the concentration that is typical of turbulent pools as well as in the sampling techniques. Together, these figures can be used to conclude that turbulence introduced by even very 
a) AVERAGE CONCENTRATION DURING CHUGGING

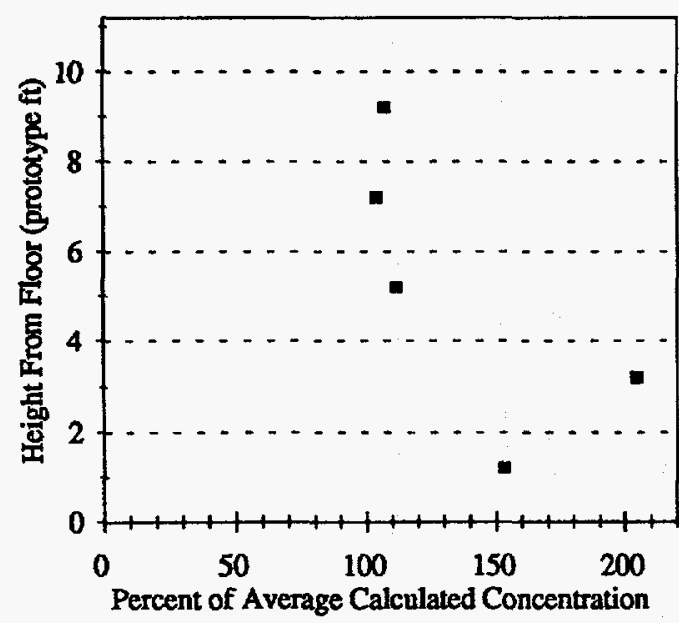

c) CONCENTRATTON VS TIME

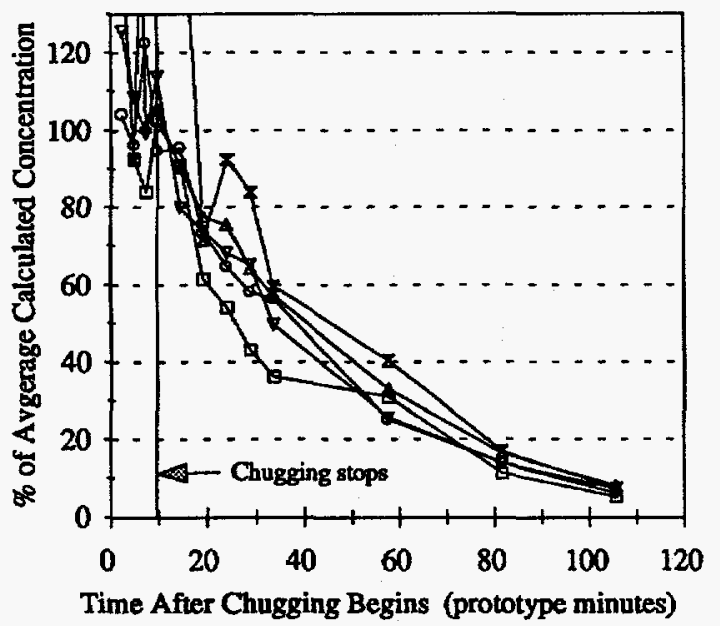

Sample Distance From Floor (prototype $\mathrm{ft}$ ) $\rightarrow 9.2-7.2 \rightarrow 5.2+3.2 \div-1.2$ b) VERTICAL CONCENIRATION PROFILES

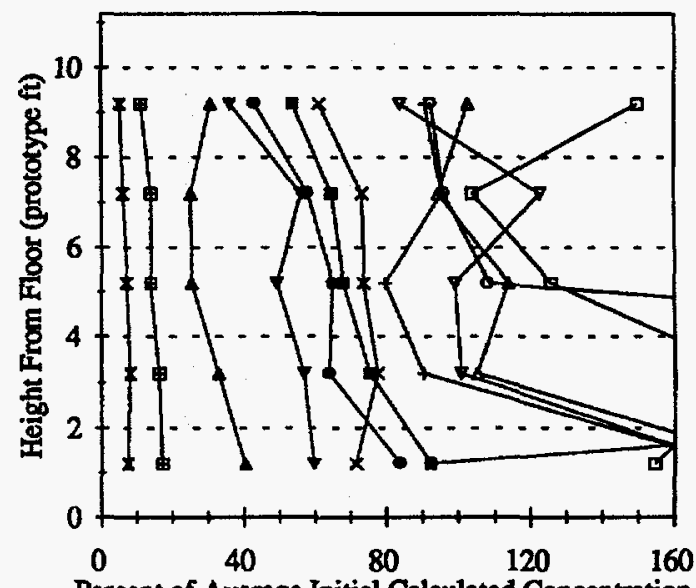

Percent of Average Initial Calculated Concentration

Time After Chugging Begins (prototype minutes)

$$
\begin{array}{lllll}
-2.4 & -4.8+7.2+9.6+14.4 * 19.2 \\
-24 & -28.8+33.6+57.6+81.6 \neq 105.6
\end{array}
$$

d) SETTLING VELOCITY AFTER CHUGGING

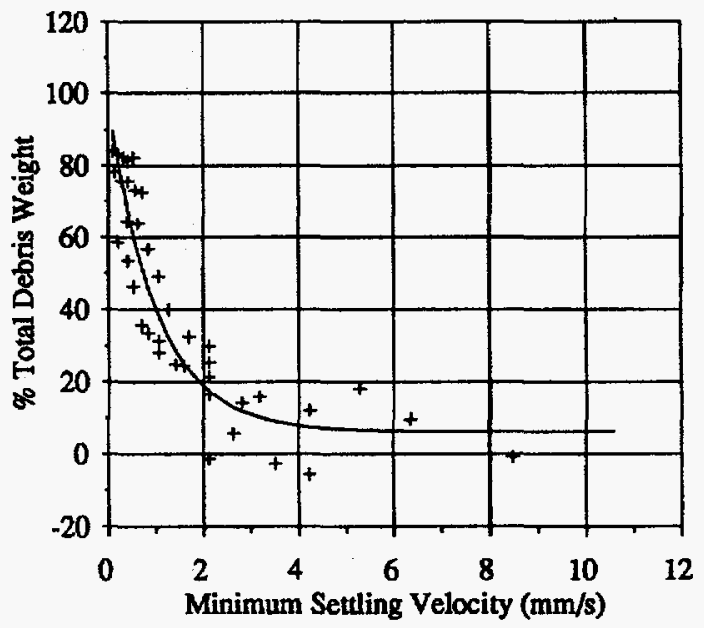

Figure 4-1. Debris Settling in Suppression Pool; Test A-1R1: $3.8 \mathrm{ft}$ amplitude; $1.6 \mathrm{Sec}$ Period (Case 3) NUKON'M: $0.0032 \%$. Class $3 \& 4$. Sludge A: $0.0 \%$ [3] 
a) AVERAGE CONCENTRATION DURING CHUGGING

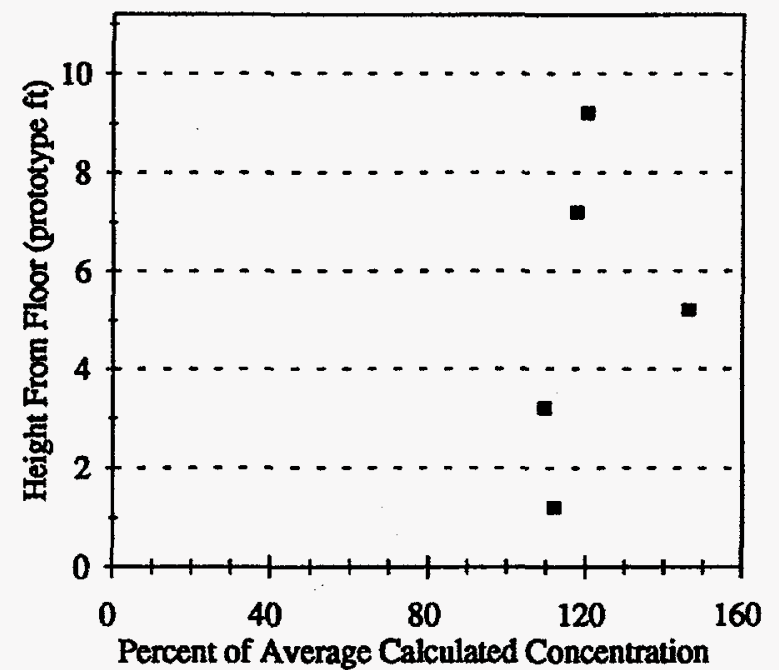

c) CONCENTRATION VS TIME

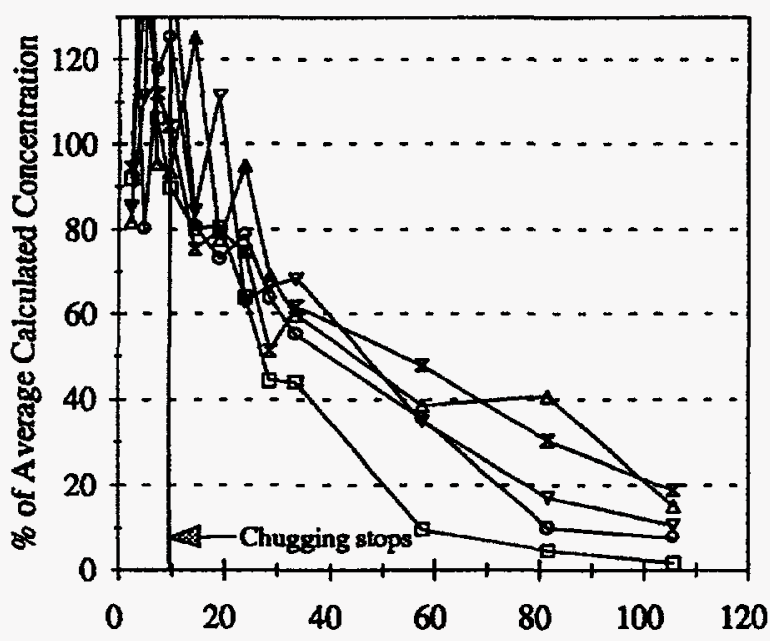

Time After Chugging Begins (prototype minutes) b) VBRTICAL CONCENTRATION PROFLES

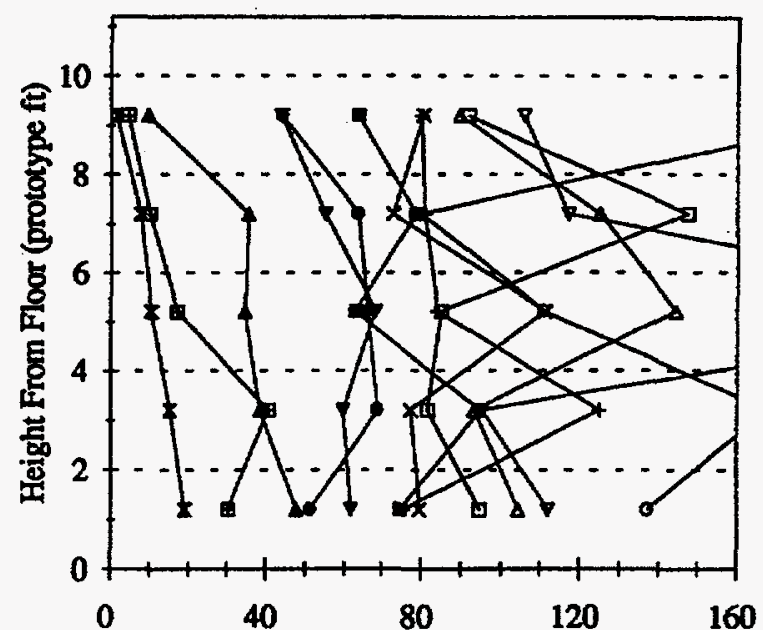

Percent of Average Initial Calculated Concentration

Time After Chugging Begins (prototype minutes)

$\begin{array}{llllll}-2.4 & -4.8 & -7.2 & \star-9.6 & +14.4 & * 19.2 \\ -24 & -28.8 & -33.6 & -57.6 & \# 81.6 & -105.6\end{array}$

d) SETTLING VELOCITY AFTER CHUGGING

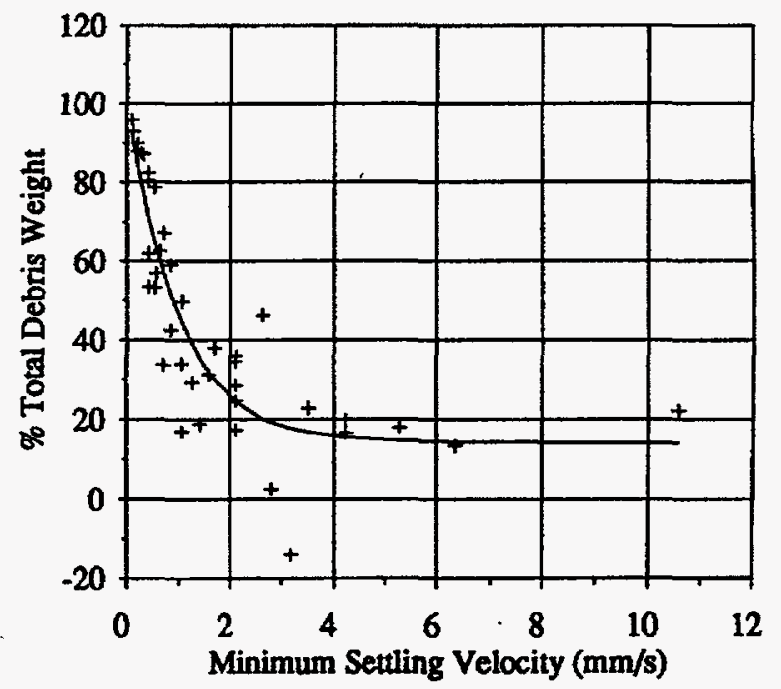

Sample Distance From Floor (prototype ft)

$$
\div 9.2-7.2+5.2 \div 3.2 \div 1.2
$$

Figure 4-2. Debris Settling in Suppression Pool; Test A-2 R1: 3.8 Ft Amplitude, 1.6 Sec Period (Case 3) NUKON ${ }^{\mathrm{TM}}: \quad 0.0032 \%$ Class 5\&6. Sludge A: $0.0 \%$ [3] 
Analysis of Experimental Results

9) AVERAGE CONCENTRATTON DURING CHUGGING

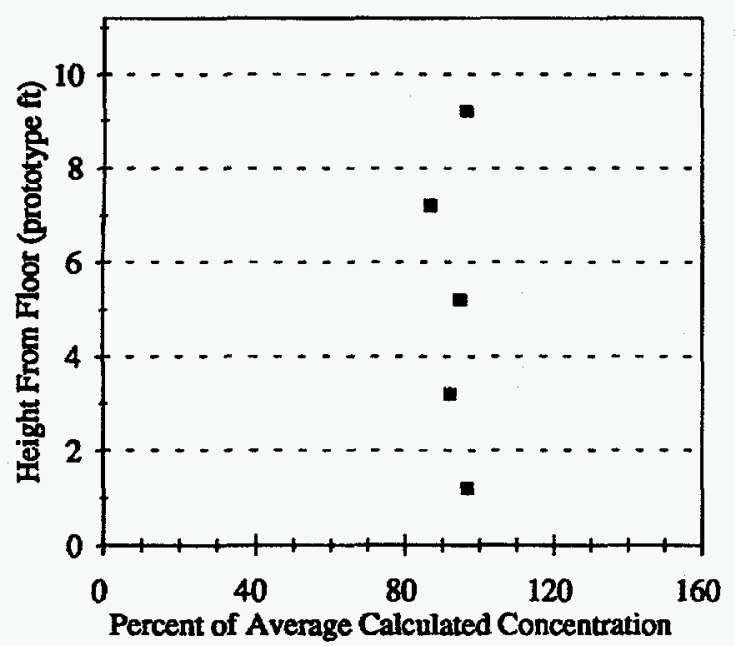

c) CONCENTRATION VS TIME

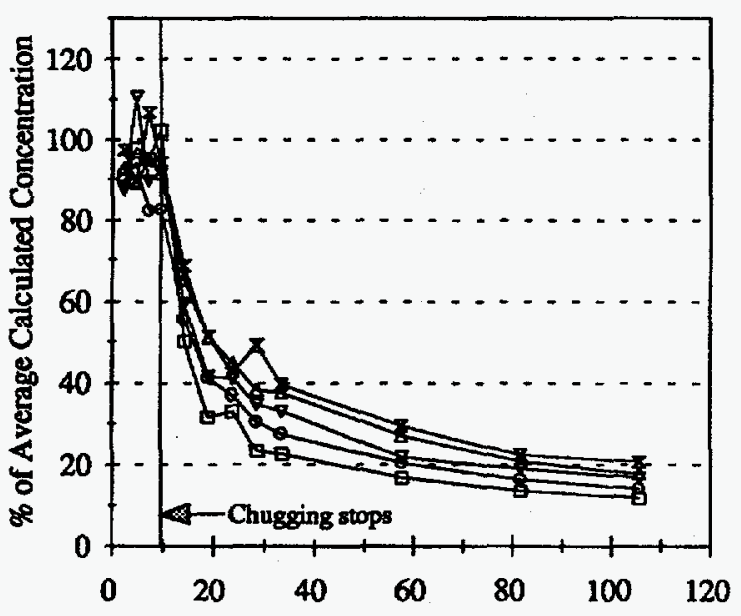

Time After Chugging Begins (prototype minutes)

Sample Distance From Floor (prototype ft)

$$
\rightarrow 9.2-7.2 \rightarrow 5.2-3.2 \div 1.2
$$

b) VERTYCAL CONCBNTRATION PROFIES

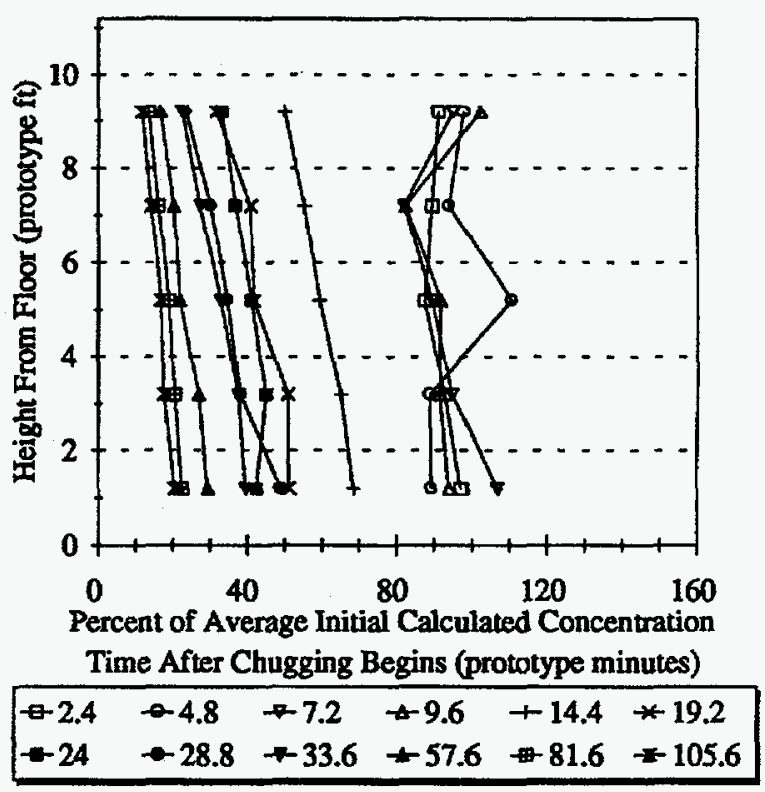

d) SETTLING VELOCTTY AFTER CHUGGING

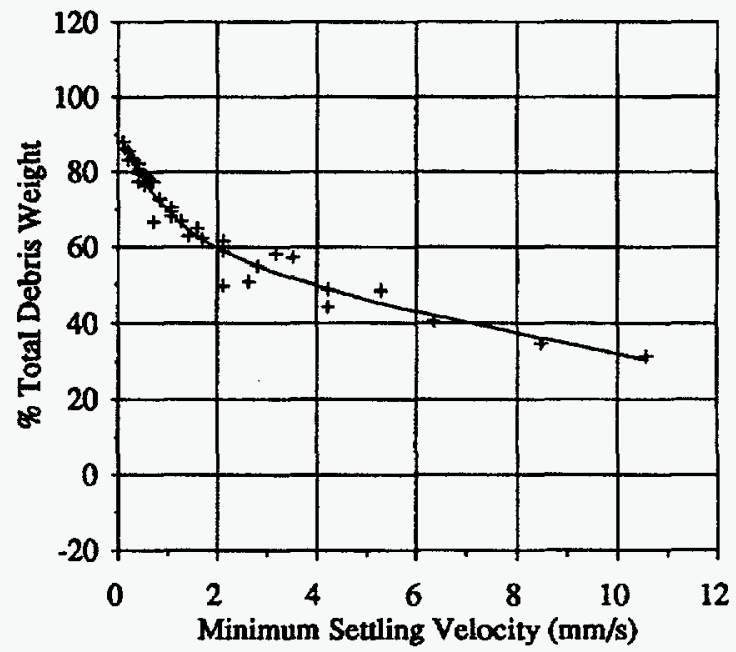

Figure 4-3. Debris Settling in Suppression Pool; Test A-3R1: $3.8 \mathrm{ft}$ amplitude; $1.6 \mathrm{Sec}$ Period (Case 3). NUKONTM: $0.0 \%$. Sludge A: $0.0213 \%$ [3] 
2) AVERAGB CONCENTRATION DURING CHUGGING

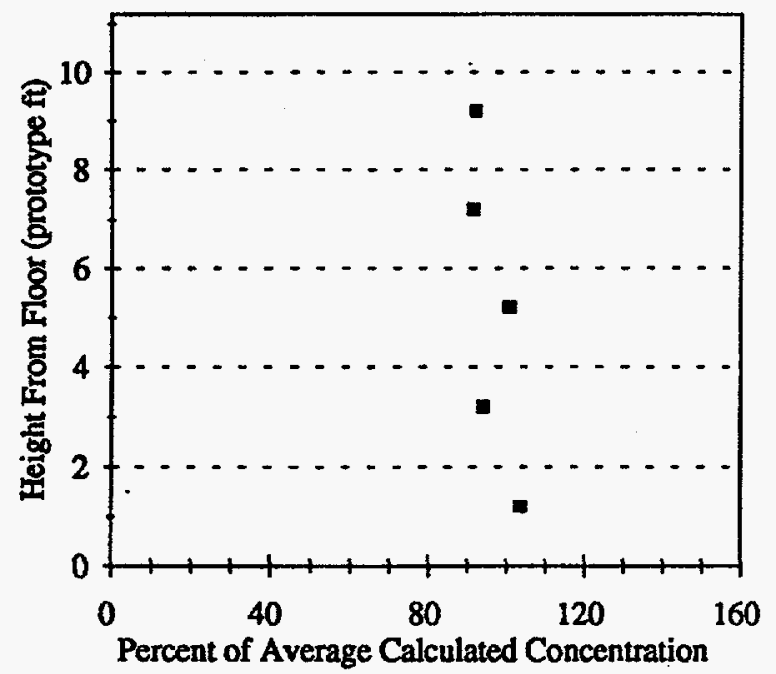

c) CONCENTRATION VS TTME

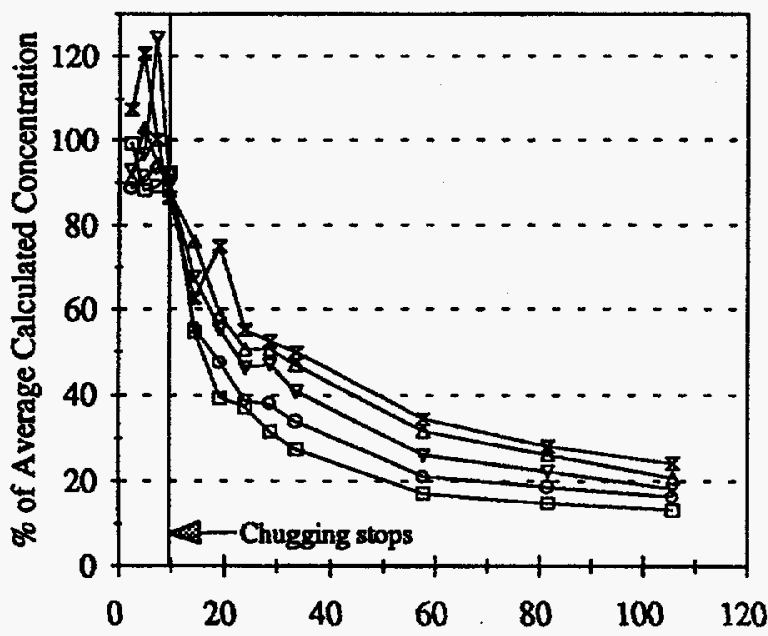

Time After Chugging Begins (prototype minutes)

\section{b) VERTICAL CONCENTRATION PROFLES}
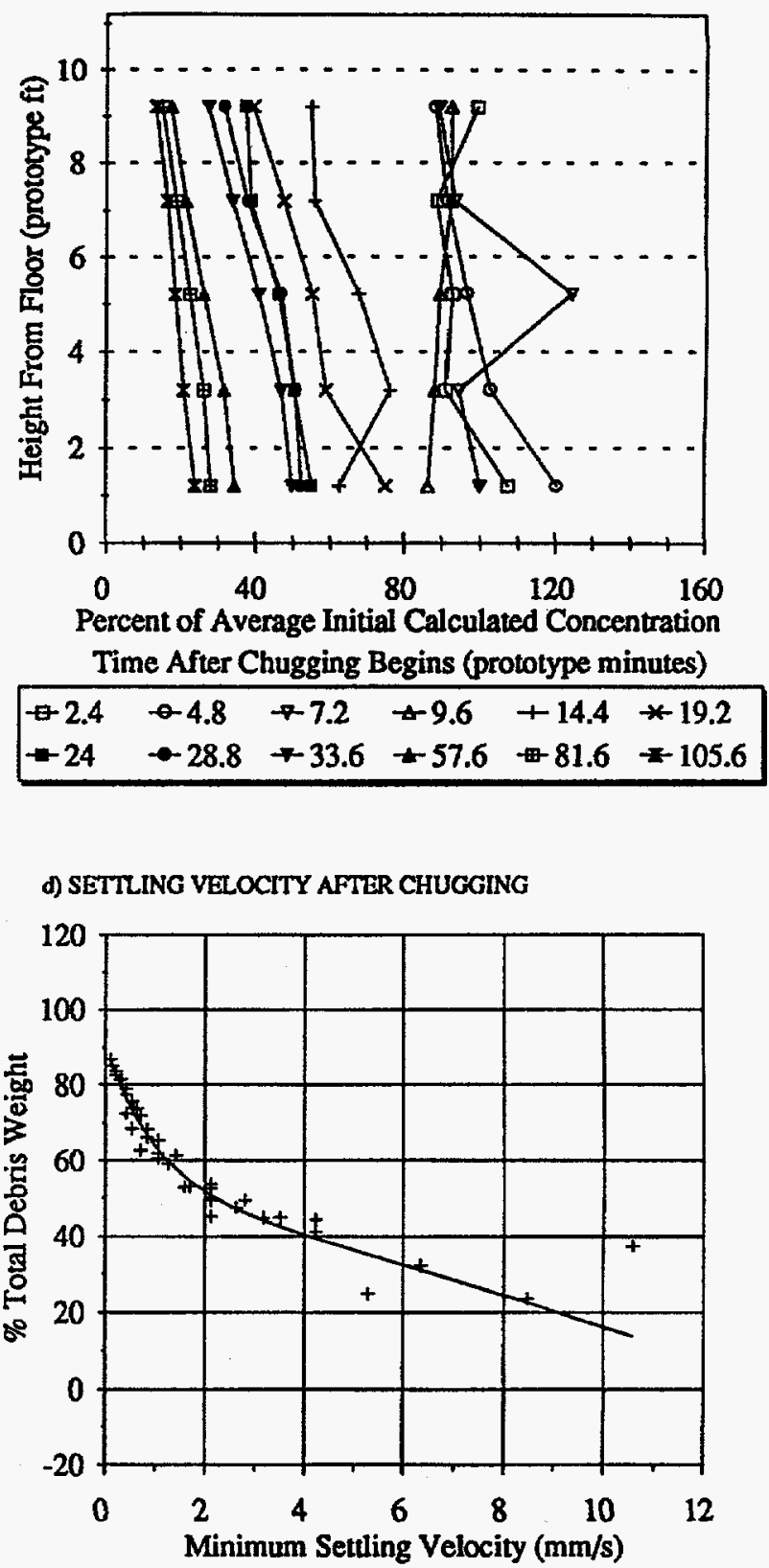

Sample Distance From Floor (prototype ft)

$\leftarrow 9.2-7.2+5.2+3.2+1.2$

Figure 4-4. Debris Settling in Suppression Pool; Test A-4 R1: 3.8 Ft Amplitude, 1.6 Sec Period (Case 3) NUKON $^{\mathrm{TM}}$ : $0.0032 \%$ Class $5 \& 6$. Sludge A: $0.0213 \%$ [3] 
Analysis of Experimental Results

a) AVERAGE CONCENTRATION DURING CHUGGING

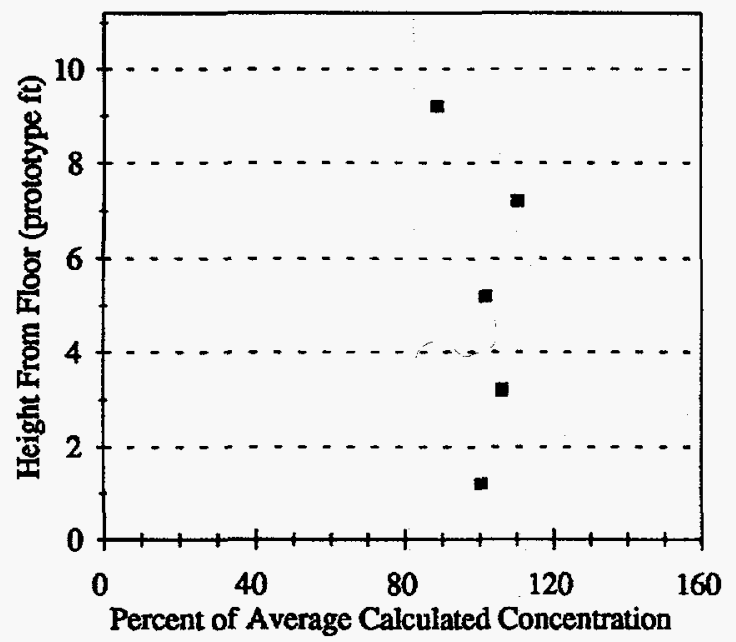

c) CONCENTRATION VS TIME

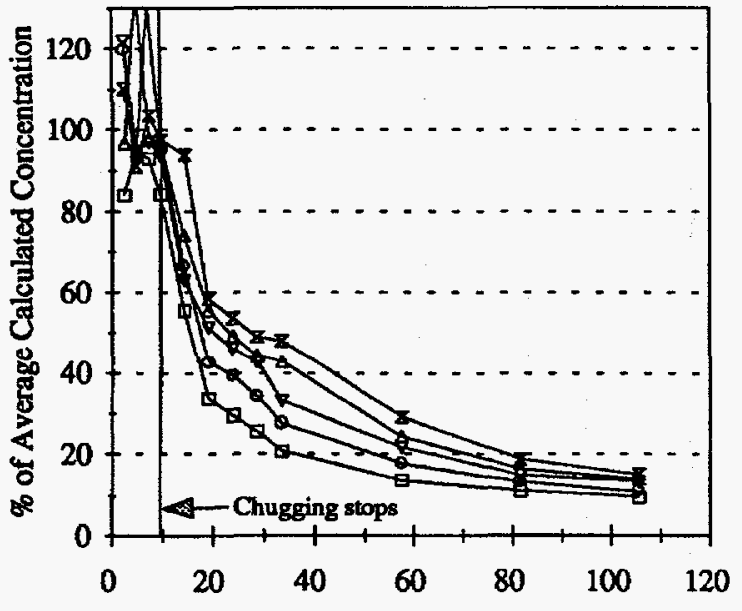

Time After Chugging Begins (prototype minutes) b) VERTICAL CONCENTRATION PROFILES

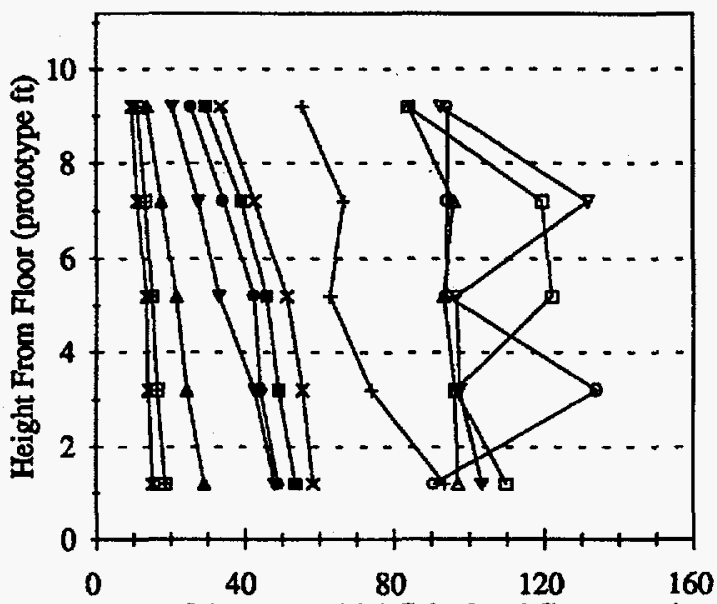

Percent of Average Initial Calculated Concentration

Time After Chugging Begins (prototype minutes)

$\begin{array}{llllll}-2.4 & -4.8 & -7.2 & \star 9.6 & +14.4 & * 19.2 \\ -24 & -28.8 & -33.6 & \star 57.6 & \# 81.6 & * 105.6\end{array}$

d) SETTLING VELOCTYY AFTER CHUGGING

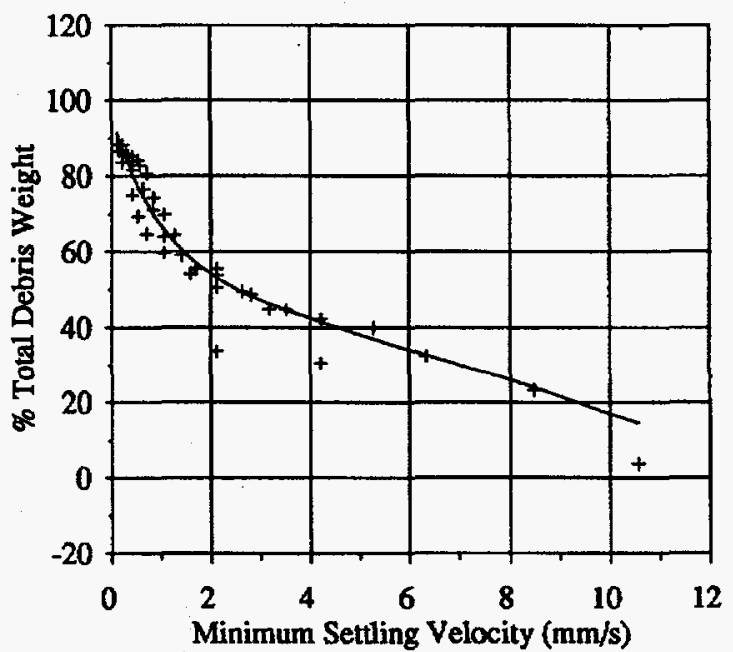

Sample Distance From Floor (prototype $\mathrm{ft}$ ) $\because 9.2-7.2 \div 5.2 \div 3.2 \div 1.2$

Figure 4-5. Debris Settling in Suppression Pool; Test A-5: $3.8 \mathrm{ft}$ amplitude, 1.6 Sec Period (Case 3). NUKONTM: $0.0032 \%$. Class 3 \& 4 . Sludge A: $0.0213 \%[3]$ 
a) AVERAGE CONCBNTRATION DURING CHUGGING

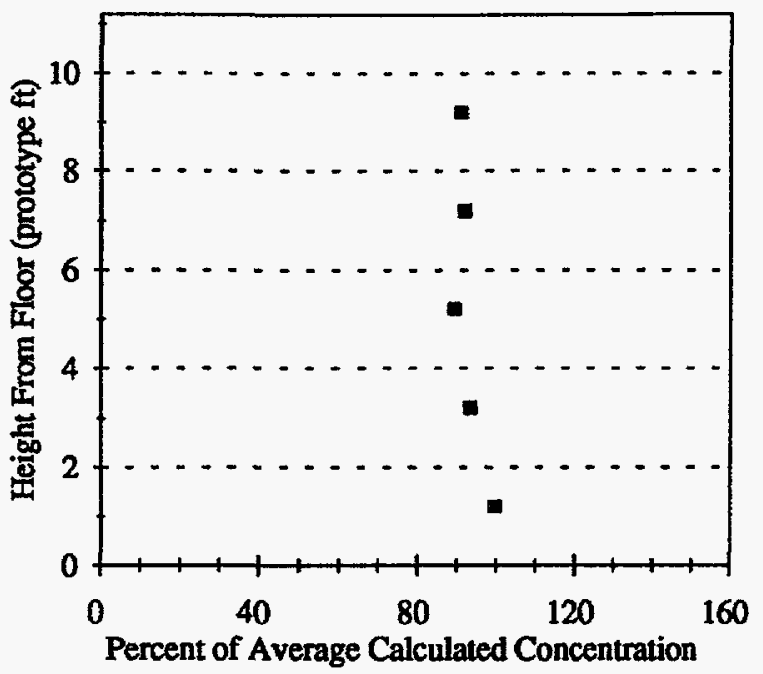

c) CONCENTRATION VS TIME

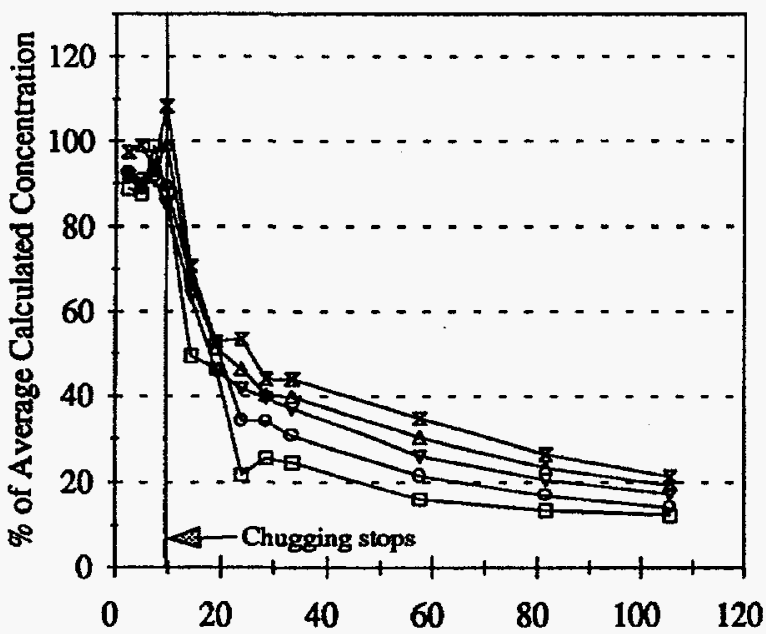

Time After Chugging Begins (prototype minutes)

\section{b) VERTICAL CONCENTRATION PROFII ES}

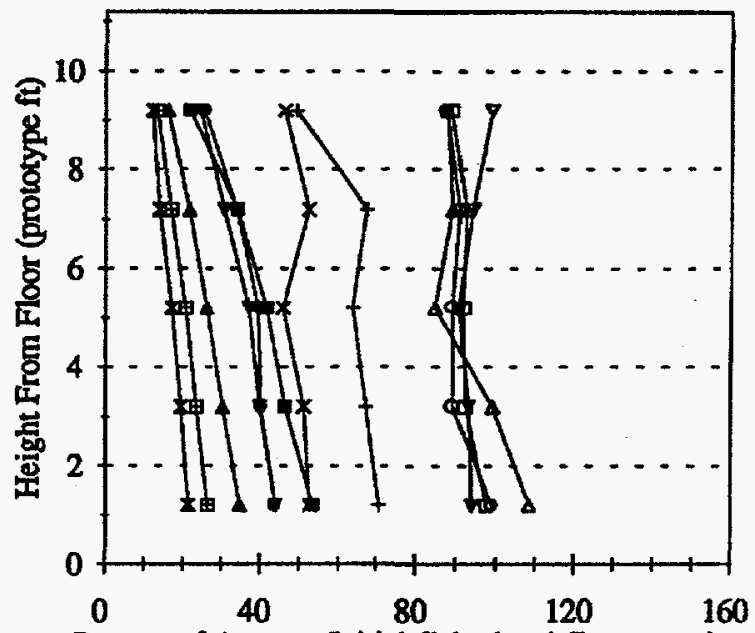

Percent of Average Initial Calculated Concentration

Time After Chugging Begins (prototype minutes)

$\begin{array}{llllll}-42.4 & -4.8 & \rightarrow 7.2 & \star 9.6 & +14.4 & * 19.2 \\ -24 & -28.8+33.6 & -57.6 & +81.6 & -105.6\end{array}$

\section{d) SETILING VELOCITY AFTER CHUGGING}

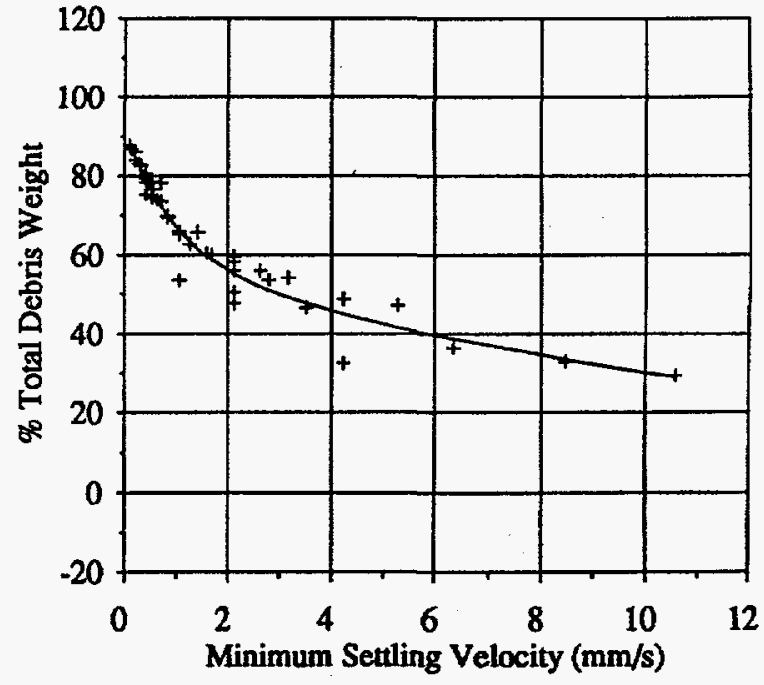

Sample Distance From Floor (prototype ft)

$\leftarrow 9.2-7.2+5.2 \leftarrow 3.2 \div 1.2$

Figure 4-6. Debris Settling in Suppression Pool; Test B-6: 3.8 Ft Amplitude, 1.6 Sec Period (Case 3) NUKONTM: $0.0011 \%$ Class $5 \& 6$. Sludge A: $0.0213 \%$ [3] 
Analysis of Experimental Results

2) AVERAGB CONCBNTRATION DURING CHUGGNG

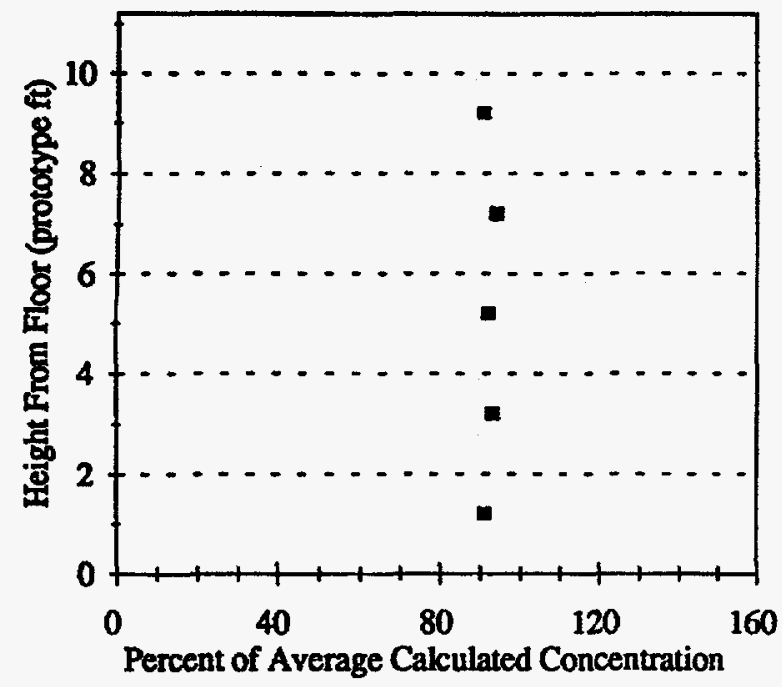

c) CONCENTRATION VS TIME

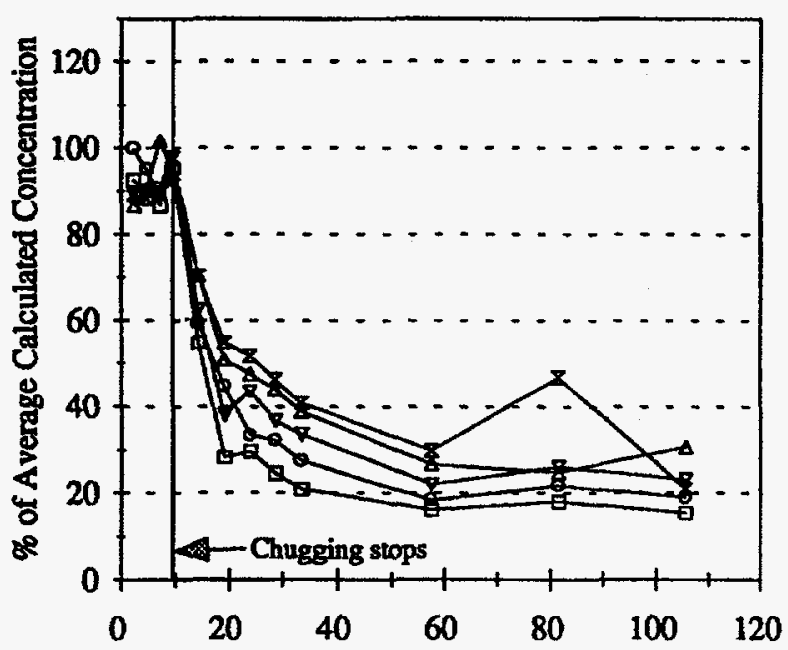

Time After Chugging Begins (prototype minutes)

Sample Distance From Floor (prototype ft) b) VERTICAL CONCENTRATION PROFILES

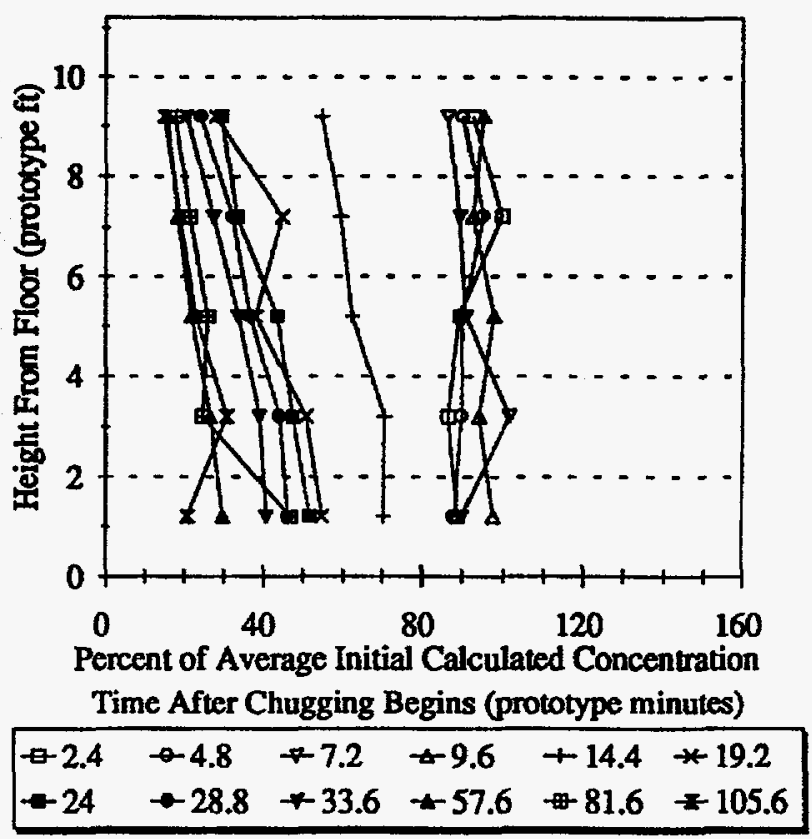

d) SETTLING VELOCITY AFTER CHUGGING

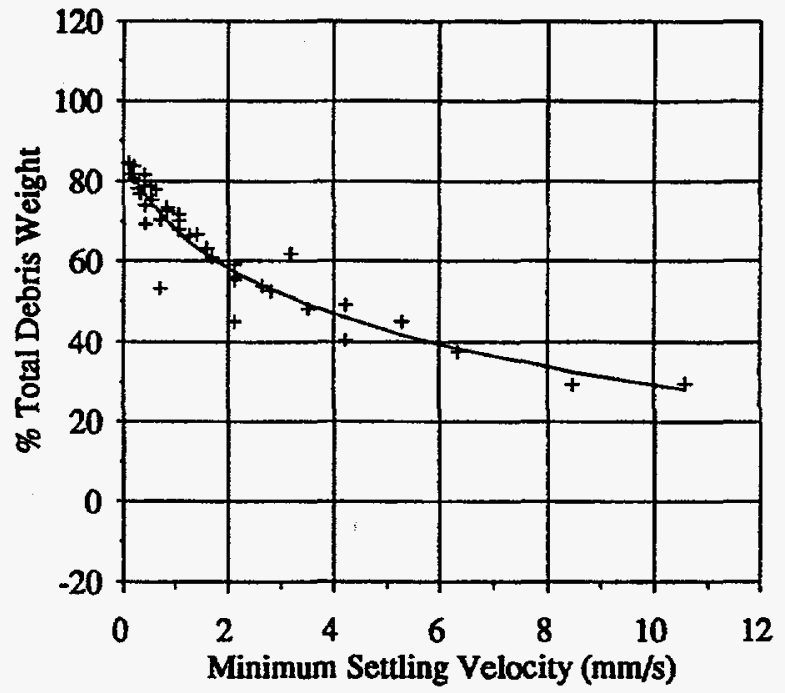

Figure 4-7. Debris Settling in Suppression Pool; Test B-7: 3.8 Ft Amplitude, 1.6 Sec Period (Case 3) NUKON ${ }^{\mathrm{TM}}$ : $0.0011 \%$ Class $3 \& 4$. Sludge A: $0.0213 \%[3]$ 
a) AVERAGE CONCENIRATION DURING CHUGGING

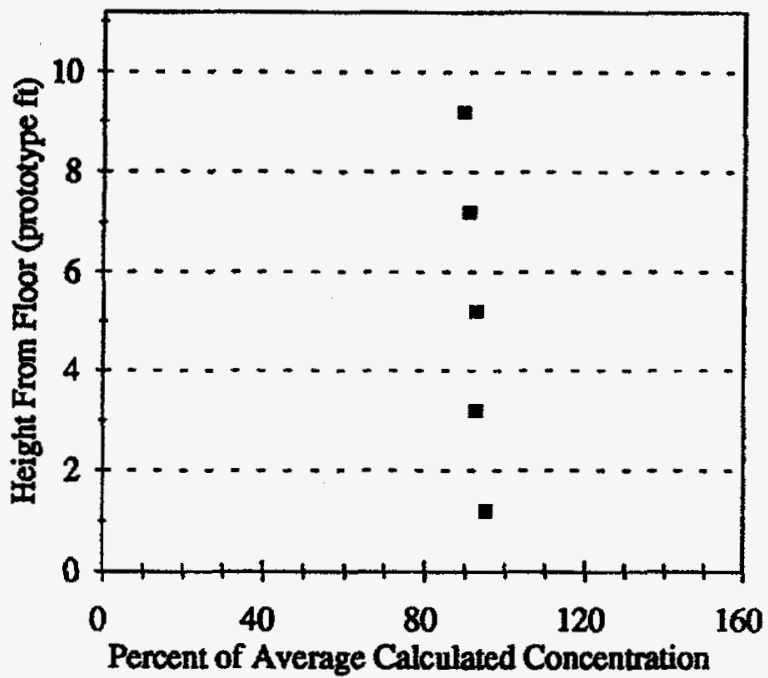

c) CONCENTRATION VS TIME

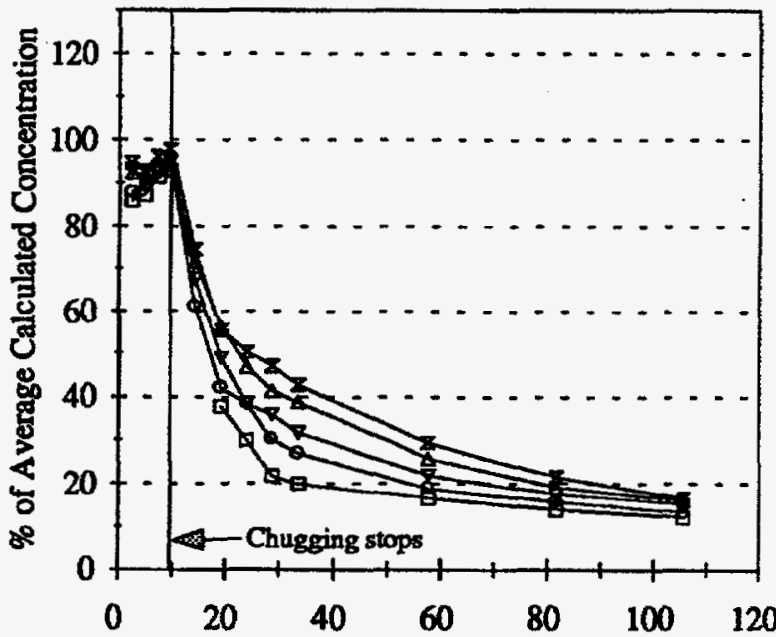

Time After Chugging Begins (prototype minutes) b) VERTICAL CONCENTRATION PROFILS

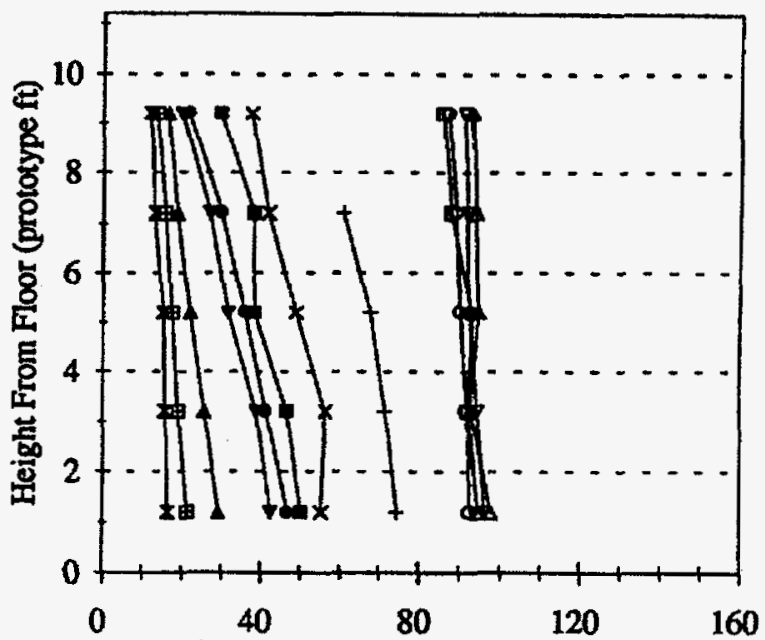

Percent of Average Initial Calculated Concentration Time After Chugging Begins (prototype minutes)

$$
\begin{array}{llllll}
-2.4 & -4.8 & -7.2 & -9.6 & +14.4 * 19.2 \\
-24 & -28.8 & -33.6 & -57.6+81.6 \neq 105.6
\end{array}
$$

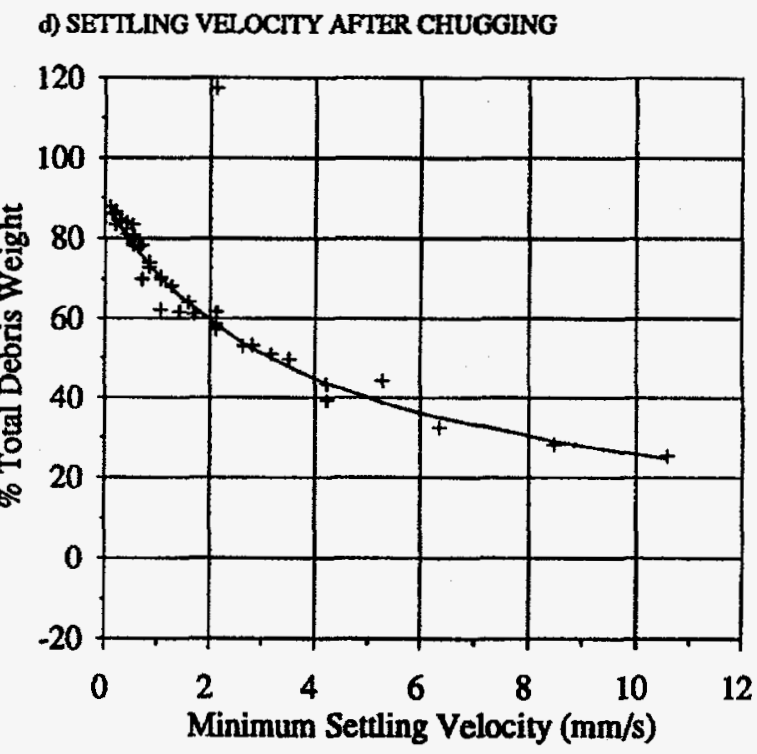

Sample Distance From Floor (prototype ft) $\nleftarrow 9.2-7.2 \rightarrow 5.2 \nleftarrow 3.2 \div 1.2$

Figure 4-8. Debris Settling in Suppression Pool; Test B-9: 3.8 Ft Amplitude, 1.6 Sec Period (Case 3) NUKONTM: $0.0 \%$. Sludge A: $0.0638 \%[3]$ 
a) AVERAGE CONCENTRATION DURING CHUGGING

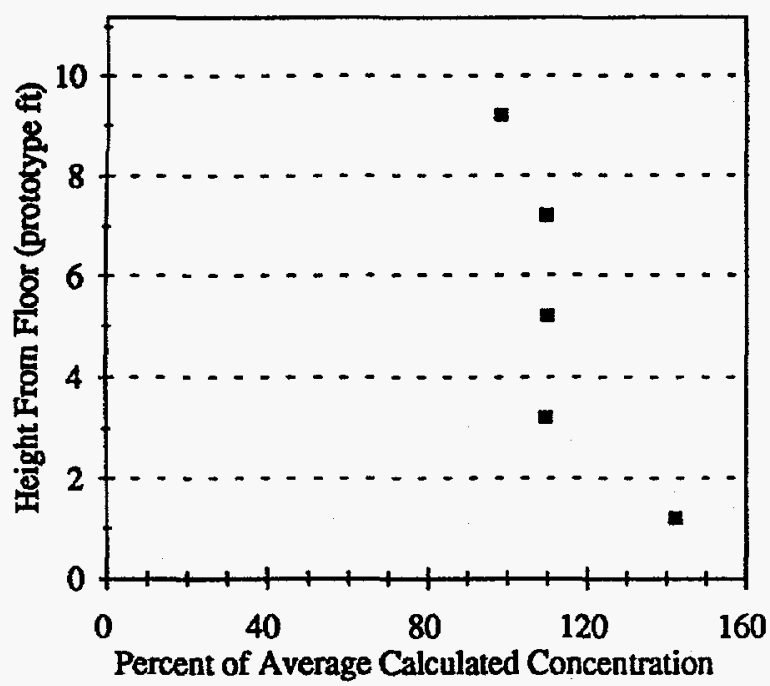

c) CONCENTRATION VS TTME

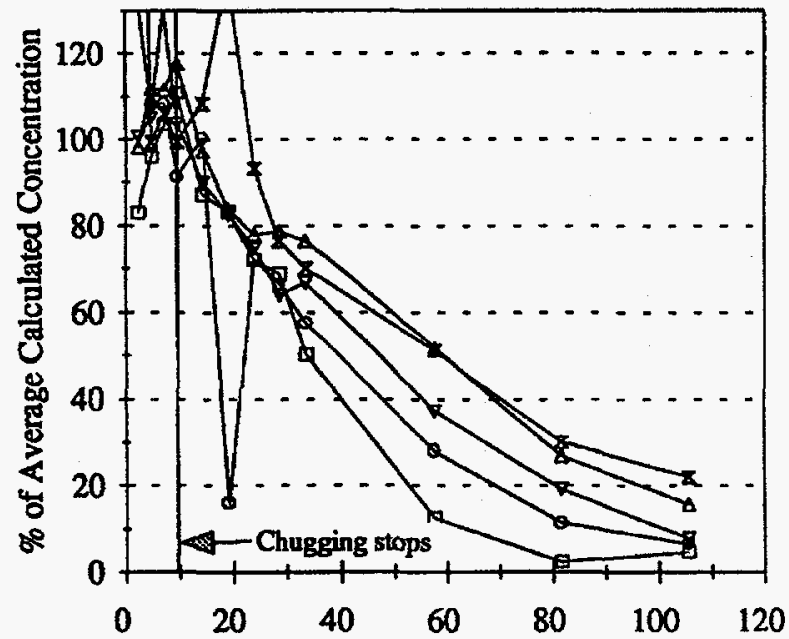

Time After Chugging Begins (prototype minutes) b) VERTICAL CONCENTRATION PROFILES

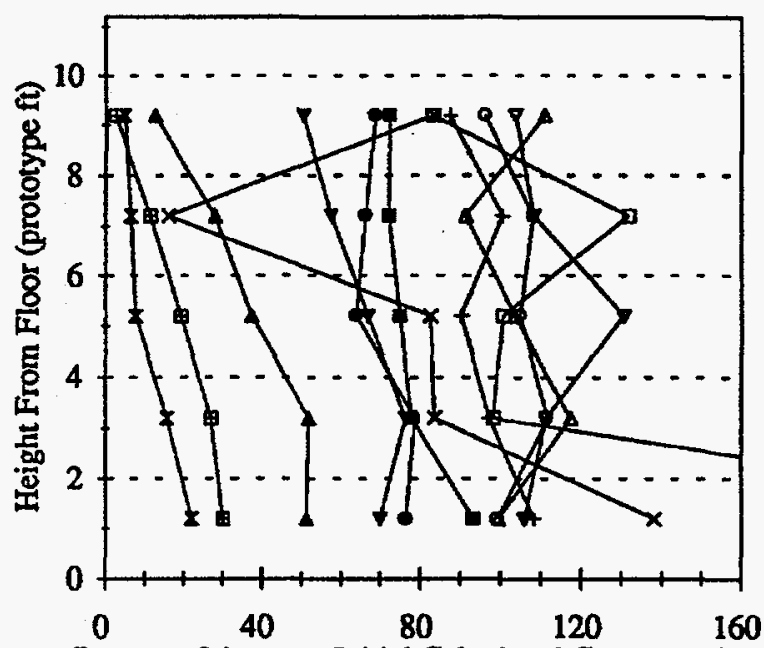

Percent of Average Initial Calculated Concentration

Time After Chugging Begins (prototype minutes)

$\begin{array}{llllll}+2.4 & -4.8 & \rightarrow 7.2 & -9.6 & +14.4 & * 19.2 \\ -24 & -28.8 & +33.6 & -57.6 & \# 81.6 & * 105.6\end{array}$

d) SETTLING VELOCTTY AFTER CHUGGING

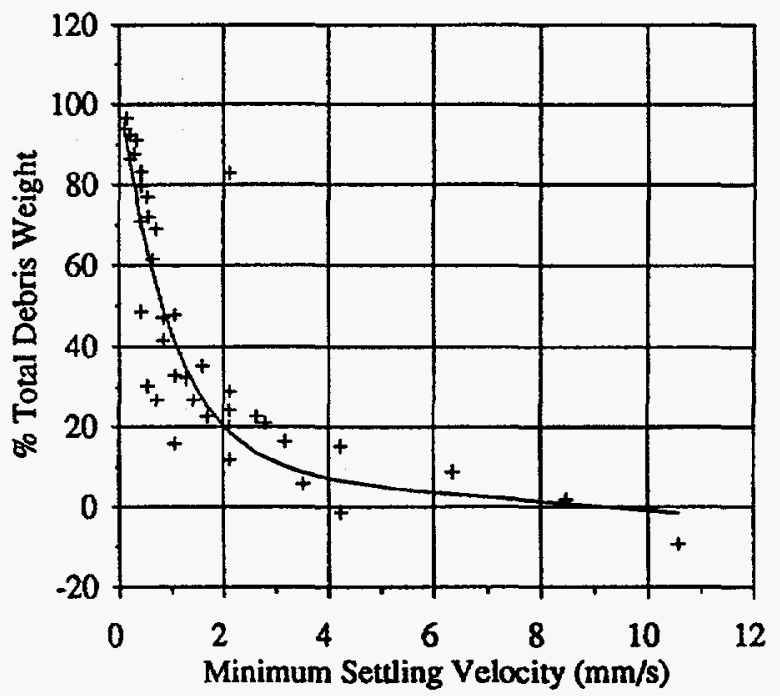

Sample Distance From Floor (prototype ft) $\nleftarrow 9.2-7.2 * 5.2+3.2 * 1.2$

Figure 4-9. Debris Settling in Suppression Pool; Test D-11 R1: 5.0 Ft Amplitude, 1.9 Sec Period (Case 2) NUKON ${ }^{\mathrm{TM}}$ : $0.0032 \%$ Class $3 \& 4$. Sludge A: $0.0 \%[3]$ 
a) AVERAGE CONCENTRATION DURING CHUGGING

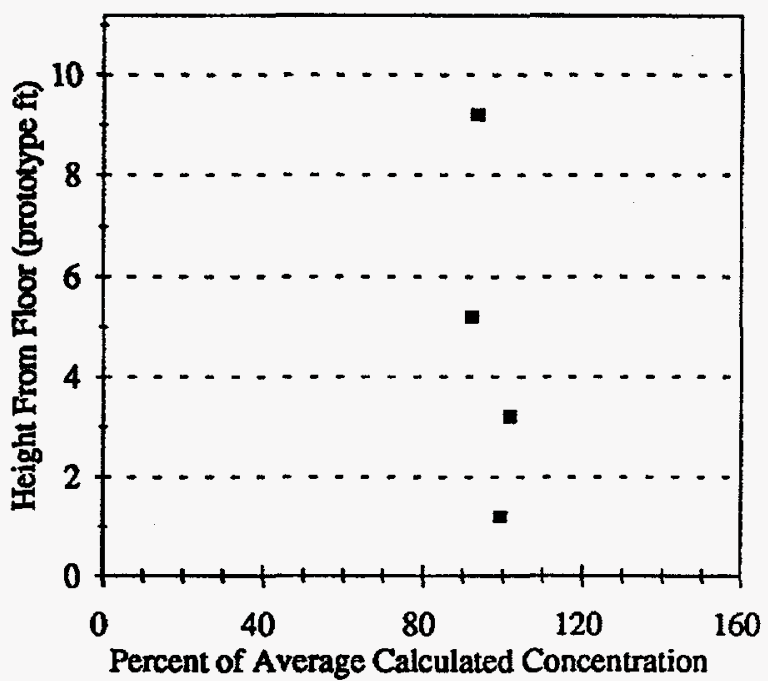

c) CONCENTRATION VS TIME

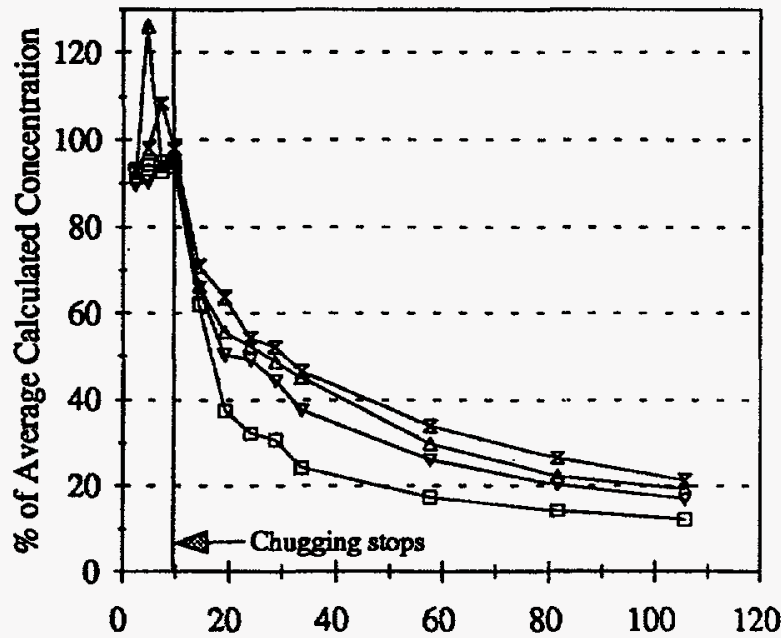

Time After Chugging Begins (prototype minutes)

\section{b) VERTICAL CONCENTRATION PROFILES}

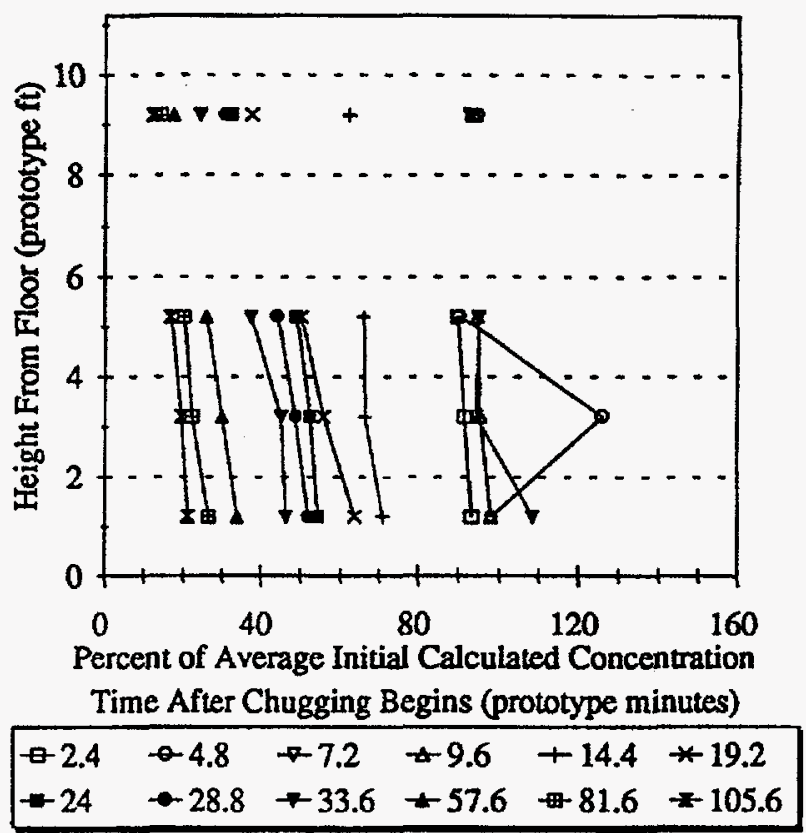

d) SETTLING VELOCITY AFTER CHUGGING

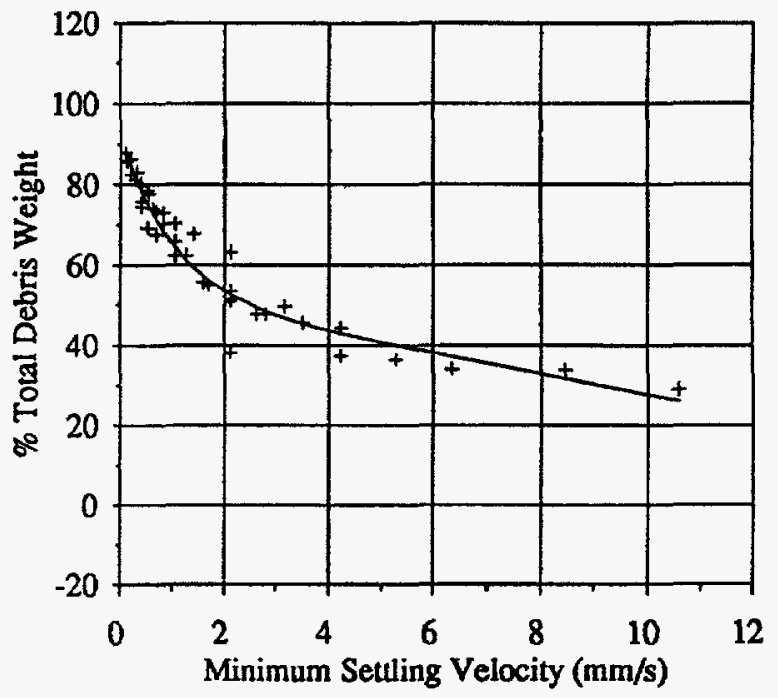

Sample Distance From Floor (prototype ft) $\rightarrow 9.2-7.2 \div 5.2 \leftarrow 3.2 \div 1.2$

Figure 4-10. Debris Settling in Suppression Pool; Test D-14 R1: 5.0 Ft Amplitude, 1.9 Sec Period (Case 2) NUKON ${ }^{\mathrm{TM}}$ : $0.0032 \%$ Class 5\&6. Sludge A: $0.0213 \%$ [3] 
Analysis of Experimental Results

2) AVERAGB CONCENTRATION DURING CHUGGING

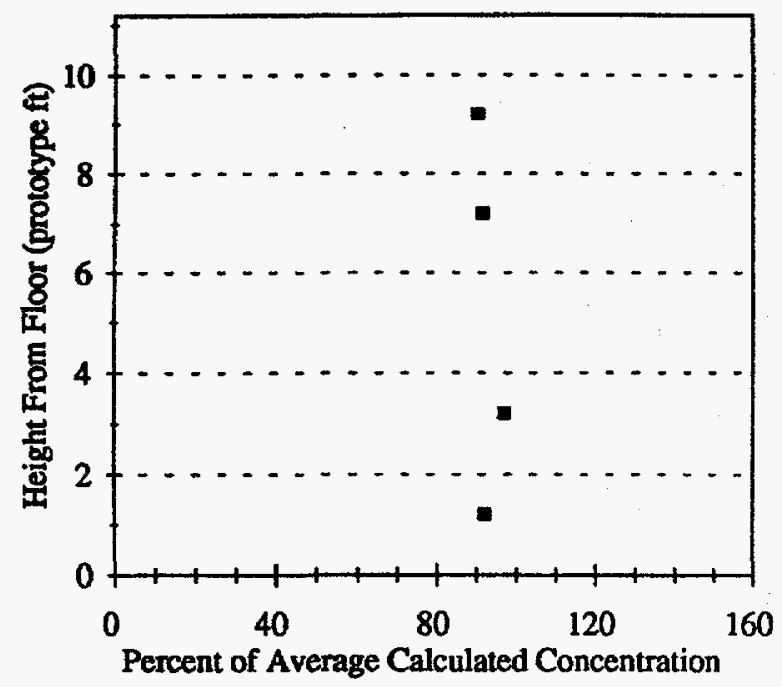

c) CONCENTRATION VS TIME

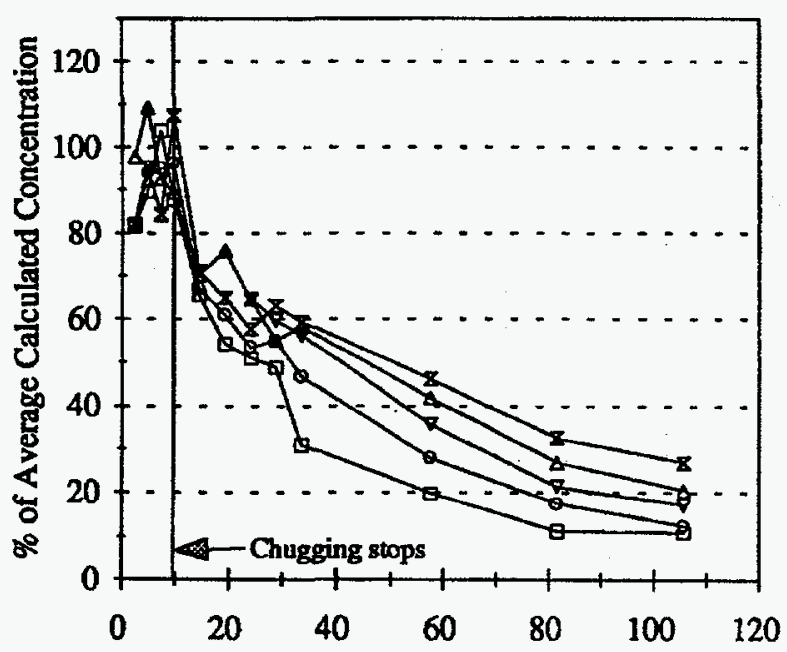

Time After Chugging Begins (prototype minutes)

Sample Distance From Floor (prototype $\mathrm{ft}$ ) $\nleftarrow 9.2-7.2 \div 5.2 \div 3.2 \div 1.2$ b) VERTICAL CONCENTRATION PROFULS

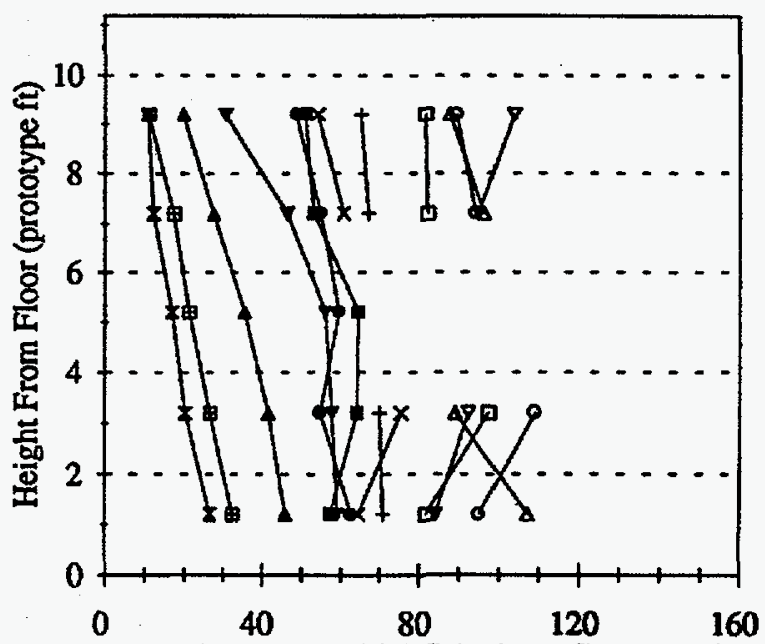

Percent of Average Initial Calculated Concentration Time After Chugging Begins (prototype minutes)

$$
\begin{array}{lllll}
\leftarrow 2.4 & -4.8 & -7.2 & \star 9.6 & +14.4 \div 19.2 \\
-24 & -28.8+33.6 & -57.6 & +81.6 \neq 105.6
\end{array}
$$

\section{d) SETTLING VELOCITY AFTER CHUGGING}

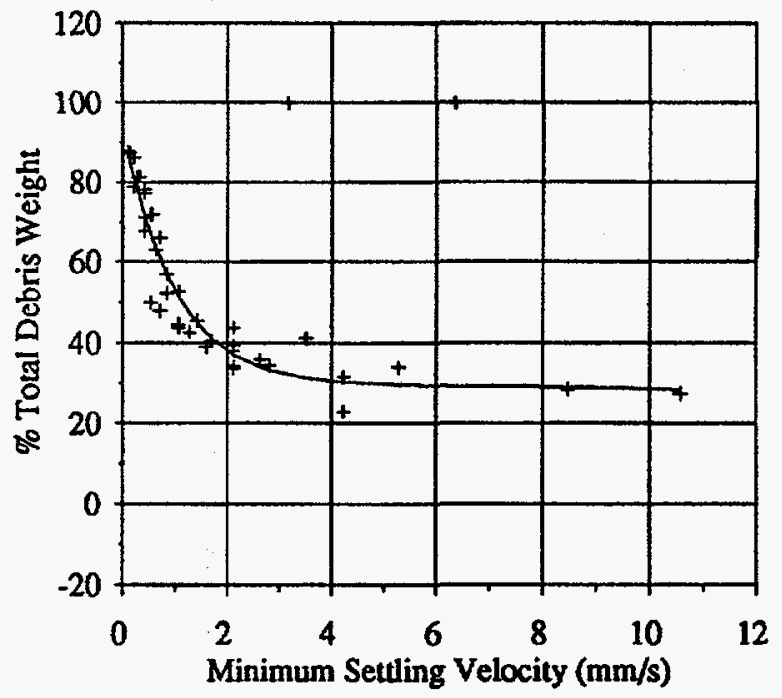

Figure 4-11. Debris Settling in Suppression Pool; Test T-17: 3.8 Ft Amplitude, 1.6 Sec Period (Case 3) NUKON $^{\mathrm{TM}}: 0.0032 \%$ Class $3 \& 4$. Sludge A: $0.0032 \%$ [3] 
a) AVERAGE CONCENTRATION DURING CHUGGING

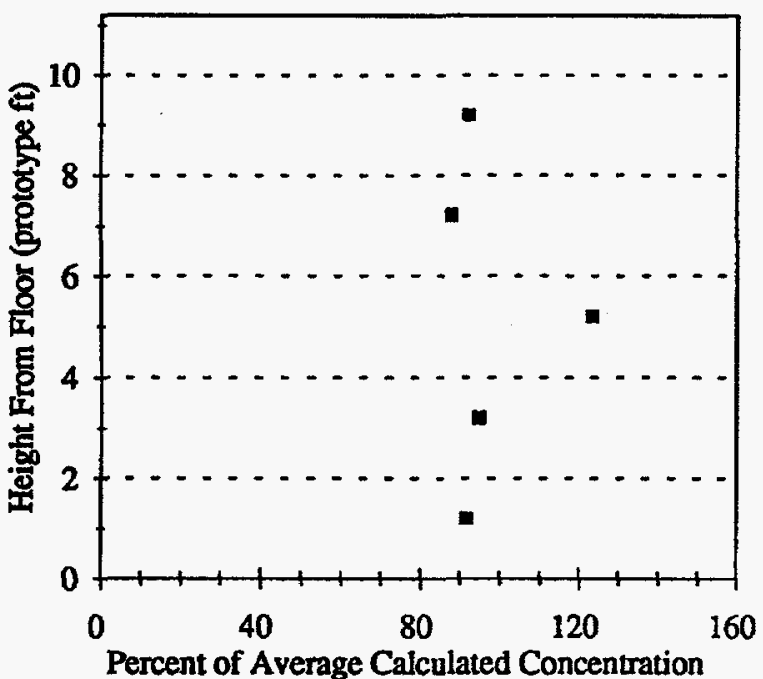

c) CONCENTRATION VS TIME

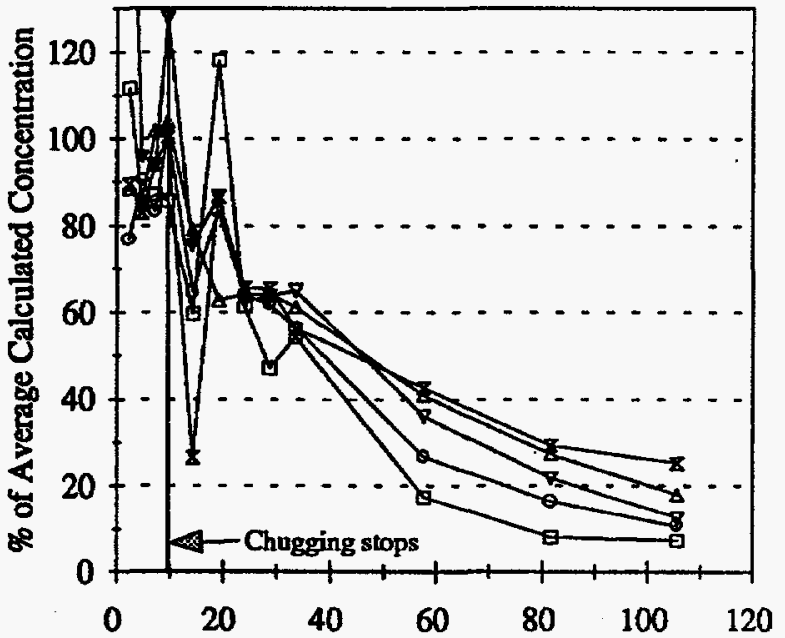

Time After Chugging Begins (protolype minutes)

Sample Distance From Floor (prototype ft) $\notin 9.2-7.2-5.2-3.2-1.2$ b) VERTICAL CONCENTRATION PROFILBS

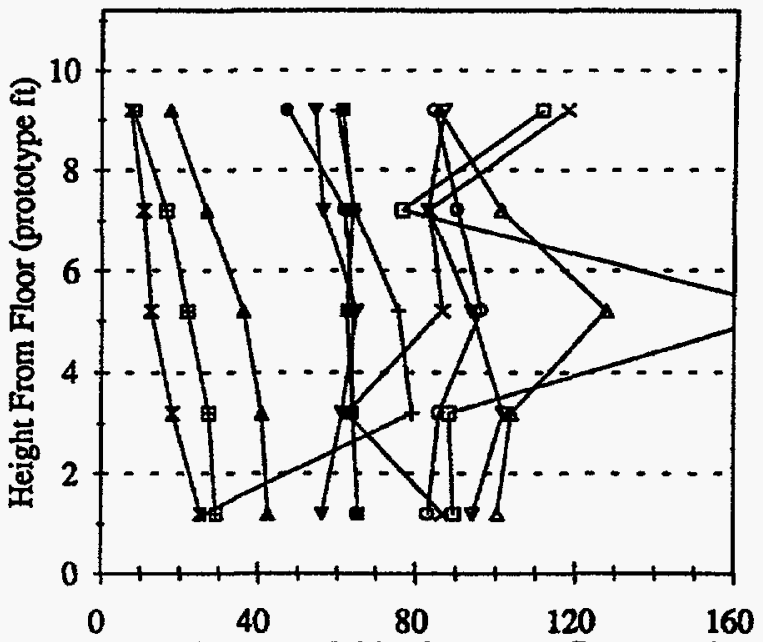

Percent of Average Initial Calculated Concentration Time After Chugging Begins (prototype minutes)

$\begin{array}{lllll}-2.4 & -4.8 & -7.2 & -9.6+14.4 * 19.2 \\ -24 & -28.8+33.6+57.6+81.6 \neq 105.6\end{array}$

d) SETTLING VELOCTTY AFTER CHUGGING

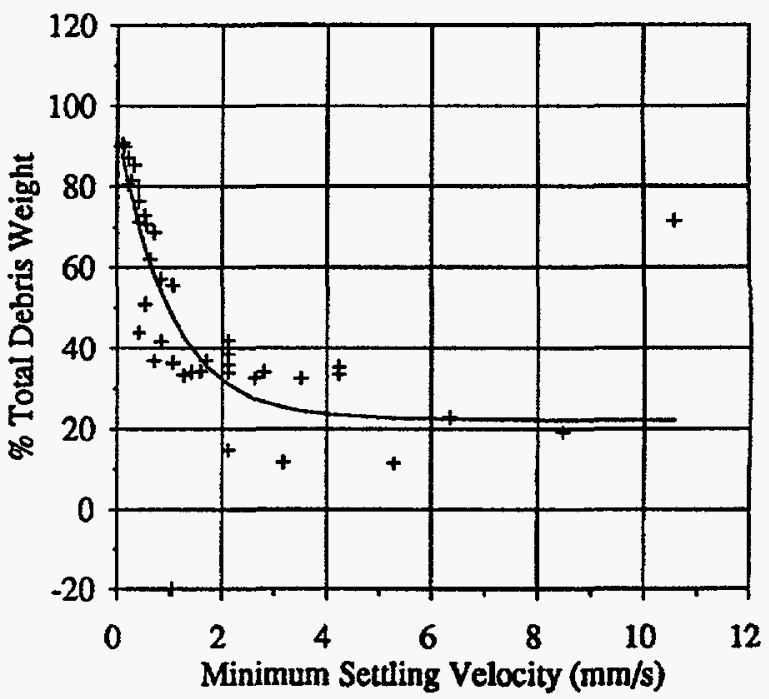

Figure 4-12. Debris Settling in Suppression Pool; Test T-18: 3.8 Ft Amplitude, 1.6 Sec Period (Case 3) NUKONTM: $0.0032 \%$ Class $3 \& 4$. Sludge A: $0.0016 \%$ [3] 
low energy chugs, such as case 3 chugs, will result in fully mixed conditions soon after the simulated chugging starts, irrespective of where the debris was introduced, i.e., on the floor or near the downcomer. These tests also demonstrate that potential for debris settling is negligible during the chugging phase.

Visual observations during simulated chugging tests with NUKON ${ }^{\mathrm{TM}}$ debris, both with classes $3 \& 4$ and $5 \& 6$, showed further disintegration of fibrous debris into smaller sizes, including a considerable amount of individual fibers. In general, the disintegration occurred close to the downcomer where the shreds are subjected to cyclic forces of downward jet and ingestion into the downcomer. This visual observation is supported by concentration measurements which reveal that more than $10-15 \%$ of the debris remains suspended for time periods larger than 100 minutes after termination of simulated chugging, which is only possible if the debris underwent disintegration.

In these tests, the debris were introduced at the bottom of the tank, which is different from the actual BWR suppression pools where the fibrous debris are introduced through the downcomers. Introduction of fibrous debris through the downcomers would heighten the potential for fragmentation of debris.

\subsection{Settling After Simulated Chugging}

In all tests, simulated chugging was terminated after 4 minutes or 9.6 actual case minutes. Visual observations suggest that debris, especially the sludge particles, start to sediment immediately after termination of simulated chugging, indicating rapid decay in turbulence levels. These observations are confirmed by concentration measurements which were plotted in caption c) of Figures 4-1 through 4-12. As can be seen from these figures, the measured concentration at each sampling position decreases with time due to gravitational settling. In addition, as can be seen from caption b) in these figures, the measured concentration at the lower elevations (e.g., $1.2 \mathrm{ft}$, or $0.32 \mathrm{~m}$, off the floor) is continually larger than the corresponding at higher elevations (e.g., $9.2 \mathrm{ft}$, or $2.80 \mathrm{~m}$, off the floor), which is also consistent with the gravitational settling. The concentration data with time were analyzed using a settling column approach to obtain settling velocities as described in Reference [9]. Caption d) in Figures 4-1 through 4-12 plot these settling velocities for the tests, as minimum settling velocities versus the fraction of debris possessing those velocities. Figure 4-13 plots settling velocity versus weight fraction for insulation debris of classes $3 \& 4$ and $5 \& 6$. Figure 4-14 presents similar curves for sludge and fiber mixtures of different sludge-to-fiber mass ratios, including the case of sludge only. These figures can be used to draw the following insights:

- As a result of fragmentation suffered by the debris during the high energy phase, settling rates are weakly dependent on the class of the fibers ( $3 \& 4$ vs $5 \& 6$ ) initially added to the tank (see Figure 4-13). Two different equations were developed for each for Classes $3 \& 4$ and Classes $5 \& 6$ and listed on Figure 4-13. The slight differences in the settling velocity suggest that possibly class $5 \& 6$ possesses slightly larger pieces at the termination of chugging. However, the differences appear to be negligible.

- In general, the sludge possesses larger settling velocities, as demonstrated by the fact that $50 \%$ of the insulation debris possesses settling velocity less than $1 \mathrm{~mm} / \mathrm{s}$, whereas $50 \%$ of the tested Sludge A possesses settling velocity in excess of $3 \mathrm{~mm} / \mathrm{s}$.

The settling velocities for sludge and fiber mixtures can be estimated using the principle of superposition. This suggests that fibrous and non-fibrous species settle independently of each other.

The settling velocity measurements can also be used to draw several insights into size distribution of the debris, especially the particulate debris. From Stokes' law it is known that for spherical particles the settling velocities, $\mathrm{V}_{\mathrm{s}^{\prime}}$ in calm pools can be estimated using the following equation:

$$
V_{s}=\frac{D_{p}^{2} g\left(\rho_{p}-\rho_{w}\right)}{18 \mu}
$$




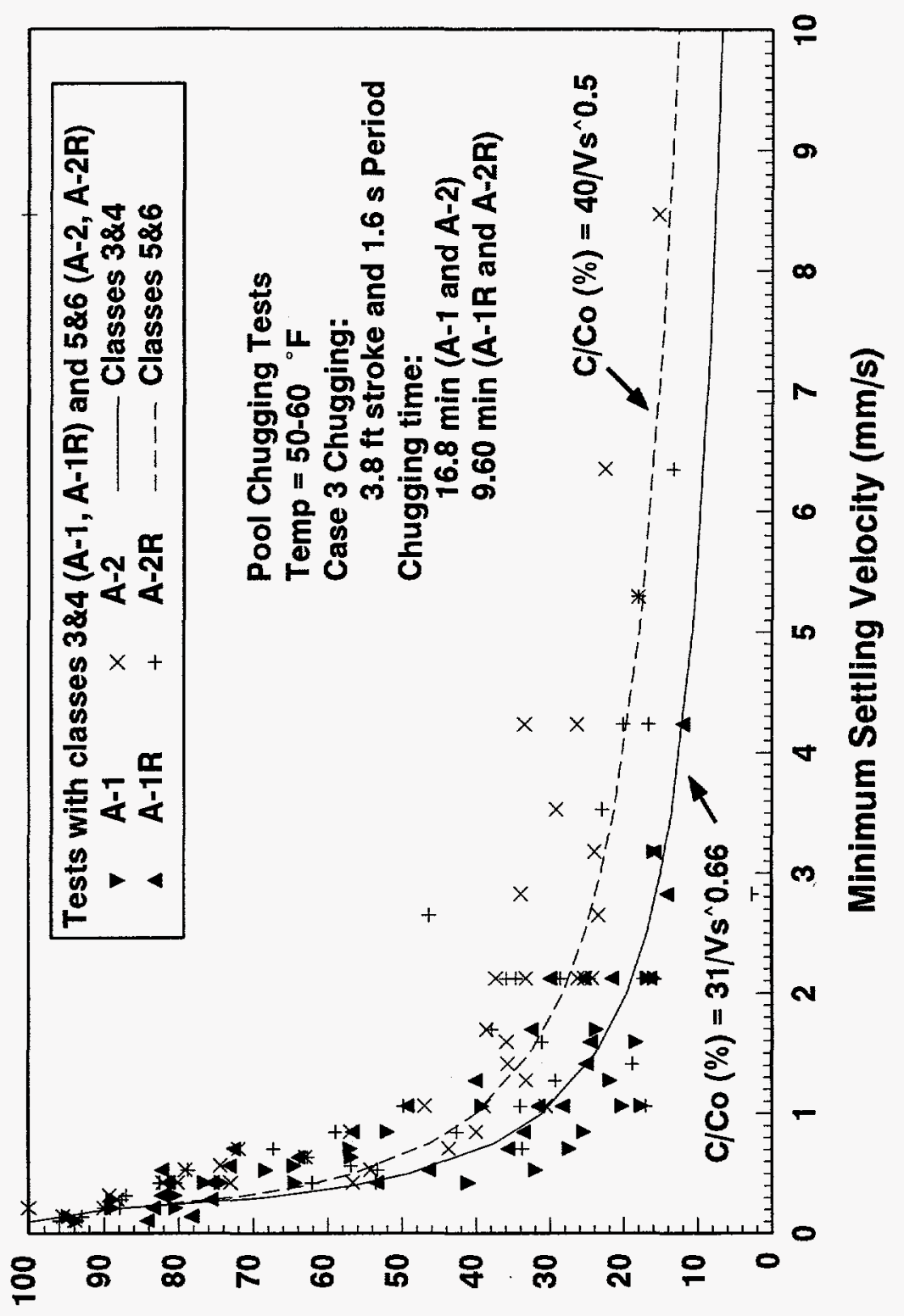




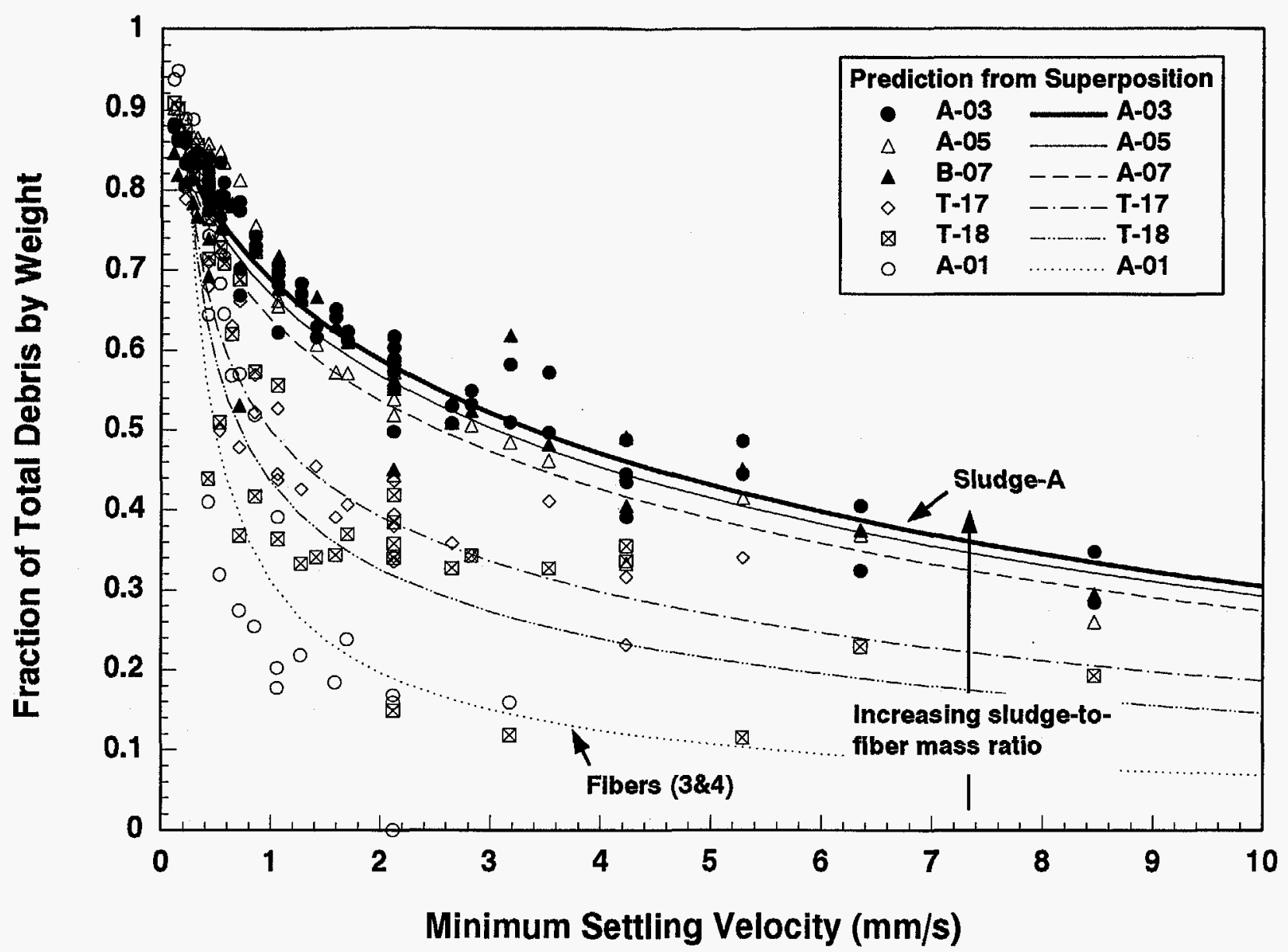

Figure 4-14. Settling Velocities for Various Sludge and Fiber Mixtures Predicting Using the Principle of Superposition (Assumes Independent Behavior) 
$D_{p} \quad$ is the equivalent diameter of the debris particle,

$\rho_{p} \quad$ is the density of the debris particle,

$\rho_{w}$ is the density of water,

$\mu \quad$ is the viscosity of water,

$\mathrm{g}$ is the acceleration of gravity.

This equation can be inversed to estimate the minimum particle diameter once the minimum settling velocity is known as follows:

$$
D_{p}=\sqrt{\frac{18 \mu V_{s}}{g\left(\rho_{p}-\rho_{w}\right)}}
$$

The minimum particle size distribution data obtained in this manner for sludge only is plotted in Figure 4-15. This figure suggests that more than $50 \%$ of the Sludge A consists of particles larger than $40 \mu \mathrm{m}$, and more than $25 \%$ are larger than $70 \mu \mathrm{m}$. Clearly, these estimates indicate that sludge particles in the tank are larger than manufacturer's specifications for powder \#2008. This observation is also consistent with the SEM pictures (e.g., Figures 3-10 and 3-11) of dry Sludge A samples. This confirms that the iron-oxide sludge particles tend to agglomerate quickly and form large agglomerates that are not easily disintegrated by turbulence. 


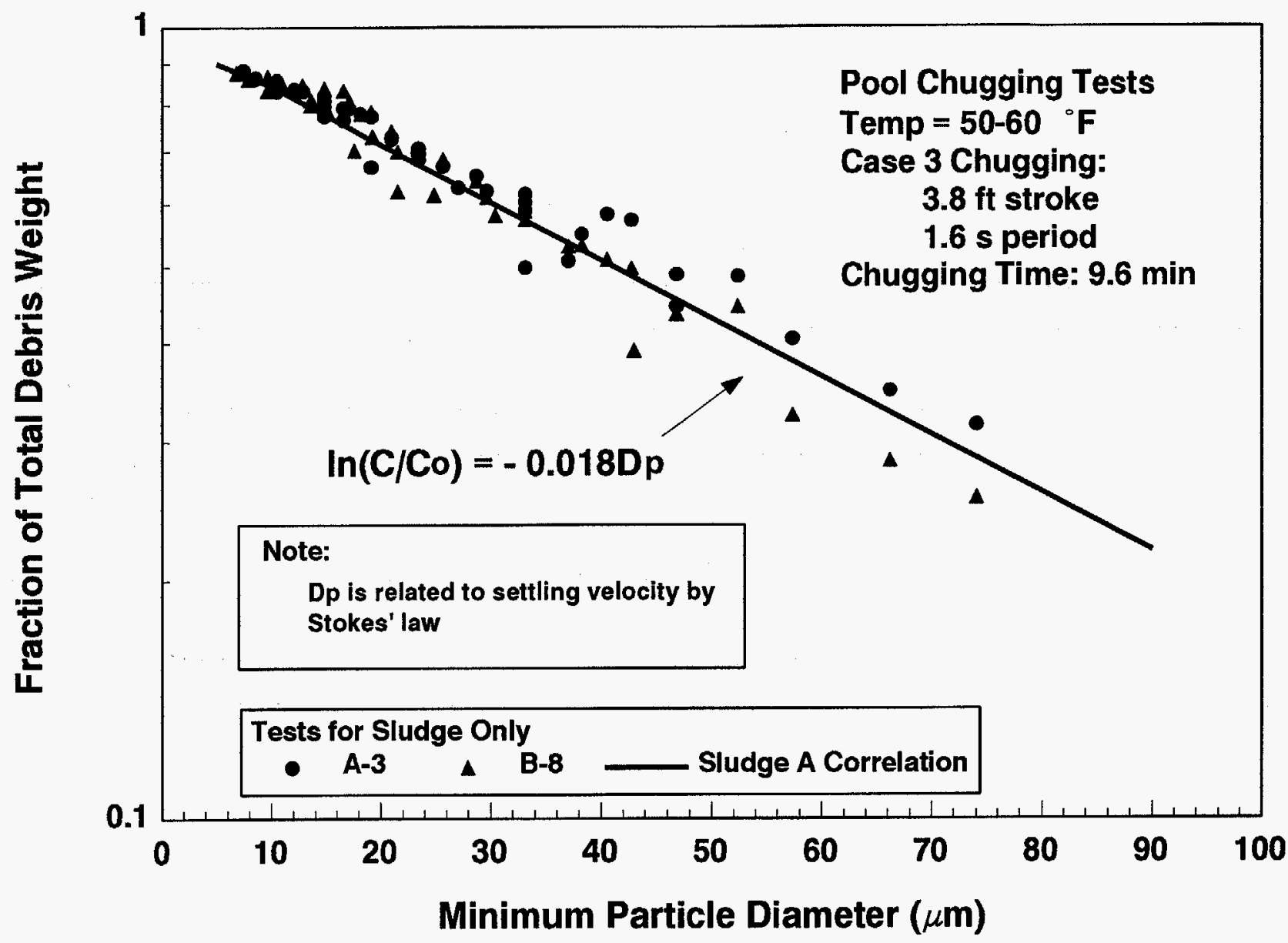

Figure 4-15. Particle Size Distribution Curve for Sludge A 


\subsection{Significant Findings}

The suppression pool tests conducted with a 1:2.4 scale model of a Mark I suppression pool segment with NUKON ${ }^{\mathrm{TM}}$ fibrous debris and iron oxide sludge indicate that:

- During simulated chugging, both the fibrous and particulate debris remained fully mixed in the tank, even at the lowest simulated chugging energies (i.e., Case 3 ). The turbulence created by these low energy simulated chugs was capable of resuspending the debris initially contained at the bottom of the tank and resulted in uniform vertical concentration profiles. Although this data was obtained for the lowest energy simulated chugs, it is believed to be equally valid for other phases of accident progression, including condensation oscillations typical of large LOCA and Case 1 and Case 2 chugging that characterize both medium LOCA and the final stages of a large LOCA.

- Even during the simulated chugging of lowest energy, the fibrous debris underwent further fragmentation into smaller sizes, including individual fibers. In general, the fragmentation occurred near the downcomers where the fibrous debris was subjected to cyclic shear forces from downward jet and ingestion into the downcomer.

- Visual observations suggest that the turbulence decays within few minutes after termination of chugging simulation. This enables settling of the debris in the post-high energy phase. The initial settling rate was more rapid for sludge compared with the fibrous debris. This observation may not be valid for the actual BWRs since in the later case additional turbulence is continually added to the suppression pool by the recirculating ECCS. Higher levels of turbulence may be present in a BWR suppression pool if the Residual Heat Removal system (RHR) is operated in the suppression pool cooling mode. Since these phenomena can not be easily simulated in the test facility, engineering judgement must be employed in estimating the correction factors that account for the effect of such phenomena on the settling velocities.

- The sludge used in the present study (Sludge A) was found to have been made up of large agglomerates that settle quickly in the posthigh energy phase. The minimum particle diameters obtained using Stokes' law suggests that more than $50 \%$ of the particles are larger than $40 \mu \mathrm{m}$. These sizes are considerably larger than BWROG specifications for suppression pool sludge (see Table 3-1). There is a possibility that these agglomerates may have been formed in the present tests because the iron oxide powders were supplied in the dry form, where the individual particles are in physical contact with each other. This potential for agglomeration may be minimized in an actual BWR case, where the particles are in suspension thereby minimizing the chance for collision. Several factors may contribute towards agglomeration in the suppression pool, and all these processes are not very well understood. One possible option for estimating the settling rates for a plantspecific sludge is to use the Stokes' law in conjunction with the actual sludge size distribution.

- In the post-high energy phase, the vertical concentration profiles are slightly nonuniform. However, for strainer blockage analysis, it is reasonable to assume that the concentration profile is uniform near the strainer.

These conclusions related to post high-energy phase do not consider the effect of recirculation flow patterns within the suppression pool established by the ECCS flow. Simulation of such flow may provide additional insights related to horizontal variation of concentration profiles, which is essential to determine near-field concentration. 


\section{References}

[1] Zigler, G.L., J. Brideau, D.V. Rao, C. Shaffer, F. Souto, and W. Thomas, "Parametric Study of the Potential for BWR ECCS Strainer Blockage Due to LOCA Generated Debris", NUREG/CR-6224 Draft for Comment, SEA No. 93-554-06-A:1, August 1994.

[2] "Mark I Full Scale Test Program. Final Report", General Electric, NEDE-24539-P, April 1979

[3] Johnson A.B., M. Padmanabhan, and G.E. Hecker, "NUKON Insulation and Sludge Settling Following a LOCA in a BWR Suppression Pool", Alden Research Laboratories, March 1995.

[4] Souto, F.J., E. Cramer, T. Kodas, and D.V. Rao, "Simulated BWR Sludge Characterization", SEA No. 95-554-06-A:7, March 1995.
[5] Appendix B of Reference 1.

[6] "Debris in Containment and the Residual Heat Removal System", NRC Information Notice 94-57, August 12, 1994.

[7] Reference 1, p. 4-24.

[8] "BWR Owners' Group ECCS Suction Strainer Committee Suppression Pool Sludge Particle Size Distribution", Letter from General Electric to A.W. Serkiz, USNRC, Dated September 13, 1994.

[9] Camp, T.R., "Sedimentation and the Design of Settling Tanks", in Proceedings of the ASCE, Paper No. 2285, April 1945. 


\section{Appendix A}

BWR Pool Simulated Chugging Tests Step By Step Test Procedures 
I. Preparation Procedure

A. Tank

1. Drain tank.

2. Drain water above pistons and clean.

3. Rinse tank with water spray; drain.

4. Mop and wipe tank floor, side walls, and pistons.

5. Rinse tank with water spray; drain.

6. Fill tank at least $1 \mathrm{ft}$ high; drain.

7. Repeat steps 5 and 6 until there is no visible residue.

8. Fill tank to 56 inches above its lowest point $\left(156 \mathrm{ft}^{3}\right)$.

B. Insulation Procedure

1. Use established insulation preparation procedure (same as for head loss tests).

C. Sludge A

1. Find the tare of a one gallon plastic pail to $\pm 1 \mathrm{~g}$.

2. Fill with $95 \%$ of the desired total weight of fine (2008) sludge.

3. Add to it $5 \%$ of the desired total weight of coarse $(9101 \mathrm{~N})$ sludge.

4. Carefully pour the dry sludge into the tank already filled with water to the required height.

5. Weigh the empty pail to find the amount of sludge adhering to the pail.

D. Sample Bottles

1. Use 1.0 liter glass bottles.

2. Empty bottles should be rinsed clean and contain less than $1 \mathrm{~g}$ of residual water.

3. The weight of the empty bottle without the lid should appear on the label of each bottle.

4. Organize twelve sets of bottles in sequence for testing. The sets are numbered from 1 through 12 and within each set, there are five bottles labeled A through $\mathrm{E}$ denoting the height from where the sample is drawn.

II. Sampling Procedure

A. Record the water temperature in the tank.

B. Record the water height in the tank.

C. At the designated sample time, open the 5 sample ports and allow to flush for 4 seconds.

D. Place the rack of five sample bottles under the sample ports while the ports are open.

E. When bottles are about $3 / 4$ full, close the sample ports.

F. Cap the bottles and replace with the next set of five empty bottles for the next sample.

G. Sample at the following times (actual times, i.e., not scaled):

1. During simulated chugging:

1 set of samples per minutes

2. After simulated chugging:

1 set every 2 minutes for 10 minutes, then

1 set every 10 minutes for 30 minutes

III. Simulated Chugging Procedure

A. To achieve a given simulated chugging period, set the controller frequency to the corresponding value. The desired controller frequency is determined from the graph of simulated chugging 
Appendix A

period versus controller frequency. The graph is a curve fit through data points of digital readout of controller frequency and simulated chugging period, as measured by the number of chugs in 10 seconds measured with a stopwatch.

B. Case 3: The motor that drives the pistons is ramped automatically to the required simulated chugging period in 36 seconds (actual case time). The beginning of simulated chugging starts approximately 18 seconds after ramping begins.

C. Case 2: The motor that drives the pistons is ramped automatically to $90 \%$ of the required simulated chugging period in 36 seconds (actual case time). The beginning of simulated chugging starts approximately 18 seconds after ramping begins. The speed is increased manually to achieve the required simulated chugging period in less than 24 seconds.

D. Case 1: To be specified later, if Case 1 testing is needed.

IV. Concentration Analysis Procedures

A. Insulation Only Tests

1. Weigh a 1.0 micron pore filter to $\pm 0.1 \mathrm{mg}$.

2. Place the filter on the filtering assembly.

3. Clean the funnel with a glass cleaner and wipe with a lint-free towel.

4. Screw the funnel to the filtering assembly.

5. Weight the sample bottle $\pm 1 \mathrm{~g}$ (without the lid) and subtract the weight of the empty bottle (written on the label) to find the weight of water.

6. Carefully pour the sample into the funnel.

7. Open the vacuum line to the filtrate bottle.

8. Rinse the bottle with distilled water and pour into funnel at least three times.

9. Rinse the funnel with distilled water.

10. When no water remains above the filter, disconnect the vacuum line and remove the filter.

11. Place the filter on a clean rack and weight after at least 20 hours of air drying.

12. Save the dried filters for at least six months.

B. Tests With Fine Particulates (and Insulation, if Present)

1. Pour a $0.2 \%$ by wt sludge concentration through the funnel.

2. Rinse the funnel with distilled water.

3. Weigh a 0.45 micron pore filter $\pm 0.1 \mathrm{mg}$.

4. Place the filter on the filtering assembly.

5. Do not clean the funnel between samples.

6. Screw the funnel to the filtering assembly.

7. Weigh the sample bottle without the lid and subtract the weight of the empty bottle (written on the label) to find the weight of water.

8. Carefully pour the sample into the funnel.

9. Open the vacuum line to the filtrate bottle.

10. Rinse the bottle with distilled water and pour into funnel at least three times.

11. Rinse the funnel with distilled water.

12. When no water remains above the filter, disconnect the vacuum line and remove the filter.

13. Place the filter on a clean rack and weigh after at least 20 hours of air drying.

14. Save the dried filters for at least six months.

C. Insulation Debris Generation

1. Heat treated insulation blanket is cut vertically into 6 " squares.

2. 2 squares are processed at a time. 
Appendix A

3. Each square is peeled into individual layers, about 10 to 12 per square.

4. All these layers are put into leaf shredder (off).

5. Leaf shredder is covered and a bag is placed beneath.

6. Leaf shredder is turned on and run for 60 seconds.

7. Bag beneath shredder is removed; larger pieces of insulation that remain in shredder are removed and kept separate from material that settles into bag. The material in the shredder is considered to represent class 5 and 6 . The rest of the material is considered to represent class 3 and 4. Any 6" × 6" squares still intact (not shredded) are removed from either sample.

8. Bag is replaced beneath shredder and steps 1 through 7 are repeated until the required amount of insulation for either size class obtained.

Instrumentation: To weigh the initial amount of sludge and fibrous insulation debris, a $6000 \mathrm{~g}$ capacity OHAUS CT6000 class A digital scale (resolution of $1 \mathrm{~g}$ ) was used; this scale was also used to weigh the water in each sample.

A 180 g capacity A\&D electronic balance, model ER180A, was used to weigh the filter papers and sludge in each sample; the resolution for this scale was set to $0.1 \mathrm{mg}$.

\section{LEAF SHREDDER FLOWTROW LEAF EATER}

\section{Setting: Fine}

Exposed length of plastic string $=3.4^{\prime \prime}$ approximately

Number of strings exposed $=4$ 
Appendix B

Raw Data for the Concentration Measurements 
Test A1 R1

$1 / 27 / 95$

\begin{tabular}{|lr|l|}
\hline & grams & $\%$ by wt of water \\
\hline Nukon: Class 3\&4 & 142 & $0.0032 \%$ \\
Sludge A & 0 & $0.0000 \%$ \\
Mix A & 0 & $0.0000 \%$ \\
\hline Total & 142 & $0.0032 \%$ \\
\hline
\end{tabular}

Appendix B

Chugging lasts 9.6 minutes

\begin{tabular}{|c|c|c|c|c|c|c|c|c|}
\hline \multirow{2}{*}{$\begin{array}{c}\text { Time } \\
\text { (Full scale } \\
\text { minutes) }\end{array}$} & \multirow{2}{*}{ Label } & \multicolumn{2}{|c|}{ Sample Bottes (g) } & \multirow{2}{*}{$\begin{array}{l}\text { Water (g) } \\
\text { full-empty }\end{array}$} & \multicolumn{2}{|c|}{ Filters $(0.1 \mathrm{mg})$} & \multirow{2}{*}{\begin{tabular}{|l} 
Residue \\
used-new
\end{tabular}} & \multirow{2}{*}{$\begin{array}{l}\text { \% of average initial } \\
\text { calculated concentration }\end{array}$} \\
\hline & & empty & full & & new & used & & \\
\hline \multirow{5}{*}{2.4} & al & 353 & 1072 & 719 & 987 & 1358 & 371 & $160.3 \%$ \\
\hline & b1 & 358 & 1128 & 770 & 1264 & 1547 & 283 & $114.2 \%$ \\
\hline & c1 & 357 & 1117 & 760 & 1193 & 1526 & 333 & $136.1 \%$ \\
\hline & d1 & 357 & 1134 & 777 & 1252 & 1731 & 479 & $191.5 \%$ \\
\hline & el & 353 & 1102 & 749 & 974 & 1372 & 398 & $165.1 \%$ \\
\hline \multirow{5}{*}{4.8} & 22 & 353 & 1119 & 766 & 1189 & $\overline{1443}$ & 254 & $103.0 \%$ \\
\hline & b2 & 357 & 1172 & 815 & 1265 & 1544 & 279 & $106.3 \%$ \\
\hline & c2 & 357 & 1157 & 800 & 978 & 1284 & 306 & $118.8 \%$ \\
\hline & $d 2$ & 353 & 1148 & 795 & 1189 & 2320 & 1131 & $441.9 \%$ \\
\hline & $\mathrm{e} 2$ & 353 & 1142 & 789 & 1258 & 1519 & 261 & $102.8 \%$ \\
\hline \multirow{5}{*}{7.2} & 23 & 352 & 1037 & 685 & 973 & 1181 & 208 & $94.3 \%$ \\
\hline & b3 & 353 & 1076 & 723 & 1200 & 1509 & 309 & $132.8 \%$ \\
\hline & c3 & 354 & 1102 & 748 & 1262 & 1526 & 264 & $109.6 \%$ \\
\hline & d3 & 352 & 1086 & 734 & 972 & 1235 & 263 & $111.3 \%$ \\
\hline & e3 & 353 & 1059 & 706 & 1195 & 1617 & 422 & $185.7 \%$ \\
\hline \multirow{5}{*}{9.6} & a4 & 353 & 1053 & 700 & 1189 & 1444 & 255 & $113.2 \%$ \\
\hline & b4 & 353 & 1103 & 750 & 1270 & 1523 & 253 & $104.8 \%$ \\
\hline & $c 4$ & 353 & 1106 & 753 & 983 & 1284 & 301 & $124.2 \%$ \\
\hline & d4 & 353 & 1104 & 751 & 1190 & 1470 & 280 & $115.8 \%$ \\
\hline & e4 & 353 & 1179 & 826 & 1265 & 1795 & 530 & $199.3 \%$ \\
\hline \multirow{5}{*}{14.4} & 25 & 353 & 1000 & 647 & 971 & 1182 & 211 & $101.3 \%$ \\
\hline & b5 & 352 & 1040 & 688 & 1189 & 1423 & 234 & $105.7 \%$ \\
\hline & c5 & 352 & 1071 & 719 & 1265 & 1474 & 209 & $90.3 \%$ \\
\hline & d5 & 353 & 1059 & 706 & 973 & 1202 & 229 & $100.8 \%$ \\
\hline & es & 353 & 1025 & 672 & 1191 & 1594 & 403 & $186.3 \%$ \\
\hline \multirow{5}{*}{19.2} & a6 & 352 & 1036 & 684 & 1262 & 1420 & 158 & $71.8 \%$ \\
\hline & 66 & 352 & 1085 & 733 & 969 & 1166 & 197 & $83.5 \%$ \\
\hline & $\infty 6$ & 352 & 1090 & 738 & 1153 & 1353 & 200 & $84.2 \%$ \\
\hline & d6 & 353 & 1098 & 745 & 1258 & 1469 & 211 & $88.0 \%$ \\
\hline & e6 & 353 & 1064 & 711 & 1211 & 1398 & 187 & $81.7 \%$ \\
\hline \multirow{5}{*}{24} & a7 & 352 & 1052 & 700 & 1155 & 1300 & 145 & $64.3 \%$ \\
\hline & b7 & 353 & 1086 & 733 & 1256 & 1433 & 177 & $75.0 \%$ \\
\hline & c7 & 353 & 1094 & 741 & 1213 & 1400 & 187 & $78.4 \%$ \\
\hline & $d 7$ & 351 & 1086 & 735 & 1157 & 1360 & 203 & $85.8 \%$ \\
\hline & e7 & 353 & 1079 & 726 & 1259 & 1499 & 240 & $102.7 \%$ \\
\hline & a8 & 354 & 1044 & 690 & 1211 & 1330 & 119 & $53.6 \%$ \\
\hline & b8 & 354 & 1098 & 744 & 1158 & 1322 & 164 & $68.5 \%$ \\
\hline 28.8 & $c 8$ & 353 & 1102 & 749 & 1209 & 1391 & 182 & $75.5 \%$ \\
\hline & $\mathrm{d} 8$ & 354 & 1096 & 742 & 1252 & 1430 & 178 & $74.5 \%$ \\
\hline & e8 & 353 & 1072 & 719 & 1164 & 1382 & 218 & $94.2 \%$ \\
\hline & a9 & 353 & 1112 & 759 & 1216 & 1330 & 114 & $46.7 \%$ \\
\hline & 69 & 354 & 1144 & 790 & 1261 & 1430 & 169 & $66.5 \%$ \\
\hline 33.6 & c9 & 353 & 1150 & 797 & 1157 & 1311 & 154 & $60.0 \%$ \\
\hline & d9 & 354 & 1132 & 778 & 1259 & 1428 & 169 & $67.5 \%$ \\
\hline & e9 & 354 & 1131 & 777 & 1208 & 1383 & 175 & $70.0 \%$ \\
\hline & 210 & 353 & 1098 & 745 & 1214 & 1313 & 99 & $41.3 \%$ \\
\hline & b10 & 353 & 1130 & 777 & 1248 & 1337 & 89 & $35.6 \%$ \\
\hline 57.6 & c10 & 351 & 1135 & 784 & 1210 & 1301 & 91 & $36.1 \%$ \\
\hline & $\mathrm{d} 10$ & 353 & 1148 & 795 & 1260 & 1371 & 111 & $43.4 \%$ \\
\hline & e10 & 353 & 1130 & 777 & 1155 & 1282 & 127 & $50.8 \%$ \\
\hline & a11 & 353 & 1111 & 758 & 1157 & 1210 & 53 & $21.7 \%$ \\
\hline & bli & 353 & 1131 & 778 & 1260 & 1321 & 61 & $24.4 \%$ \\
\hline 81.6 & c11 & 353 & 1114 & 761 & 1212 & 1272 & 60 & $24.5 \%$ \\
\hline & d11 & 353 & 1141 & 788 & 1156 & 1224 & 68 & $26.8 \%$ \\
\hline & el1 & 353 & 1112 & 759 & 1260 & 1327 & 67 & $27.4 \%$ \\
\hline & a12 & 353 & 984 & 631 & 1221 & 1253 & 32 & $15.8 \%$ \\
\hline & b12 & 352 & 1026 & 674 & 1153 & 1189 & 36 & $16.6 \%$ \\
\hline 105.6 & c12 & 353 & 1057 & 704 & 1259 & 1299 & 40 & $17.6 \%$ \\
\hline & $\mathrm{d} 12$ & 353 & 1040 & 687 & 1213 & 1254 & 41 & $18.5 \%$ \\
\hline & e12 & 353 & 1000 & 647 & 1163 & 1200 & 37 & $17.8 \%$ \\
\hline
\end{tabular}


Appendix B Test A-2 R1 $1 / 30 / 95$

\begin{tabular}{|lr|l|}
\hline & grams & \% by wr of water \\
\hline Nukon: Class 5\&6 & 142 & $0.0032 \%$ \\
Shudge A & 0 & $0.0000 \%$ \\
Mix A & 0 & $0.0000 \%$ \\
\hline Total & 142 & $0.0032 \%$ \\
\hline
\end{tabular}

Chugging lasts 9.6 minutes

\begin{tabular}{|c|c|c|c|c|c|c|c|c|}
\hline \multirow{2}{*}{$\begin{array}{c}\text { Time } \\
\text { (Full scale } \\
\text { minutes) }\end{array}$} & \multirow{2}{*}{ Label } & \multicolumn{2}{|c|}{ Sample Bottles (g) } & \multirow{2}{*}{\begin{tabular}{|l} 
Water (g) \\
full-empty
\end{tabular}} & \multicolumn{2}{|c|}{ Filters $(0.1 \mathrm{mg})$} & \multirow{2}{*}{$\begin{array}{l}\text { Residue } \\
\text { used-new }\end{array}$} & \multirow{2}{*}{$\begin{array}{l}\% \text { of average initial } \\
\text { calculated concentration }\end{array}$} \\
\hline & & empty & full & & new & used & & \\
\hline \multirow{5}{*}{2.4} & 21 & 353 & 1098 & 745 & 1207 & 1433 & 226 & $94.2 \%$ \\
\hline & bl & 358 & 1129 & 771 & 1259 & 1631 & 372 & $149.9 \%$ \\
\hline & cl & 357 & 1126 & 769 & 1157 & 1374 & 217 & $87.7 \%$ \\
\hline & d1 & 357 & 1140 & 783 & 1209 & 1421 & 212 & $84.1 \%$ \\
\hline & el & 353 & 1110 & 757 & 1260 & 1496 & 236 & $96.8 \%$ \\
\hline \multirow{5}{*}{4.8} & a2 & 353 & 1177 & 824 & 1155 & 1676 & 521 & $196.4 \%$ \\
\hline & b2 & 357 & 1189 & 832 & 1206 & 1427 & 221 & $82.5 \%$ \\
\hline & $c 2$ & 357 & 1173 & 816 & 1251 & 1550 & 299 & $113.8 \%$ \\
\hline & d2 & 353 & 1154 & 801 & 1158 & 1597 & 439 & $170.2 \%$ \\
\hline & $e^{2}$ & 353 & 1158 & 805 & 1219 & 1581 & 362 & $139.7 \%$ \\
\hline \multirow{5}{*}{7.2} & 23 & 352 & 1174 & 822 & 1259 & 1546 & 287 & $108.5 \%$ \\
\hline & b3 & 353 & 1187 & 834 & 1155 & 1477 & 322 & $119.9 \%$ \\
\hline & c3 & 354 & 1174 & 820 & 1220 & 1871 & 651 & $246.6 \%$ \\
\hline & d3 & 352 & 1162 & 810 & 1260 & 1515 & 255 & $97.8 \%$ \\
\hline & e3 & 353 & 1154 & 801 & 1153 & 1448 & 295 & $114.4 \%$ \\
\hline \multirow{5}{*}{9.6} & 24 & 353 & 1081 & 728 & 1214 & 1430 & 216 & $92.2 \%$ \\
\hline & b4 & 353 & 1138 & 785 & 1262 & 1585 & 323 & $127.8 \%$ \\
\hline & c4 & 353 & 1126 & 773 & 1159 & 1525 & 366 & $147.1 \%$ \\
\hline & d4 & 353 & 1151 & 798 & 1161 & 1407 & 246 & $95.8 \%$ \\
\hline & e4 & 353 & 1148 & 795 & 1214 & 1487 & 273 & $106.7 \%$ \\
\hline \multirow{5}{*}{14.4} & 25 & 353 & 1113 & 760 & 1265 & 1467 & 202 & $82.6 \%$ \\
\hline & b5 & 352 & 1131 & 779 & 1256 & 1465 & 209 & $83.3 \%$ \\
\hline & $c 5$ & 352 & 1133 & 781 & 1157 & 1375 & 218 & $86.7 \%$ \\
\hline & d5 & 353 & 1151 & 798 & 1218 & 1546 & 328 & $127.7 \%$ \\
\hline & es & 353. & 1160 & 807 & 1257 & 1459 & 202 & $77.8 \%$ \\
\hline \multirow{5}{*}{19.2} & 26 & 352 & 1168 & 816 & 1156 & 1374 & 218 & $83.0 \%$ \\
\hline & 66 & 352 & 1165 & 813 & 1211 & 1408 & 197 & $75.3 \%$ \\
\hline & o6 & 352 & 1126 & 774 & 1258 & 1542 & 284 & $114.0 \%$ \\
\hline & d6 & 353 & 1142 & 789 & 1157 & 1360 & 203 & $79.9 \%$ \\
\hline & $e 6$ & 353 & 1134 & 781 & 1160 & 1366 & 206 & $81.9 \%$ \\
\hline \multirow{5}{*}{24} & 27 & 352 & 1064 & 712 & 1262 & 1414 & 152 & $66.3 \%$ \\
\hline & b7 & 353 & 1111 & 758 & 1208 & 1406 & 198 & $81.1 \%$ \\
\hline & c7 & 353 & 1127 & 774 & 1161 & 1324 & 163 & $65.4 \%$ \\
\hline & d7 & 351 & 1095 & 744 & 1256 & 1489 & 233 & $97.3 \%$ \\
\hline & e7 & 353 & 1083 & 730 & 1206 & 1387 & 181 & $77.0 \%$ \\
\hline & 28 & 354 & 939 & 585 & 1161 & 1249 & 88 & $46.7 \%$ \\
\hline & b8 & 354 & 984 & 630 & 1269 & 1403 & 134 & $66.1 \%$ \\
\hline 28.8 & C8 & 353 & 1007 & 654 & 1201 & 1346 & 145 & $68.9 \%$ \\
\hline & d8 & 354 & 989 & 635 & 1159 & 1305 & 146 & $71.4 \%$ \\
\hline & e8 & 353 & 961 & 608 & 1211 & 1316 & 105 & $53.6 \%$ \\
\hline & a9 & 353 & 1155 & 802 & 1153 & 1273 & 120 & $46.5 \%$ \\
\hline & $b 9$ & 354 & 1170 & 816 & 1206 & 1357 & 151 & $57.5 \%$ \\
\hline 33.6 & c9 & 353 & 1165 & 812 & 1257 & 1442 & 185 & $70.8 \%$ \\
\hline & $d 9$ & 354 & 1159 & 805 & 1155 & 1316 & 161 & $62.1 \%$ \\
\hline & eq & 354 & 1158 & 804 & 1209 & 1375 & 166 & $64.1 \%$ \\
\hline & a10 & 353 & 1047 & 694 & 1258 & 1285 & 27 & $12.1 \%$ \\
\hline & b10 & 353 & 1090 & 737 & 1153 & 1243 & 90 & $37.9 \%$ \\
\hline 57.6 & c10 & 351 & 1118 & 767 & 1163 & 1255 & 92 & $37.3 \%$ \\
\hline & d10 & 353 & 1095 & 742 & 1211 & 1309 & 98 & $41.0 \%$ \\
\hline & elo & 353 & 1076 & 723 & 1158 & 1275 & 117 & $50.3 \%$ \\
\hline & all & 353 & 1101 & 748 & 1152 & 1169 & 17 & $7.1 \%$ \\
\hline & b11 & 353 & 1133 & 780 & 1209 & 1240 & 31 & $12.3 \%$ \\
\hline 81.6 & c1l & 353 & 1132 & 779 & 1251 & 1300 & 49 & $19.5 \%$ \\
\hline & dil & 353 & 1138 & 785 & 1157 & 1266 & 109 & $43.1 \%$ \\
\hline & ell & 353 & 1122 & 769 & 1212 & 1293 & 81 & $32.7 \%$ \\
\hline & a12 & 353 & 1047 & 694 & 1253 & 1262 & 9 & $4.0 \%$ \\
\hline & b12 & 352 & 1093 & 741 & 1155 & 1179 & 24 & $10.1 \%$ \\
\hline 105.6 & cl2 & 353 & 1098 & 745 & 1270 & 1301 & 31 & $12.9 \%$ \\
\hline & d12 & 353 & 1100 & 747 & 1205 & 1247 & 42 & $17.5 \%$ \\
\hline & el2 & 353 & 1069 & 716 & 1215 & 1264 & 49 & $21.3 \%$ \\
\hline
\end{tabular}


Test A-3 R1 1/20/95

\begin{tabular}{|lr|l|}
\hline & grams & \% by wt of water \\
\hline Nukon: Class 5\&6 & 0 & $0.0000 \%$ \\
Sludge A & 938 & $0.0213 \%$ \\
Mix A & 0 & $0.0000 \%$ \\
\hline Total & 938 & $0.0213 \%$ \\
\hline
\end{tabular}

Appendix B

Chugging lasts 9.6 minutes

\begin{tabular}{|c|c|c|c|c|c|c|c|c|}
\hline \multirow{2}{*}{$\begin{array}{c}\text { Time } \\
\text { (Full scale } \\
\text { minutes) }\end{array}$} & \multirow{2}{*}{ Label } & \multicolumn{2}{|c|}{ Sample Boules (g) } & \multirow{2}{*}{\begin{tabular}{|l|} 
Water (g) \\
full-empty
\end{tabular}} & \multicolumn{2}{|c|}{ Filters $(0.1 \mathrm{mg})$} & \multirow{2}{*}{\begin{tabular}{|l} 
Residue \\
used-new
\end{tabular}} & \multirow{2}{*}{$\begin{array}{c}\text { \%o of average initial } \\
\text { calculated concentration }\end{array}$} \\
\hline & & empty & full & & new & used & & \\
\hline \multirow{5}{*}{2.4} & a1 & 353 & 1105 & 752 & 899 & 2356 & 1457 & $91.1 \%$ \\
\hline & b1 & 358 & 1154 & 796 & 896 & 2412 & 1516 & $89.6 \%$ \\
\hline & cl & 357 & 1162 & 805 & 875 & 2374 & 1499 & $87.6 \%$ \\
\hline & dl & 357 & 1151 & 794 & 903 & 2472 & 1569 & $92.9 \%$ \\
\hline & el & 353 & 1133 & 780 & 895 & 2509 & 1614 & $97.3 \%$ \\
\hline \multirow{5}{*}{4.8} & 22 & 353 & 1150 & 797 & 916 & 2574 & 1658 & $97.8 \%$ \\
\hline & b2 & 357 & 1180 & 823 & 907 & 2555 & 1648 & $94.2 \%$ \\
\hline & c2 & 357 & 1156 & 799 & 919 & 2798 & 1879 & $110.6 \%$ \\
\hline & $d 2$ & 353 & 1148 & 795 & 911 & 2417 & 1506 & $89.1 \%$ \\
\hline & e2 & 353 & 1147 & 794 & 917 & 2427 & 1510 & $89.4 \%$ \\
\hline \multirow{5}{*}{7.2} & 23 & 352 & 1051 & 699 & 890 & 2305 & 1415 & $95.2 \%$ \\
\hline & b3 & 353 & 1097 & 744 & 887 & 2187 & 1300 & $82.2 \%$ \\
\hline & c3 & 354 & 1119 & 765 & 883 & 2341 & 1458 & $89.6 \%$ \\
\hline & d3 & 352 & 1117 & 765 & 904 & 2449 & 1545 & $95.0 \%$ \\
\hline & e3 & 353 & 1087 & 734 & 893 & 2560 & 1667 & $106.8 \%$ \\
\hline \multirow{5}{*}{9.6} & 24 & 353 & 1039 & 686 & 908 & 2400 & 1492 & $102.3 \%$ \\
\hline & $b 4$ & 353 & 1150 & 797 & 908 & 2307 & 1399 & $82.5 \%$ \\
\hline & c4 & 353 & 1143 & 790 & 892 & 2439 & 1547 & $92.1 \%$ \\
\hline & d4 & 353 & 1140 & 787 & 882 & 2414 & 1532 & $91.5 \%$ \\
\hline & 4 & 353 & 1152 & 799 & 886 & 2484 & 1598 & $94.1 \%$ \\
\hline \multirow{5}{*}{14.4} & 25 & 353 & 1173 & 820 & 890 & 1765 & 875 & $50.2 \%$ \\
\hline & b5 & 352 & 1154 & 802 & 887 & 1834 & 947 & $55.5 \%$ \\
\hline & c5 & 352 & 1144 & 792 & 889 & 1891 & 1002 & $59.5 \%$ \\
\hline & dS & 353 & 1242 & 889 & 886 & 2119 & 1233 & $65.2 \%$ \\
\hline & 25 & 353 & 1145 & 792 & 900 & 2053 & 1153 & $68.5 \%$ \\
\hline \multirow{5}{*}{19.2} & 96 & 352 & 1084 & 732 & 896 & 1391 & 495 & $31.8 \%$ \\
\hline & $b 6$ & 352 & 1135 & 783 & 891 & 1576 & 685 & $41.1 \%$ \\
\hline & $\infty$ & 352 & 1140 & 788 & 891 & 1592 & 701 & $41.8 \%$ \\
\hline & $d 6$ & 353 & 1128 & 775 & 893 & 1736 & 843 & $51.2 \%$ \\
\hline & 66 & 353 & 1121 & 768 & 894 & 1733 & 839 & $51.4 \%$ \\
\hline \multirow{5}{*}{24} & a7 & 352 & 1068 & 716 & 885 & 1390 & 505 & $33.2 \%$ \\
\hline & b7 & 353 & 1123 & 770 & 891 & 1498 & 607 & $37.1 \%$ \\
\hline & c7 & 353 & 1131 & 778 & 879 & 1561 & 682 & $41.2 \%$ \\
\hline & d) & 351 & 1128 & 777 & 883 & 1629 & 746 & $45.1 \%$ \\
\hline & $e 7$ & 353 & 1102 & 749 & 871 & 1552 & 681 & $42.8 \%$ \\
\hline & 28 & 354 & 1068 & 714 & 878 & 1234 & 356 & $23.4 \%$ \\
\hline & b8 & 354 & 1120 & 766 & 865 & 1362 & 497 & $30.5 \%$ \\
\hline 28.8 & $c 8$ & 353 & 1118 & 765 & 871 & 1438 & 567 & $34.9 \%$ \\
\hline & d8 & 354 & 1117 & 763 & 875 & 1497 & 622 & $38.3 \%$ \\
\hline & $e 8$ & 353 & 1099 & 746 & 874 & 1654 & 780 & $49.2 \%$ \\
\hline & 89 & 353 & 1163 & 810 & 873 & 1263 & 390 & $22.6 \%$ \\
\hline & b9 & 354 & 1157 & 803 & 877 & 1348 & 471 & $27.6 \%$ \\
\hline 33.6 & c9 & 353 & 1142 & 789 & 883 & 1437 & 554 & $33.0 \%$ \\
\hline & d9 & 354 & 1156 & 802 & 879 & 1522 & 643 & $37.7 \%$ \\
\hline & $e 9$ & 354 & 1132 & 778 & 883 & 1540 & 657 & $39.7 \%$ \\
\hline & a10 & 353 & 1122 & 769 & 872 & 1146 & 274 & $16.8 \%$ \\
\hline & b10 & 353 & 1149 & 796 & 879 & 1225 & 346 & $20.4 \%$ \\
\hline 57.6 & c10 & 351 & 1135 & 784 & 876 & 1242 & 366 & $22.0 \%$ \\
\hline & d10 & 353 & 1151 & 798 & 898 & 1358 & 460 & $27.1 \%$ \\
\hline & e10 & 353 & 1149 & 796 & 870 & 1369 & 499 & $29.5 \%$ \\
\hline & all & 353 & 1136 & 783 & 874 & 1100 & 226 & $13.6 \%$ \\
\hline & bll & 353 & 1235 & 882 & 900 & 1205 & 305 & $16.3 \%$ \\
\hline 81.6 & cll & 353 & 1144 & 791 & 883 & 1203 & 320 & $19.0 \%$ \\
\hline & d11 & 353 & 1141 & 788 & 894 & 1242 & 348 & $20.8 \%$ \\
\hline & ell & 353 & 1157 & 804 & 894 & 1280 & 386 & $22.6 \%$ \\
\hline & 912 & 353 & 1148 & 795 & 893 & 1092 & 199 & $11.8 \%$ \\
\hline & b12 & 352 & 1161 & 809 & 898 & 1143 & 245 & $14.2 \%$ \\
\hline 105.6 & $\mathrm{cl}$ & 353 & 1149 & 796 & 880 & 1164 & 284 & $16.8 \%$ \\
\hline & $d 12$ & 353 & 1147 & 794 & 894 & 1194 & 300 & $17.8 \%$ \\
\hline & e12 & 353 & 1145 & 792 & 884 & 1233 & 349 & $20.7 \%$ \\
\hline
\end{tabular}


Appendix B Test A-4 R1 $1 / 13 / 95$

\begin{tabular}{|lr|l|}
\hline & grams & \% by wt of water \\
\hline Nukon: Class 5\&6 & 142 & $0.0032 \%$ \\
Sludge A & 938 & $0.0213 \%$ \\
Mix A & 0 & $0.0000 \%$ \\
\hline Total & 1080 & $0.0245 \%$ \\
\hline
\end{tabular}

Chugging lasts 9.6 minutes

\begin{tabular}{|c|c|c|c|c|c|c|c|c|}
\hline \multirow{2}{*}{$\begin{array}{c}\text { Time } \\
\text { (Full scale } \\
\text { minutes) }\end{array}$} & \multirow{2}{*}{ Label } & \multicolumn{2}{|c|}{ Sample Bottles (g) } & \multirow{2}{*}{\begin{tabular}{|l} 
Water $(\mathrm{g})$ \\
full-empy
\end{tabular}} & \multicolumn{2}{|c|}{ Filters $(0.1 \mathrm{mg})$} & \multirow{2}{*}{$\begin{array}{l}\text { Residue } \\
\text { used-new }\end{array}$} & \multirow{2}{*}{$\begin{array}{l}\text { \% of average initial } \\
\text { calculated concentration }\end{array}$} \\
\hline & & empty & full & & new & used & & \\
\hline \multirow{5}{*}{2.4} & a1 & 353 & 1094 & 741 & 788 & 2588 & 1800 & $99.2 \%$ \\
\hline & bl & 358 & 1140 & 782 & 790 & 2488 & 1698 & $88.7 \%$ \\
\hline & cl & 357 & 1215 & 858 & 781 & 2730 & 1949 & $92.8 \%$ \\
\hline & d1 & 357 & 1231 & 874 & 784 & 2733 & 1949 & $91.1 \%$ \\
\hline & el & 353 & 1116 & 763 & 784 & 2792 & 2008 & $107.5 \%$ \\
\hline \multirow{5}{*}{4.8} & a2 & 353 & 1054 & 701 & 795 & 2311 & 1516 & $88.3 \%$ \\
\hline & b2 & 357 & 1106 & 749 & 782 & 2458 & 1676 & $91.4 \%$ \\
\hline & c2 & 357 & 1133 & 776 & 782 & 2619 & 1837 & $96.7 \%$ \\
\hline & d2 & 353 & 1120 & 767 & 785 & 2719 & 1934 & $103.0 \%$ \\
\hline & e2 & 353 & 1085 & 732 & 785 & 2947 & 2162 & $120.6 \%$ \\
\hline \multirow{5}{*}{7.2} & a3 & 352 & 1124 & 772 & 796 & 2483 & 1687 & $89.3 \%$ \\
\hline & b3 & 353 & 1166 & 813 & 794 & 2653 & 1859 & $93.4 \%$ \\
\hline & c3 & 354 & 1145 & 791 & 787 & 3198 & 2411 & $124.5 \%$ \\
\hline & d3 & 352 & 1142 & 790 & 777 & 2605 & 1828 & $94.5 \%$ \\
\hline & e3 & 353 & 1139 & 786 & 785 & 2711 & 1926 & $100.1 \%$ \\
\hline \multirow{5}{*}{9.6} & a4 & 353 & 1073 & 720 & 779 & 2407 & 1628 & $92.3 \%$ \\
\hline & b4 & 353 & 1138 & 785 & 779 & 2554 & 1775 & $92.4 \%$ \\
\hline & c4 & 353 & 1165 & 812 & 778 & 2559 & 1781 & $89.6 \%$ \\
\hline & $d 4$ & 353 & 1145 & 792 & 775 & 2484 & 1709 & $88.1 \%$ \\
\hline & e4 & 353 & 1107 & 754 & 778 & 2375 & 1597 & $86.5 \%$ \\
\hline \multirow{5}{*}{14.4} & 25 & 353 & 1099 & 746 & 784 & 1785 & 1001 & $54.8 \%$ \\
\hline & b5 & 352 & 1149 & 797 & 786 & 1874 & 1088 & $55.8 \%$ \\
\hline & c5 & 352 & 1152 & 800 & 793 & 2120 & 1327 & $67.7 \%$ \\
\hline & dS & 353 & 1140 & 787 & 842 & 2312 & 1470 & $76.3 \%$ \\
\hline & e5 & 353 & 1080 & 727 & 821 & 1937 & 1116 & $62.7 \%$ \\
\hline \multirow{5}{*}{19.2} & $\overline{96}$ & 352 & 1046 & 694 & 844 & 1513 & 669 & $39.4 \%$ \\
\hline & $b 6$ & 352 & 1095 & 743 & 830 & 1695 & 865 & $47.5 \%$ \\
\hline & $\infty$ & 352 & 1108 & 756 & 831 & 1855 & 1024 & $55.3 \%$ \\
\hline & d6 & 353 & 1109 & 756 & 830 & 1921 & 1091 & $58.9 \%$ \\
\hline & 66 & 353 & 1140 & 787 & 821 & 2267 & 1446 & $75.0 \%$ \\
\hline \multirow{5}{*}{24} & a7 & 352 & $\overline{1124}$ & 772 & 819 & 1524 & 705 & $37.3 \%$ \\
\hline & b7 & 353 & 1148 & 795 & 840 & 1593 & 753 & $38.7 \%$ \\
\hline & c7 & 353 & 1154 & 801 & 829 & 1737 & 908 & $46.3 \%$ \\
\hline & d7 & 351 & 1142 & 791 & 824 & 1803 & 979 & $50.5 \%$ \\
\hline & e7 & 353 & 1155 & 802 & 826 & 1910 & 1084 & $55.2 \%$ \\
\hline & a8 & 354 & 1088 & 734 & 824 & 1392 & 568 & $31.6 \%$ \\
\hline & b8 & 354 & 1140 & 786 & 819 & 1548 & 729 & $37.9 \%$ \\
\hline 28.8 & 28 & 353 & 1156 & 803 & 830 & 1756 & 926 & $47.1 \%$ \\
\hline & $d 8$ & 354 & 1136 & 782 & 848 & 1819 & 971 & $50.7 \%$ \\
\hline & $e 8$ & 353 & 1123 & 770 & 839 & 1829 & 990 & $52.5 \%$ \\
\hline & 99 & 353 & 1088 & 735 & 849 & 1342 & 493 & $27.4 \%$ \\
\hline & 69 & 354 & 1132 & 778 & 831 & 1476 & 645 & $33.9 \%$ \\
\hline 33.6 & c9 & 353 & 1146 & 793 & 845 & 1639 & 794 & $40.9 \%$ \\
\hline & d9 & 354 & 1136 & 782 & 833 & 1732 & 899 & $47.0 \%$ \\
\hline & eq & 354 & 1123 & 769 & 838 & 1778 & 940 & $49.9 \%$ \\
\hline & a10 & 353 & 1219 & 866 & 843 & 1210 & 367 & $17.3 \%$ \\
\hline & b10 & 353 & 1196 & 843 & 825 & 1261 & 436 & $21.1 \%$ \\
\hline 57.6 & c10 & 351 & 1165 & 814 & 838 & 1357 & 519 & $26.0 \%$ \\
\hline & d10 & 353 & 1193 & 840 & 844 & 1495 & 651 & $31.7 \%$ \\
\hline & elo & 353 & 1216 & 863 & 837 & 1567 & 730 & $34.5 \%$ \\
\hline & 211 & 353 & 1153 & 800 & 833 & 1125 & 292 & $14.9 \%$ \\
\hline & b11 & 353 & 1162 & 809 & 839 & 1209 & 370 & $18.7 \%$ \\
\hline 81.6 & cl1 & 353 & 1138 & 785 & 834 & 1264 & 430 & $22.4 \%$ \\
\hline & d11 & 353 & 1163 & 810 & 835 & 1353 & 518 & $26.1 \%$ \\
\hline & ell & 353 & 1150 & 797 & 850 & 1398 & 548 & $28.1 \%$ \\
\hline & a12 & 353 & 1126 & 773 & 832 & 1083 & 251 & $13.3 \%$ \\
\hline & b12 & 352 & 1145 & 793 & 830 & 1149 & 319 & $16.4 \%$ \\
\hline 105.6 & c12 & 353 & 1148 & 795 & 843 & 1200 & 357 & $18.3 \%$ \\
\hline & d12 & 353 & 1153 & 800 & 837 & 1246 & 409 & $20.9 \%$ \\
\hline & e12 & 353 & 1153 & 800 & 834 & 1306 & 472 & $24.1 \%$ \\
\hline
\end{tabular}


Test A-5

$1 / 9 / 95$

\begin{tabular}{|lr|l|}
\hline & grams & \% by wt of water \\
\hline Nukon: Class 3\&4 & 142 & $0.0032 \%$ \\
Sludge A & 938 & $0.0213 \%$ \\
Mix A & 0 & $0.0000 \%$ \\
\hline Total & 1080 & $0.0245 \%$ \\
\hline
\end{tabular}

Appendix B

Chugging lasts 9.6 minutes

\begin{tabular}{|c|c|c|c|c|c|c|c|c|}
\hline \multirow{2}{*}{$\begin{array}{c}\text { Time } \\
\text { (Full scale } \\
\text { minutes) }\end{array}$} & \multirow{2}{*}{ Label } & \multicolumn{2}{|c|}{ Sample Bottles (g) } & \multirow{2}{*}{$\begin{array}{l}\text { Water (g) } \\
\text { full-empry }\end{array}$} & \multicolumn{2}{|c|}{ Filters $(0.1 \mathrm{mg})$} & \multirow{2}{*}{$\begin{array}{l}\text { Residue } \\
\text { used-new }\end{array}$} & \multirow{2}{*}{$\begin{array}{l}\text { \% of average initial } \\
\text { calculated concentration }\end{array}$} \\
\hline & & empty & full & & new & used & & \\
\hline \multirow{5}{*}{2.4} & a1 & 353 & 1064 & 711 & 838 & 2302 & 1464 & $84.1 \%$ \\
\hline & b1 & 358 & 1101 & 743 & 837 & 3014 & 2177 & $119.7 \%$ \\
\hline & cl & 357 & 1092 & 735 & 841 & 3039 & 2198 & $122.1 \%$ \\
\hline & dI & 357 & 1069 & 712 & 850 & 2534 & 1684 & $96.6 \%$ \\
\hline & el & 353 & 1066 & 713 & 840 & 2762 & 1922 & $110.1 \%$ \\
\hline \multirow{5}{*}{4.8} & .2 & 353 & 992 & 639 & 834 & 2314 & 1480 & $94.6 \%$ \\
\hline & b2 & 357 & 1099 & 742 & 832 & 2549 & 1717 & $94.5 \%$ \\
\hline & c2 & 357 & 1019 & 662 & 831 & 2361 & 1530 & $94.4 \%$ \\
\hline & d2 & 353 & 997 & 644 & 843 & 2961 & 2118 & $134.3 \%$ \\
\hline & e2 & 353 & 1001 & 648 & 837 & 2282 & 1445 & $91.1 \%$ \\
\hline \multirow{5}{*}{7.2} & a3 & 352 & 1031 & 679 & 838 & 2382 & 1544 & $92.9 \%$ \\
\hline & b3 & 353 & 1064 & 711 & 847 & 3144 & 2297 & $131.9 \%$ \\
\hline & c3 & 354 & 1059 & 705 & 850 & 2523 & 1673 & $96.9 \%$ \\
\hline & d3 & 352 & 1042 & 690 & 850 & 2503 & 1653 & $97.8 \%$ \\
\hline & e3 & 353 & 1044 & 691 & 846 & 2599 & 1753 & $103.6 \%$ \\
\hline \multirow{5}{*}{9.6} & 24 & 353 & 1049 & 696 & 848 & 2282 & 1434 & $84.1 \%$ \\
\hline & b4 & 353 & 1075 & 722 & 839 & 2540 & 1701 & $96.2 \%$ \\
\hline & $c 4$ & 353 & 1072 & 719 & 835 & 2481 & 1646 & $93.5 \%$ \\
\hline & d4 & 353 & 1057 & 704 & 843 & 2506 & 1663 & $96.5 \%$ \\
\hline & e4 & 353 & 1040 & 687 & 857 & 2497 & 1640 & $97.5 \%$ \\
\hline \multirow{5}{*}{14.4} & 25 & 353 & 1105 & 752 & 851 & 1875 & 1024 & $55.6 \%$ \\
\hline & b5 & 352 & 1125 & 773 & 846 & 2108 & 1262 & $66.7 \%$ \\
\hline & c5 & 352 & 1127 & 775 & 849 & 2046 & 1197 & $63.1 \%$ \\
\hline & d5 & 353 & 1111 & 758 & 857 & 2231 & 1374 & $74.0 \%$ \\
\hline & es & 353 & 1103 & 750 & 853 & 2576 & 1723 & $93.8 \%$ \\
\hline \multirow{5}{*}{19.2} & 26 & 352 & 1143 & 791 & 843 & 1499 & 656 & $33.9 \%$ \\
\hline & $b 6$ & 352 & 1141 & 789 & 837 & 1664 & 827 & $42.8 \%$ \\
\hline & $\infty 6$ & 352 & 1143 & 791 & 841 & 1838 & 997 & $51.5 \%$ \\
\hline & $d 6$ & 353 & 1140 & 787 & 853 & 1927 & 1074 & $55.7 \%$ \\
\hline & 6 & 353 & 1145 & 792 & 841 & 1975 & 1134 & $58.5 \%$ \\
\hline \multirow{5}{*}{24} & a7 & 352 & 1146 & 794 & 847 & 1424 & 577 & $29.7 \%$ \\
\hline & b7 & 353 & 1140 & 787 & 851 & 1609 & 758 & $39.3 \%$ \\
\hline & c7 & 353 & 1141 & 788 & 851 & 1740 & 889 & $46.1 \%$ \\
\hline & d7 & 351 & 1137 & 786 & 854 & 1805 & 951 & $49.4 \%$ \\
\hline & e7 & 353 & 1139 & 786 & 845 & 1880 & 1035 & $53.8 \%$ \\
\hline & 28 & 354 & 1165 & 811 & 847 & 1357 & 510 & $25.7 \%$ \\
\hline & 68 & 354 & 1128 & 774 & 854 & 1507 & 653 & $34.5 \%$ \\
\hline 28.8 & c8 & 353 & 1144 & 791 & 843 & 1671 & 828 & $42.8 \%$ \\
\hline & d8 & 354 & 1141 & 787 & 842 & 1697 & 855 & $44.4 \%$ \\
\hline & $e 8$ & 353 & 1143 & 790 & 851 & 1801 & 950 & $49.1 \%$ \\
\hline & a9 & 353 & 1115 & 762 & 851 & 1238 & 387 & $20.7 \%$ \\
\hline & 69 & 354 & 1136 & 782 & 843 & 1373 & 530 & $27.7 \%$ \\
\hline 33.6 & c9 & 353 & 1130 & 777 & 843 & 1476 & 633 & $33.3 \%$ \\
\hline & d9 & 354 & 1116 & 762 & 842 & 1642 & 800 & $42.9 \%$ \\
\hline & eq & 354 & 1095 & 741 & 845 & 1718 & 873 & $48.1 \%$ \\
\hline & a10 & 353 & 1164 & 811 & 839 & 1113 & 274 & $13.8 \%$ \\
\hline & b10 & 353 & 1151 & 798 & 857 & 1202 & 345 & $17.7 \%$ \\
\hline 57.6 & $\mathrm{c} 10$ & 351 & 1132 & 781 & 849 & 1263 & 414 & $21.7 \%$ \\
\hline & d10 & 353 & 1160 & 807 & 850 & 1334 & 484 & $24.5 \%$ \\
\hline & e10 & 353 & 1151 & 798 & 849 & 1422 & 573 & $29.3 \%$ \\
\hline & a11 & 353 & 1135 & 782 & 859 & 1075 & 216 & $11.3 \%$ \\
\hline & b11 & 353 & 1144 & 791 & 846 & 1106 & 260 & $13.4 \%$ \\
\hline 81.6 & c11 & 353 & 1140 & 787 & 845 & 1136 & 291 & $15.1 \%$ \\
\hline & d11 & 353 & 1140 & 787 & 847 & 1165 & 318 & $16.5 \%$ \\
\hline & $e 11$ & 353 & 1124 & 771 & 848 & 1202 & 354 & $18.8 \%$ \\
\hline & a12 & 353 & 1152 & 799 & 844 & 1035 & 191 & $9.8 \%$ \\
\hline & b12 & 352 & 1136 & 784 & 833 & 1047 & 214 & $11.1 \%$ \\
\hline 105.6 & $\mathrm{cl} 2$ & 353 & 1134 & 781 & 834 & 1092 & 258 & $13.5 \%$ \\
\hline & d12 & 353 & 1133 & 780 & 848 & 1119 & 271 & $14.2 \%$ \\
\hline & $\mathrm{e} 12$ & 353 & 1123 & 770 & 853 & 1141 & 288 & $15.3 \%$ \\
\hline
\end{tabular}


Appendix B Test B-6

\begin{tabular}{|lr|l|}
\hline & grams & \% by wt of water \\
\hline Nukon: Class 5\&6 & 47 & $0.0011 \%$ \\
Sludge A & 938 & $0.0213 \%$ \\
Mix A & 0 & $0.0000 \%$ \\
\hline Total & 985 & $0.0223 \%$ \\
\hline
\end{tabular}

Chugging lasts 9.6 minutes

\begin{tabular}{|c|c|c|c|c|c|c|c|c|}
\hline \multirow{2}{*}{$\begin{array}{c}\text { Time } \\
\text { (Full scale } \\
\text { minutes) }\end{array}$} & \multirow{2}{*}{ Label } & \multicolumn{2}{|c|}{ Sample Bottles (g) } & \multirow{2}{*}{$\begin{array}{l}\text { Water (g) } \\
\text { full-empry }\end{array}$} & \multicolumn{2}{|c|}{ Filters (0.1 mg) } & \multirow{2}{*}{\begin{tabular}{|l} 
Residue \\
used-new
\end{tabular}} & \multirow{2}{*}{$\begin{array}{l}\text { \%o of average initial } \\
\text { calculated concentration }\end{array}$} \\
\hline & & empty & full & & new & used & & \\
\hline \multirow{5}{*}{2.4} & al & 353 & 1116 & 763 & 851 & 2364 & 1513 & $88.8 \%$ \\
\hline & b1 & 358 & 1164 & 806 & 817 & 2482 & 1665 & $92.5 \%$ \\
\hline & c1 & 357 & 1150 & 793 & 808 & 2432 & 1624 & $91.7 \%$ \\
\hline & dl & 357 & 1155 & 798 & 840 & 2484 & 1644 & $92.3 \%$ \\
\hline & el & 353 & 1145 & 792 & 848 & 2570 & 1722 & $97.4 \%$ \\
\hline \multirow{5}{*}{4.8} & a2 & 353 & 1146 & 793 & 840 & 2391 & 1551 & $87.6 \%$ \\
\hline & b2 & 357 & 1167 & 810 & 867 & 2513 & 1646 & $91.0 \%$ \\
\hline & $c 2$ & 357. & 1172 & 815 & 867 & 2490 & 1623 & $89.2 \%$ \\
\hline & d2 & 353 & 1159 & 806 & 865 & 2470 & 1605 & $89.2 \%$ \\
\hline & e2 & 353 & 1149 & 796 & 859 & 2617 & 1758 & $98.9 \%$ \\
\hline \multirow{5}{*}{7.2} & 23 & 352 & 1130 & 778 & 861 & 2578 & 1717 & $98.8 \%$ \\
\hline & b3 & 353 & 1170 & 817 & 869 & 2584 & 1715 & $94.0 \%$ \\
\hline & c3 & 354 & 1156 & 802 & 852 & 2476 & 1624 & $90.7 \%$ \\
\hline & $d 3$ & 352 & 1143 & 791 & 855 & 2499 & 1644 & $93.1 \%$ \\
\hline & e3 & 353 & 1162 & 809 & 852 & 2547 & 1695 & $93.8 \%$ \\
\hline \multirow{5}{*}{9.6} & 24 & 353 & 1125 & 772 & 862 & 2377 & 1515 & $87.9 \%$ \\
\hline & b4 & 353 & 1168 & 815 & 866 & 2491 & 1625 & $89.3 \%$ \\
\hline & c4 & 353 & 1164 & 811 & 846 & 2384 & 1538 & $84.9 \%$ \\
\hline & d4 & 353 & 1164 & 811 & 866 & 2660 & 1794 & $99.1 \%$ \\
\hline & 4 & 353 & 1158 & 805 & 869 & 2817 & 1948 & $108.4 \%$ \\
\hline \multirow{5}{*}{14.4} & as & 353 & 1163 & 810 & 883 & 1777 & 894 & $49.4 \%$ \\
\hline & b5 & 352 & 1160 & 808 & 883 & 2100 & 1217 & $67.4 \%$ \\
\hline & $\omega$ & 352 & 1144 & 792 & 876 & 2001 & 1125 & $63.6 \%$ \\
\hline & d5 & 353 & 1165 & 812 & 875 & 2093 & 1218 & $67.2 \%$ \\
\hline & es & 353 & 1157 & 804 & 884 & 2152 & 1268 & $70.6 \%$ \\
\hline \multirow{5}{*}{19.2} & 26 & 352 & 1128 & 776 & 879 & 1683 & 804 & $46.4 \%$ \\
\hline & $b 6$ & 352 & 1152 & 800 & 871 & 1806 & 935 & $52.3 \%$ \\
\hline & $\infty$ & 352 & 1114 & 762 & 866 & 1645 & 779 & $45.8 \%$ \\
\hline & d6 & 353 & 1132 & 779 & 876 & 1767 & 891 & $51.2 \%$ \\
\hline & $e 6$ & 353 & 1145 & 792 & 877 & 1810 & 933 & $52.8 \%$ \\
\hline \multirow{5}{*}{24} & a7 & 352 & 1149 & 797 & 874 & 1263 & 389 & $21.9 \%$ \\
\hline & b7 & 353 & 1159 & 806 & 880 & 1497 & 617 & $34.3 \%$ \\
\hline & c7 & 353 & 1160 & 807 & 876 & 1628 & 752 & $41.7 \%$ \\
\hline & $d 7$ & 351 & 1147 & 796 & 877 & 1701 & 824 & $46.4 \%$ \\
\hline & e7 & 353 & 1146 & 793 & 872 & 1817 & 945 & $53.4 \%$ \\
\hline & 98 & 354 & 1175 & 821 & 876 & 1346 & 470 & $25.6 \%$ \\
\hline & b8 & 354 & 1168 & 814 & 880 & 1499 & 619 & $34.1 \%$ \\
\hline 28.8 & c8 & 353 & 1147 & 794 & 878 & 1578 & 700 & $39.5 \%$ \\
\hline & $d 8$ & 354 & 1145 & 791 & 877 & 1590 & 713 & $40.4 \%$ \\
\hline & e8 & 353 & 1147 & 794 & 866 & 1646 & 780 & $44.0 \%$ \\
\hline & 29 & 353 & 1111 & 758 & 871 & 1288 & 417 & $24.6 \%$ \\
\hline & 69 & 354 & 1151 & 797 & 882 & 1428 & 546 & $30.7 \%$ \\
\hline 33.6 & c9 & 353 & 1150 & 797 & 876 & 1537 & 661 & $37.1 \%$ \\
\hline & dg & 354 & 1121 & 767 & 866 & 1549 & 683 & $39.9 \%$ \\
\hline & $e 9$ & 354 & 1144 & 790 & 872 & 1647 & 775 & $43.9 \%$ \\
\hline & alo & 353 & 1100 & 747 & 873 & 1140 & 267 & $16.0 \%$ \\
\hline & blo & 353 & 1139 & 786 & 838 & 1217 & 379 & $21.6 \%$ \\
\hline 57.6 & c10 & 351 & 1140 & 789 & 826 & 1285 & 459 & $26.1 \%$ \\
\hline & d10 & 353 & 1135 & 782 & 840 & 1368 & 528 & $30.2 \%$ \\
\hline & elo & 353 & 1132 & 779 & 827 & 1431 & 604 & $34.7 \%$ \\
\hline & all & 353 & 1069 & 716 & 843 & 1057 & 214 & $13.4 \%$ \\
\hline & bll & 353 & 1108 & 755 & 831 & 1116 & 285 & $16.9 \%$ \\
\hline 81.6 & cll & 353 & 1141 & 788 & 832 & 1195 & 363 & $20.6 \%$ \\
\hline & d11 & 353 & 1130 & 777 & 834 & 1240 & 406 & $23.4 \%$ \\
\hline & ell & 353 & 1105 & 752 & 841 & 1285 & 444 & $26.4 \%$ \\
\hline & a12 & 353 & 1095 & 742 & 839 & 1043 & 204 & $12.3 \%$ \\
\hline & b12 & 352 & 1156 & 804 & 833 & 1084 & 251 & $14.0 \%$ \\
\hline 105.6 & $\mathrm{cl} 2$ & 353 & 1155 & 802 & 836 & 1143 & 307 & $17.1 \%$ \\
\hline & d12 & 353 & 1116 & 763 & 834 & 1164 & 330 & $19.4 \%$ \\
\hline & $\mathrm{e} 12$ & 353 & 1120 & 767 & 830 & 1197 & 367 & $21.4 \%$ \\
\hline
\end{tabular}


Test B-7

\begin{tabular}{|lr|l|}
\hline & grams & \% by wt of water \\
\hline Nukon: Class 3\&4 & 47 & $0.0011 \%$ \\
Sludge A & 938 & $0.0213 \%$ \\
Mix A & 0 & $0.0000 \%$ \\
\hline Total & 985 & $0.0223 \%$ \\
\hline
\end{tabular}

Appendix B

$1 / 17 / 95$

Chugging lasts 9.6 minutes

\begin{tabular}{|c|c|c|c|c|c|c|c|c|}
\hline \multirow{2}{*}{$\begin{array}{c}\text { Time } \\
\text { (Full scale } \\
\text { minutes) }\end{array}$} & \multirow{2}{*}{ Label } & \multicolumn{2}{|c|}{ Sample Bottles (g) } & \multirow{2}{*}{\begin{tabular}{|l|} 
Water (g) \\
full-empty
\end{tabular}} & \multicolumn{2}{|c|}{ Filters $(0.1 \mathrm{mg})$} & \multirow{2}{*}{\begin{tabular}{|l} 
Residue \\
used-new \\
\end{tabular}} & \multirow{2}{*}{$\begin{array}{l}\text { \%o of average initial } \\
\text { calculated concentration }\end{array}$} \\
\hline & & empty & full & & new & used & & \\
\hline \multirow{5}{*}{2.4} & al & 353 & 1072 & 719 & 786 & 2275 & 1489 & $92.7 \%$ \\
\hline & bl & 358 & 1118 & 760 & 838 & 2531 & 1693 & $99.8 \%$ \\
\hline & cl & 357 & 1128 & 771 & 837 & 2378 & 1541 & $89.5 \%$ \\
\hline & dl & 357 & 1132 & 775 & 845 & 2345 & 1500 & $86.7 \%$ \\
\hline & el & 353 & 1095 & 742 & 840 & 2313 & 1473 & $88.9 \%$ \\
\hline \multirow{5}{*}{4.8} & 22 & 353 & 1128 & 775 & 826 & 2391 & 1565 & $90.4 \%$ \\
\hline & b2 & 357 & 1168 & 811 & 829 & 2550 & 1721 & $95.0 \%$ \\
\hline & c2 & 357 & 1162 & 805 & 880 & 2503 & 1623 & $90.3 \%$ \\
\hline & $\mathrm{d} 2$ & 353 & 1160 & 807 & 837 & 2460 & 1623 & $90.1 \%$ \\
\hline & e2 & 353 & 1153 & 800 & 883 & 2459 & 1576 & $88.2 \%$ \\
\hline \multirow{5}{*}{7.2} & a3 & 352 & 1148 & 796 & 877 & 2418 & 1541 & $86.7 \%$ \\
\hline & b3 & 353 & 1158 & 805 & 878 & 2486 & 1608 & $89.5 \%$ \\
\hline & c3 & 354 & 1143 & 789 & 854 & 2456 & 1602 & $90.9 \%$ \\
\hline & d3 & 352 & 1157 & 805 & 865 & 2691 & 1826 & $101.6 \%$ \\
\hline & e3 & 353 & 1145 & 792 & 847 & 2439 & 1592 & $90.0 \%$ \\
\hline \multirow{5}{*}{9.6} & 24 & 353 & 1280 & 927 & 852 & 2826 & 1974 & $95.4 \%$ \\
\hline & b4 & 353 & 1180 & 827 & 838 & 2548 & 1710 & $92.6 \%$ \\
\hline & c4 & 353 & 1160 & 807 & 862 & 2627 & 1765 & $97.9 \%$ \\
\hline & d4 & 353 & 1172 & 819 & 848 & 2570 & 1722 & $94.2 \%$ \\
\hline & $e 4$ & 353 & 1157 & 804 & 849 & 2604 & 1755 & $97.8 \%$ \\
\hline \multirow{5}{*}{14.4} & 25 & 353 & 1037 & 684 & 848 & 1687 & 839 & $54.9 \%$ \\
\hline & b5 & 352 & 1080 & 728 & 852 & 1820 & 968 & $59.5 \%$ \\
\hline & c5 & 352 & 1108 & 756 & 859 & 1914 & 1055 & $62.5 \%$ \\
\hline & d5 & 353 & 1096 & 743 & 854 & 2024 & 1170 & $70.5 \%$ \\
\hline & 5 & 353 & 1066 & 713 & 872 & 1991 & 1119 & $70.3 \%$ \\
\hline \multirow{5}{*}{19.2} & a6 & 352 & 1103 & 751 & 862 & 1336 & 474 & $28.3 \%$ \\
\hline & $b 6$ & 352 & 1162 & 810 & 863 & 1673 & 810 & $44.8 \%$ \\
\hline & $\infty$ & 352 & 1157 & 805 & 872 & 1558 & 686 & $38.2 \%$ \\
\hline & d6 & 353 & 1133 & 780 & 857 & 1743 & 886 & $50.9 \%$ \\
\hline & $\infty$ & 353 & 1142 & 789 & 860 & 1828 & 968 & $54.9 \%$ \\
\hline \multirow{5}{*}{24} & a7 & 352 & 1050 & 698 & 833 & 1295 & 462 & $29.6 \%$ \\
\hline & b7 & 353 & 1095 & 742 & 858 & 1412 & 554 & $33.4 \%$ \\
\hline & c7 & 353 & 1020 & 667 & 884 & 1535 & 651 & $43.7 \%$ \\
\hline & d7 & 351 & 1099 & 748 & 882 & 1677 & 795 & $47.6 \%$ \\
\hline & e7 & 353 & 1075 & 722 & 866 & 1701 & 835 & $51.8 \%$ \\
\hline & 98 & 354 & 977 & 623 & 874 & 1217 & 343 & $24.7 \%$ \\
\hline & b8 & 354 & 1017 & 663 & 880 & 1358 & 478 & $32.3 \%$ \\
\hline 28.8 & c8 & 353 & 1042 & 689 & 828 & 1395 & 567 & $36.9 \%$ \\
\hline & d8 & 354 & 1029 & 675 & 877 & 1542 & 665 & $44.1 \%$ \\
\hline & e8 & 353 & 1001 & 648 & 879 & 1550 & 671 & $46.4 \%$ \\
\hline & 99 & 353 & 1115 & 762 & 870 & 1226 & 356 & $20.9 \%$ \\
\hline & b9 & 354 & 1160 & 806 & 872 & 1367 & 495 & 27.5\% \\
\hline 33.6 & c9 & 353 & 1155 & 802 & 870 & 1473 & 603 & $33.7 \%$ \\
\hline & $d 9$ & 354 & 1138 & 784 & 845 & 1528 & 683 & $39.0 \%$ \\
\hline & $e 9$ & 354 & 1150 & 796 & 869 & 1597 & 728 & $41.0 \%$ \\
\hline & 910 & 353 & 1146 & 793 & 873 & 1159 & 286 & $16.2 \%$ \\
\hline & b10 & 353 & 1173 & 820 & 873 & 1210 & 337 & $18.4 \%$ \\
\hline 57.6 & c10 & 351 & 1137 & 786 & 869 & 1256 & 387 & $22.0 \%$ \\
\hline & d10 & 353 & 1165 & 812 & 866 & 1350 & 484 & $26.7 \%$ \\
\hline & e10 & 353 & 1157 & 804 & 877 & 1413 & 536 & $29.99 \%$ \\
\hline & 211 & 353 & 1109 & 756 & 861 & 1166 & 305 & $18.1 \%$ \\
\hline & bl1 & 353 & 1153 & 800 & 872 & 1258 & 386 & $21.6 \%$ \\
\hline 81.6 & c11 & 353 & 1148 & 795 & 862 & 1326 & 464 & $26.1 \%$ \\
\hline & d11 & 353 & 1138 & 785 & 870 & 1304 & 434 & $24.8 \%$ \\
\hline & ell & 353 & 1135 & 782 & 871 & 1690 & 819 & $46.9 \%$ \\
\hline & a12 & 353 & 1174 & 821 & 867 & 1149 & 282 & $15.4 \%$ \\
\hline & b12 & 352 & 1165 & 813 & 871 & 1216 & 345 & $19.0 \%$ \\
\hline 105.6 & cl2 & 353 & 1140 & 787 & 867 & 1276 & 409 & $23.3 \%$ \\
\hline & d12 & 353 & 1153 & 800 & 881 & 1431 & 550 & $30.8 \%$ \\
\hline & e12 & 353 & 1161 & 808 & 867 & 1247 & 380 & $21.1 \%$ \\
\hline
\end{tabular}


Appendix B Test B-8

$1 / 18 / 95$

\begin{tabular}{|lr|l|}
\hline & grams & $\%$ by wt of water \\
\hline Nukon: Class 5\&6 & 0 & $0.0000 \%$ \\
Sludge A & 2814 & $0.0638 \%$ \\
Mix A & 0 & $0.0000 \%$ \\
\hline Total & 2814 & $0.0638 \%$ \\
\hline
\end{tabular}

Chugging lasts 9.6 minutes

\begin{tabular}{|c|c|c|c|c|c|c|c|c|}
\hline \multirow{2}{*}{$\begin{array}{c}\text { Time } \\
\text { (Full scale } \\
\text { minutes) }\end{array}$} & \multirow{2}{*}{ Label } & \multicolumn{2}{|c|}{ Sample Botules (g) } & \multirow{2}{*}{$\begin{array}{l}\text { Water }(\mathrm{g}) \\
\text { full-empxy }\end{array}$} & \multicolumn{2}{|c|}{ Filters $(0.1 \mathrm{mg})$} & \multirow{2}{*}{\begin{tabular}{|l} 
Residue \\
used-new
\end{tabular}} & \multirow{2}{*}{$\begin{array}{l}\text { \% of average initial } \\
\text { calculated concentration }\end{array}$} \\
\hline & & empty & full & & new & used & & \\
\hline \multirow{5}{*}{2.4} & $\mathrm{al}$ & 353 & 1053 & 700 & 855 & 4690 & 3835 & $85.9 \%$ \\
\hline & bl & 358 & 1111 & 753 & 855 & 5080 & 4225 & $88.0 \%$ \\
\hline & c1 & 357 & 1131 & 774 & 866 & 5465 & 4599 & $93.1 \%$ \\
\hline & d1 & 357 & 1123 & 766 & 850 & 5356 & 4506 & $92.2 \%$ \\
\hline & el & 353 & 1145 & 792 & 855 & 5633 & 4778 & $94.6 \%$ \\
\hline \multirow{5}{*}{4.8} & a2 & 353 & 1120 & 767 & 853 & 5121 & 4268 & $87.2 \%$ \\
\hline & b2 & 357 & 1179 & 822 & 834 & 5515 & 4681 & $89.3 \%$ \\
\hline & c2 & 357 & 1159 & 802 & 853 & 5468 & 4615 & $90.2 \%$ \\
\hline & d2 & 353 & 1150 & 797 & 848 & 5525 & 4677 & $92.0 \%$ \\
\hline & e2 & 353 & 1094 & 741 & 875 & 5258 & 4383 & $92.7 \%$ \\
\hline \multirow{5}{*}{7.2} & a3 & 352 & 1093 & 741 & 884 & 5200 & 4316 & $91.3 \%$ \\
\hline & b3 & 353 & 1148 & 795 & 880 & 5551 & 4671 & $92.1 \%$ \\
\hline & c3 & 354 & 1142 & 788 & 873 & 5517 & 4644 & $92.4 \%$ \\
\hline & d3 & 352 & 1136 & 784 & 875 & 5591 & 4716 & $94.3 \%$ \\
\hline & e3 & 353 & 1123 & 770 & 877 & 5598 & 4721 & $96.1 \%$ \\
\hline \multirow{5}{*}{9.6} & a4 & 353 & 1132 & 779 & 886 & 5507 & 4621 & $93.0 \%$ \\
\hline & $b 4$ & 353 & 1150 & 797 & 880 & 5656 & 4776 & $93.9 \%$ \\
\hline & 04 & 353 & 1154 & 801 & 879 & 5715 & 4836 & $94.6 \%$ \\
\hline & d4 & 353 & 1145 & 792 & 872 & 5565 & 4693 & $92.9 \%$ \\
\hline & e4 & 353 & 1151 & 798 & 930 & 5906 & 4976 & $97.7 \%$ \\
\hline \multirow{5}{*}{14.4} & 25 & 353 & 1131 & 778 & 870 & & -870 & $-17.5 \%$ \\
\hline & b5 & 352 & 1152 & 800 & 876 & 3982 & 3106 & $60.9 \%$ \\
\hline & $c 5$ & 352 & 1142 & 790 & 866 & 4271 & 3405 & $67.6 \%$ \\
\hline & d5 & 353 & 1149 & 796 & 837 & 4473 & 3636 & $71.6 \%$ \\
\hline & e5 & 353 & 1141 & 788 & 889 & 4633 & 3744 & $74.5 \%$ \\
\hline \multirow{5}{*}{19.2} & 26 & 352 & 1075 & 723 & 883 & 2625 & 1742 & $37.8 \%$ \\
\hline & $b 6$ & 352 & 1137 & 785 & 866 & 2970 & 2104 & $42.0 \%$ \\
\hline & $\infty 6$ & 352 & 1133 & 781 & 859 & 3300 & 2441 & $49.0 \%$ \\
\hline & d6 & 353 & 1142 & 789 & 869 & 3711 & 2842 & $56.5 \%$ \\
\hline & ef & 353 & 1117 & 764 & 875 & 3580 & 2705 & $55.5 \%$ \\
\hline \multirow{5}{*}{24} & a7 & 352 & 1121 & 769 & 883 & 2352 & 1469 & $29.9 \%$ \\
\hline & b7 & 353 & 1131 & 778 & 876 & 2780 & 1904 & $38.4 \%$ \\
\hline & c7 & 353 & 1136 & 783 & 864 & 2781 & 1917 & $38.4 \%$ \\
\hline & d7 & 351 & 1151 & 800 & 850 & 3238 & 2388 & $46.8 \%$ \\
\hline & e7 & 353 & 1155 & 802 & 849 & 3423 & 2574 & $50.3 \%$ \\
\hline & 28 & 354 & 1057 & 703 & 867 & 1844 & 977 & $21.8 \%$ \\
\hline & 68 & 354 & 1110 & 756 & 862 & 2313 & 1451 & $30.1 \%$ \\
\hline 28.8 & c8 & 353 & 1135 & 782 & 876 & 2667 & 1791 & $35.9 \%$ \\
\hline & d8 & 354 & 1116 & 762 & 875 & 2885 & 2010 & $41.3 \%$ \\
\hline & es & 353 & 1093 & 740 & 887 & 3105 & 2218 & $47.0 \%$ \\
\hline & a9 & 353 & 1119 & 766 & 868 & 1846 & 978 & $20.0 \%$ \\
\hline & b9 & 354 & 1160 & 806 & 881 & 2270 & 1389 & $27.0 \%$ \\
\hline 33.6 & c9 & 353 & 1139 & 786 & 873 & 2461 & 1588 & $31.7 \%$ \\
\hline & d9 & 354 & 1154 & 800 & 895 & 2876 & 1981 & $38.8 \%$ \\
\hline & eq & 354 & 1148 & 794 & 873 & 3038 & 2165 & $42.7 \%$ \\
\hline & a10 & 353 & 1092 & 739 & 875 & 1657 & 782 & $16.6 \%$ \\
\hline & b10 & 353 & 1136 & 783 & 893 & 1836 & 943 & $18.9 \%$ \\
\hline 57.6 & c10 & 351 & 1126 & 775 & 864 & 1949 & 1085 & $21.9 \%$ \\
\hline & d10 & 353 & 1128 & 775 & 865 & 2141 & 1276 & $25.8 \%$ \\
\hline & elo & 353 & 1126 & 773 & 882 & 2331 & 1449 & $29.4 \%$ \\
\hline & a11 & 353 & 1115 & 762 & 883 & 1558 & 675 & $13.9 \%$ \\
\hline & bl1 & 353 & 1098 & 745 & 881 & 1633 & 752 & $15.8 \%$ \\
\hline 81.6 & c11 & 353 & 1102 & 749 & 877 & 1715 & 838 & $17.5 \%$ \\
\hline & d11 & 353 & 1108 & 755 & 878 & 1799 & 921 & $19.1 \%$ \\
\hline & ell & 353 & 1073 & 720 & 876 & 1865 & 989 & $21.5 \%$ \\
\hline & al2 & 353 & 1260 & 907 & 885 & 1592 & 707 & $12.2 \%$ \\
\hline & b12 & 352 & 1231 & 879 & 872 & 1617 & 745 & $13.3 \%$ \\
\hline 105.6 & $\mathrm{cl} 2$ & 353 & 1194 & 841 & 874 & 1696 & 822 & $15.3 \%$ \\
\hline & d12 & 353 & 1146 & 793 & 866 & 1674 & 808 & $16.0 \%$ \\
\hline & $\mathrm{e} 12$ & 353 & 1234 & 881 & 881 & 1815 & 934 & $16.6 \%$ \\
\hline
\end{tabular}


Test D-11 R1 $1 / 23 / 95$

\begin{tabular}{|lr|l|}
\hline & grams & \% by wh of water \\
\hline Nukon: Class 3\&4 & 142 & $0.0032 \%$ \\
Sludge A & 0 & $0.0000 \%$ \\
Mix A & 0 & $0.0000 \%$ \\
\hline Toual & 142 & $0.0032 \%$ \\
\hline
\end{tabular}

Chugging lasts 9.6 minutes

\begin{tabular}{|c|c|c|c|c|c|c|c|c|}
\hline \multirow{2}{*}{$\begin{array}{c}\text { Time } \\
\text { (Full scale } \\
\text { minutes) }\end{array}$} & \multirow{2}{*}{ Label } & \multicolumn{2}{|c|}{ Sample Boules (g) } & \multirow{2}{*}{$\begin{array}{l}\text { Water }(\mathrm{g}) \\
\text { full-empty }\end{array}$} & \multicolumn{2}{|c|}{ Filters $(0.1 \mathrm{mg})$} & \multirow{2}{*}{$\begin{array}{l}\text { Residue } \\
\text { used-new }\end{array}$} & \multirow{2}{*}{$\begin{array}{l}\text { \%o of average initial } \\
\text { calculated concentration }\end{array}$} \\
\hline & & empty & full & & new & used & & \\
\hline \multirow{5}{*}{2.4} & al & 353 & 1145 & 792 & 876 & 1090 & 214 & $83.9 \%$ \\
\hline & bl & 358 & 1183 & 825 & 877 & 1230 & 353 & $132.9 \%$ \\
\hline & cl & 357 & 1189 & 832 & 864 & 1136 & 272 & $101.6 \%$ \\
\hline & d1 & 357 & 1171 & 814 & 895 & 1155 & 260 & $99.2 \%$ \\
\hline & el & 353 & 1152 & 799 & 905 & 1588 & 683 & $265.5 \%$ \\
\hline \multirow{5}{*}{4.8} & 22 & 353 & 1183 & 830 & 889 & 1148 & 259 & $96.9 \%$ \\
\hline & b2 & 357 & 1181 & 824 & 836 & 1125 & 289 & $108.9 \%$ \\
\hline & c2 & 357 & 1184 & 827 & 826 & 1108 & 282 & $105.9 \%$ \\
\hline & d2 & 353 & 1186 & 833 & 842 & 1144 & 302 & $112.6 \%$ \\
\hline & e2 & 353 & 1165 & 812 & 824 & 1086 & 262 & $100.2 \%$ \\
\hline \multirow{5}{*}{7.2} & a3 & 352 & 1155 & 803 & 831 & 1101 & 270 & $104.4 \%$ \\
\hline & b3 & 353 & 1178 & 825 & 837 & 1127 & 290 & $109.2 \%$ \\
\hline & c3 & 354 & 1152 & 798 & 839 & 1177 & 338 & $131.6 \%$ \\
\hline & d3 & 352 & 1156 & 804 & 836 & 1127 & 291 & $112.4 \%$ \\
\hline & e3 & 353 & 1155 & 802 & 823 & 1099 & 276 & $106.9 \%$ \\
\hline \multirow{5}{*}{9.6} & a4 & 353 & 1117 & 764 & 822 & 1097 & 275 & $111.8 \%$ \\
\hline & b4 & 353 & 1151 & 798 & 825 & 1062 & 237 & $92.3 \%$ \\
\hline & c4 & 353 & 1143 & 790 & 828 & 1094 & 266 & $104.6 \%$ \\
\hline & $\mathrm{d} 4$ & 353 & 1163 & 810 & 837 & 1146 & 309 & $118.5 \%$ \\
\hline & e4 & 353 & 1149 & 796 & 825 & 1082 & 257 & $100.3 \%$ \\
\hline \multirow{5}{*}{14.4} & a5 & 353 & 1125 & 772 & 829 & 1048 & 219 & $88.1 \%$ \\
\hline & b5 & 352 & 1131 & 779 & 826 & 1080 & 254 & $101.3 \%$ \\
\hline & c5 & 352 & 1122 & 770 & 831 & 1057 & 226 & $91.2 \%$ \\
\hline & d5 & 353 & 1147 & 794 & 825 & 1076 & 251 & $98.2 \%$ \\
\hline & e5 & 353 & 1124 & 771 & 836 & 1107 & 271 & $109.2 \%$ \\
\hline \multirow{5}{*}{19.2} & 96 & 352 & 1120 & 768 & 841 & 1049 & 208 & $84.1 \%$ \\
\hline & b6 & 352 & 1157 & 805 & 837 & 881 & 44 & $17.0 \%$ \\
\hline & $\infty 6$ & 352 & 1144 & 792 & 834 & 1047 & 213 & $83.5 \%$ \\
\hline & $d 6$ & 353 & 1145 & 792 & 833 & 1049 & 216 & $84.7 \%$ \\
\hline & e6 & 353 & 1146 & 793 & 825 & 1180 & 355 & $139.1 \%$ \\
\hline \multirow{5}{*}{24} & a7 & 352 & 1130 & 778 & 836 & 1019 & 183 & $73.1 \%$ \\
\hline & b7 & 353 & 1152 & 799 & 834 & 1022 & 188 & $73.1 \%$ \\
\hline & c7 & 353 & 1144 & 791 & 829 & 1022 & 193 & $75.8 \%$ \\
\hline & $d 7$ & 351 & 1142 & 791 & 828 & 1029 & 201 & $78.9 \%$ \\
\hline & e7 & 353 & 1178 & 825 & 827 & 1077 & 250 & $94.1 \%$ \\
\hline & 28 & 354 & 1184 & 830 & 825 & 1011 & 186 & $69.6 \%$ \\
\hline & b8 & 354 & 1176 & 822 & 826 & 1004 & 178 & $67.3 \%$ \\
\hline 28.8 & c8 & 353 & 1157 & 804 & 823 & 991 & 168 & $64.9 \%$ \\
\hline & d8 & 354 & 1165 & 811 & 833 & 1041 & 208 & $79.7 \%$ \\
\hline & $e 8$ & 353 & 1132 & 779 & 828 & 1022 & 194 & $77.4 \%$ \\
\hline & a9 & 353 & 1092 & 739 & 831 & 953 & 122 & $51.3 \%$ \\
\hline & 69 & 354 & 1141 & 787 & 830 & 978 & 148 & $58.4 \%$ \\
\hline 33.6 & c9 & 353 & 1155 & 802 & 834 & 1009 & 175 & $67.8 \%$ \\
\hline & $d 9$ & 354 & 1137 & 783 & 833 & 1028 & 195 & $77.4 \%$ \\
\hline & eq & 354 & 1129 & 775 & 835 & 1012 & 177 & $70.9 \%$ \\
\hline & a10 & 353 & 1089 & 736 & 833 & 865 & 32 & $13.5 \%$ \\
\hline & b10 & 353 & 1135 & 782 & 831 & 904 & 73 & $29.0 \%$ \\
\hline 57.6 & c10 & 351 & 1128 & 777 & 837 & 933 & 96 & $38.4 \%$ \\
\hline & d10 & 353 & 1147 & 794 & 830 & 965 & 135 & $52.8 \%$ \\
\hline & el0 & 353 & 1120 & 767 & 821 & 950 & 129 & $52.2 \%$ \\
\hline & a11 & 353 & 1085 & 732 & 825 & 833 & 8 & $3.4 \%$ \\
\hline & b11 & 353 & 1135 & 782 & 828 & 859 & 31 & $12.3 \%$ \\
\hline 81.6 & c11 & 353 & 1136 & 783 & 825 & 876 & 51 & $20.2 \%$ \\
\hline & d11 & 353 & 1142 & 789 & 822 & 893 & 71 & $28.0 \%$ \\
\hline & ell & 353 & 1122 & 769 & 820 & 897 & 77 & $31.1 \%$ \\
\hline & a12 & 353 & 1112 & 759 & 835 & 849 & 14 & $5.7 \%$ \\
\hline & b12 & 352 & 1144 & 792 & 837 & 856 & 19 & $7.5 \%$ \\
\hline 105.6 & $\mathrm{c} 12$ & 353 & 1138 & 785 & 841 & 863 & 22 & $8.7 \%$ \\
\hline & $d 12$ & 353 & 1136 & 783 & 825 & 867 & 42 & $16.7 \%$ \\
\hline & e12 & 353 & 1123 & 770 & 830 & 887 & 57 & $23.0 \%$ \\
\hline
\end{tabular}


$\begin{array}{ll}\text { Appendix B } & \text { Test D-14 R1 } \\ & 1 / 24 / 95\end{array}$

\begin{tabular}{|lr|l|}
\hline & grams & $\%$ by wr of water \\
\hline Nukon: Class 5\&6 & 142 & $0.0032 \%$ \\
Sludge A & 938 & $0.0213 \%$ \\
Mix A & 0 & $0.0000 \%$ \\
\hline Total & 1080 & $0.0245 \%$ \\
\hline
\end{tabular}

Chugging lasts 9.6 minutes

\begin{tabular}{|c|c|c|c|c|c|c|c|c|}
\hline \multirow{2}{*}{$\begin{array}{c}\text { Time } \\
\text { (Full scale } \\
\text { minutes) }\end{array}$} & \multirow{2}{*}{ Label } & \multicolumn{2}{|c|}{ Sample Bottles (g) } & \multirow{2}{*}{$\begin{array}{l}\text { Water }(g) \\
\text { full-empty }\end{array}$} & \multicolumn{2}{|c|}{ Filters $(0.1 \mathrm{mg})$} & \multirow{2}{*}{$\begin{array}{l}\text { Residue } \\
\text { used-new }\end{array}$} & \multirow{2}{*}{$\begin{array}{l}\% \text { of average initial } \\
\text { calculated concentration }\end{array}$} \\
\hline & & empty & full & & new & used & & \\
\hline \multirow{5}{*}{2.4} & a1 & 353 & 1013 & 660 & 829 & 2332 & 1503 & 93.08 \\
\hline & b1 & 358 & 1053 & 695 & 825 & 2437 & 1612 & $94.7 \%$ \\
\hline & $\mathrm{cl}$ & 357 & 1076 & 719 & 829 & 2409 & 1580 & $89.8 \%$ \\
\hline & dI & 357 & 1063 & 706 & 831 & 2411 & 1580 & $91.4 \%$ \\
\hline & el & 353 & 1035 & 682 & 823 & 2379 & 1556 & $93.2 \%$ \\
\hline \multirow{5}{*}{4.8} & 22 & 353 & 1091 & 738 & 827 & 2533 & 1706 & $94.4 \%$ \\
\hline & b2 & 357 & 896 & 539 & 839 & 2051 & 1212 & $91.8 \%$ \\
\hline & $c 2$ & 357 & 1161 & 804 & 830 & 2609 & 1779 & $90.4 \%$ \\
\hline & d2 & 353 & 1139 & 786 & 837 & 3264 & 2427 & $126.1 \%$ \\
\hline & e2 & 353 & 1123 & 770 & 840 & 2688 & 1848 & $98.0 \%$ \\
\hline \multirow{5}{*}{7.2} & 23 & 352 & 1132 & 780 & 828 & 2600 & 1772 & $92.8 \%$ \\
\hline & b3 & 353 & 827 & 474 & 824 & 1807 & 983 & $84.7 \%$ \\
\hline & $c 3$ & 354 & 1140 & 786 & 845 & 2673 & 1828 & $95.0 \%$ \\
\hline & $\mathrm{d} 3$ & 352 & 1144 & 792 & 835 & 2658 & 1823 & $94.0 \%$ \\
\hline & e3 & 353 & 1144 & 791 & 836 & 2936 & 2100 & $108.4 \%$ \\
\hline \multirow{5}{*}{9.6} & 24 & 353 & 1074 & 721 & 836 & 2493 & 1657 & $93.9 \%$ \\
\hline & b4 & 353 & 722 & 369 & 838 & 1574 & 736 & $81.5 \%$ \\
\hline & $c 4$ & 353 & 1212 & 859 & 823 & 2812 & 1989 & $94.6 \%$ \\
\hline & d4 & 353 & 1133 & 780 & 834 & 2652 & 1818 & $95.2 \%$ \\
\hline & $e 4$ & 353 & 1108 & 755 & 842 & 2652 & 1810 & $97.9 \%$ \\
\hline \multirow{5}{*}{14.4} & 25 & 353 & 1018 & 665 & 903 & 1913 & 1010 & $62.0 \%$ \\
\hline & b5 & 352 & 673 & 321 & 889 & 1381 & 492 & $62.6 \%$ \\
\hline & $\omega$ & 352 & 1093 & 741 & 886 & 2082 & 1196 & $65.9 \%$ \\
\hline & d5 & 353 & 1082 & 729 & 891 & 2074 & 1183 & $66.3 \%$ \\
\hline & e5 & 353 & 1050 & 697 & 888 & 2098 & 1210 & $70.9 \%$ \\
\hline \multirow{5}{*}{19.2} & 26 & 352 & 1068 & 716 & 881 & 1540 & 659 & $37.6 \%$ \\
\hline & $b 6$ & 352 & 667 & 315 & 890 & 1174 & 284 & $36.8 \%$ \\
\hline & $\infty 6$ & 352 & 1127 & 775 & 882 & 1837 & 955 & $50.3 \%$ \\
\hline & $d 6$ & 353 & 1126 & 773 & 890 & 1944 & 1054 & $55.7 \%$ \\
\hline & 66 & 353 & 1102 & 749 & 883 & 2050 & 1167 & $63.6 \%$ \\
\hline \multirow{5}{*}{24} & 27 & 352 & 1139 & 787 & 915 & 1539 & 624 & $32.4 \%$ \\
\hline & b7 & 353 & 670 & 317 & 913 & 1163 & 250 & $32.2 \%$ \\
\hline & c7 & 353 & 1151 & 798 & 906 & 1867 & 961 & $49.2 \%$ \\
\hline & 87 & 351 & 1157 & 806 & 904 & 1937 & 1033 & $52.3 \%$ \\
\hline & e7 & 353 & 1158 & 805 & 900 & 1971 & 1071 & $54.3 \%$ \\
\hline & 28 & 354 & 954 & 600 & 908 & 1360 & 452 & $30.8 \%$ \\
\hline & b8 & 354 & 595 & 241 & 908 & 1083 & 175 & $29.7 \%$ \\
\hline 28.8 & c8 & 353 & 1023 & 670 & 903 & 1632 & 729 & $44.4 \%$ \\
\hline & d8 & 354 & 1005 & 651 & 889 & 1667 & 778 & $48.8 \%$ \\
\hline & e8 & 353 & 978 & 625 & 889 & 1687 & 798 & $52.1 \%$ \\
\hline & 29 & 353 & 1092 & 739 & 887 & 1325 & $4 \overline{438}$ & $24.2 \%$ \\
\hline & 69 & 354 & 590 & 236 & 878 & 1034 & 156 & $27.0 \%$ \\
\hline 33.6 & $c 9$ & 353 & 1139 & 786 & 880 & 1604 & 724 & $37.6 \%$ \\
\hline & $d 9$ & 354 & 1141 & 787 & 876 & 1746 & 870 & $45.2 \%$ \\
\hline & $e 9$ & 354 & 1132 & 778 & 911 & 1797 & 886 & $46.5 \%$ \\
\hline & a10 & 353 & 1048 & 695 & 899 & 1195 & 296 & $17.4 \%$ \\
\hline & b10 & 353 & 591 & 238 & 909 & 1058 & 149 & $25.6 \%$ \\
\hline 57.6 & c10 & 351 & 1132 & 781 & 894 & 1391 & 497 & $26.0 \%$ \\
\hline & d10 & 353 & 1128 & 775 & 893 & 1459 & 566 & $29.8 \%$ \\
\hline & $e 10$ & 353 & 1095 & 742 & 877 & 1496 & 619 & $34.1 \%$ \\
\hline & all & 353 & 1196 & 843 & 892 & 1185 & 293 & $14.2 \%$ \\
\hline & bll & 353 & 608 & 255 & 882 & 998 & 116 & $18.6 \%$ \\
\hline 81.6 & cl1 & 353 & 1132 & 779 & 886 & 1272 & 386 & $20.2 \%$ \\
\hline & dII & 353 & 1140 & 787 & 882 & 1310 & 428 & $22.2 \%$ \\
\hline & ell & 353 & 1125 & 772 & 900 & 1401 & 501 & $26.5 \%$ \\
\hline & a12 & 353 & 1133 & 780 & 894 & 1126 & 232 & $12.1 \%$ \\
\hline & b12 & 352 & 610 & 258 & 884 & 970 & 86 & $13.6 \%$ \\
\hline 105.6 & $\mathrm{cl} 2$ & 353 & 1139 & 786 & 886 & 1213 & 327 & $17.0 \%$ \\
\hline & d12 & 353 & 1152 & 799 & 897 & 1278 & 381 & $19.5 \%$ \\
\hline & el2 & 353 & 1133 & 780 & 899 & 1306 & 407 & $21.3 \%$ \\
\hline
\end{tabular}


Test T-17

2/8/95

\begin{tabular}{|lr|l|}
\hline & \multicolumn{1}{c|}{ grams } & \% by wt of water \\
\hline Nukon: Class 3\&4 & 142 & $0.0032 \%$ \\
Sludge A & 142 & $0.0032 \%$ \\
Mix A & 0 & $0.0000 \%$ \\
\hline Total & 284 & $0.0064 \%$ \\
\hline
\end{tabular}

Chugging lasts 9.6 minutes
\begin{tabular}{|c|c|c|c|c|}
\hline Time & Sample Boules (g) & Water $(\mathrm{g})$ & Filters $(0.1 \mathrm{mg})$ & Residue \\
\hline
\end{tabular} \begin{tabular}{|c|c|c|c|c|c|c|}
\hline $\begin{array}{c}\text { (Full scale } \\
\text { minutes) }\end{array}$ & Label & empty $\perp$ full & full-empty & new & used & used-new \\
\cline { 2 - 7 }
\end{tabular}

\begin{tabular}{|c|c|c|c|c|c|c|c|c|}
\hline minutes) & Label & empty & full & full-empty & new & used & Jused-new & \\
\hline \multirow{5}{*}{2.4} & $\mathrm{a} 1$ & 353 & 1177 & 824 & 894 & 1333 & 439 & $82.7 \%$ \\
\hline & bl & 358 & 1163 & 805 & 883 & 1315 & 432 & $83.4 \%$ \\
\hline & cl & 357 & 357 & 0 & 887 & & -887 & \\
\hline & d1 & 357 & 1234 & 877 & 898 & 1456 & 558 & $98.8 \%$ \\
\hline & e1 & 353 & 1227 & 874 & 900 & 1368 & 468 & $83.2 \%$ \\
\hline \multirow{5}{*}{4.8} & 22 & 353 & 1056 & 703 & 880 & 1290 & 410 & $90.6 \%$ \\
\hline & b2 & 357 & 1110 & 753 & 875 & 1337 & 462 & $95.3 \%$ \\
\hline & c2 & 357 & 357 & 0 & 880 & & -880 & \\
\hline & $\mathrm{d} 2$ & 353 & 1197 & 844 & 878 & 1478 & 600 & $110.4 \%$ \\
\hline & $e 2$ & 353 & 1167 & 814 & 878 & 1384 & 506 & $96.5 \%$ \\
\hline \multirow{5}{*}{7.2} & a3 & 352 & 1019 & 667 & 877 & 1328 & 451 & 105.09 \\
\hline & b3 & 353 & 1065 & 712 & 888 & 1329 & 441 & $96.2 \%$ \\
\hline & c3 & 354 & 354 & 0 & 881 & & -881 & \\
\hline & d3 & 352 & 1065 & 713 & 885 & 1315 & 430 & $93.7 \%$ \\
\hline & e3 & 353 & 1054 & 701 & 891 & 1277 & 386 & $85.5 \%$ \\
\hline \multirow{5}{*}{9.6} & 24 & 353 & 1102 & 749 & 882 & 1311 & 429 & $89.0 \%$ \\
\hline & b4 & 353 & 1143 & 790 & 880 & 1376 & 496 & $97.5 \%$ \\
\hline & 04 & 353 & 353 & 0 & 883 & & -883 & \\
\hline & d4 & 353 & 1155 & 802 & 876 & 1343 & 467 & $90.4 \%$ \\
\hline & e4 & 353 & 1133 & 780 & 898 & 1443 & 545 & $108.5 \%$ \\
\hline \multirow{5}{*}{14.4} & 25 & 353 & 1105 & 752 & 885 & 1207 & 322 & $66.5 \%$ \\
\hline & b5 & 352 & 1138 & 786 & 882 & 1228 & 346 & $68.4 \%$ \\
\hline & c5 & 352 & 352 & 0 & 888 & & .888 & \\
\hline & d5 & 353 & 1165 & 812 & 884 & 1257 & 373 & $71.3 \%$ \\
\hline & es & 353 & 1122 & 769 & 881 & 1239 & 358 & $72.3 \%$ \\
\hline \multirow{5}{*}{19.2} & 96 & 352 & 1094 & 742 & 884 & 1149 & 265 & $55.5 \%$ \\
\hline & b6 & 352 & 1146 & 794 & 899 & 1216 & 317 & $62.0 \%$ \\
\hline & $\infty$ & 352 & 352 & 0 & 865 & & -865 & \\
\hline & d6 & 353 & 1151 & 798 & 856 & 1251 & 395 & $76.9 \%$ \\
\hline & e6 & 353 & 1129 & 776 & 896 & 1226 & 330 & $66.0 \%$ \\
\hline \multirow{5}{*}{24} & a7 & 352 & 1149 & 797 & 891 & 1159 & 268 & 52.26 \\
\hline & b7 & 353 & 1162 & 809 & 886 & 1170 & 284 & $54.5 \%$ \\
\hline & c7 & 353 & 1224 & 871 & 904 & 1273 & 369 & $65.8 \%$ \\
\hline & d7 & 351 & 1167 & 816 & 880 & 1225 & 345 & $65.7 \%$ \\
\hline & e7 & 353 & 1155 & 802 & 929 & 1233 & 304 & $58.9 \%$ \\
\hline \multirow{5}{*}{28.8} & a8 & 354 & 1108 & 754 & 899 & 1142 & 243 & $50.1 \%$ \\
\hline & b8 & 354 & 1152 & 798 & 878 & 1167 & 289 & $56.2 \%$ \\
\hline & c8 & 353 & 1217 & 864 & 879 & 1218 & 339 & $60.9 \%$ \\
\hline & d8 & 354 & 1157 & 803 & 904 & 1195 & 291 & $56.3 \%$ \\
\hline & e8 & 353 & 1147 & 794 & 903 & 1231 & 328 & $64.2 \%$ \\
\hline \multirow{5}{*}{33,6} & a9 & 353 & 1049 & 696 & 878 & 1022 & 144 & $32.1 \%$ \\
\hline & 69 & 354 & 1098 & 744 & 872 & 1101 & 229 & $47.8 \%$ \\
\hline & $c 9$ & 353 & 1108 & 755 & 868 & 1147 & 279 & $57.4 \%$ \\
\hline & $d 9$ & 354 & 1111 & 757 & 876 & 1165 & 289 & $59.3 \%$ \\
\hline & $e 9$ & 354 & 1081 & 727 & 869 & 1152 & 283 & $60.5 \%$ \\
\hline \multirow{5}{*}{57.6} & a10 & 353 & 1111 & 758 & 874 & 977 & 103 & $21.1 \%$ \\
\hline & b10 & 353 & 1152 & 799 & 870 & 1019 & 149 & $29.0 \%$ \\
\hline & c10 & 351 & 1137 & 786 & 869 & 1056 & 187 & $37.0 \%$ \\
\hline & d10 & 353 & 1161 & 808 & 874 & 1098 & 224 & $43.1 \%$ \\
\hline & elo & 353 & 1134 & 781 & 867 & 1105 & 238 & $47.3 \%$ \\
\hline \multirow{5}{*}{81.6} & all & 353 & 1074 & 721 & 873 & 931 & 58 & $12.5 \%$ \\
\hline & b11 & 353 & 1118 & 765 & 864 & 956 & 92 & $18.7 \%$ \\
\hline & c11 & 353 & 1140 & 787 & 884 & 999 & 115 & $22.7 \%$ \\
\hline & d11 & 353 & 1138 & 785 & 875 & 1017 & 142 & $28.1 \%$ \\
\hline & el1 & 353 & 1110 & 757 & 878 & 1043 & 165 & $33.9 \%$ \\
\hline \multirow{5}{*}{105.6} & a12 & 353 & 1106 & 753 & 873 & 932 & 59 & $12.2 \%$ \\
\hline & b12 & 352 & 1149 & 797 & 871 & 941 & 70 & $13.6 \%$ \\
\hline & c12 & 353 & 1154 & 801 & 874 & 969 & 95 & $18.4 \%$ \\
\hline & d12 & 353 & 1153 & 800 & 877 & 989 & 112 & $21.7 \%$ \\
\hline & e12 & 353 & 1150 & 797 & 866 & 1010 & 144 & $28.1 \%$ \\
\hline
\end{tabular}


Appendix B Test T-18

2/9/95

\begin{tabular}{|lr|l|}
\hline & grams & \% by wh of water \\
\hline Nukon: Class 3\&4 & 142 & $0.0032 \%$ \\
Sludge A & 71 & $0.0016 \%$ \\
Mix A & 0 & $0.0000 \%$ \\
\hline Total & 213 & $0.0048 \%$ \\
\hline
\end{tabular}

Chugging lasts 9.6 minutes

\begin{tabular}{|c|c|c|c|c|c|c|c|c|}
\hline \multirow{2}{*}{$\begin{array}{c}\text { Time } \\
\text { (Full scale } \\
\text { minutes) }\end{array}$} & \multirow{2}{*}{ Label } & \multicolumn{2}{|c|}{ Sample Bottles (g) } & \multirow{2}{*}{$\begin{array}{l}\text { Water (g) } \\
\text { full-empty }\end{array}$} & \multicolumn{2}{|c|}{ Filters $(0.1 \mathrm{mg})$} & \multirow{2}{*}{$\begin{array}{l}\text { Residue } \\
\text { used-new }\end{array}$} & \multirow{2}{*}{$\begin{array}{l}\text { \% of average initial } \\
\text { calculated concentration }\end{array}$} \\
\hline & & empy & full & & new & used & & \\
\hline \multirow{5}{*}{2.4} & al & 353 & 1112 & 759 & 862 & 1278 & 416 & $113.5 \%$ \\
\hline & b1 & 358 & 1165 & 807 & 874 & 1180 & 306 & $78.5 \%$ \\
\hline & cl & 357 & 1161 & 804 & 877 & 1566 & 689 & $177.5 \%$ \\
\hline & dl & 357 & 1173 & 816 & 872 & 1227 & 355 & $90.1 \%$ \\
\hline & el & 353 & 1136 & 783 & 866 & 1211 & 345 & $91.2 \%$ \\
\hline \multirow{5}{*}{4.8} & 22 & 353 & 1183 & 830 & 871 & 1218 & 347 & $86.6 \%$ \\
\hline & $b 2$ & 357 & 1207 & 850 & 864 & 1243 & 379 & $92.3 \%$ \\
\hline & c2 & 357 & 1189 & 832 & 873 & 1266 & 393 & $97.8 \%$ \\
\hline & d2 & 353 & 1186 & 833 & 874 & 1226 & 352 & $87.5 \%$ \\
\hline & e2 & 353 & 1149 & 796 & 865 & 1191 & 326 & $84.8 \%$ \\
\hline \multirow{5}{*}{7.2} & a3 & 352 & 1163 & 811 & 868 & 1216 & 348 & $88.9 \%$ \\
\hline & b3 & 353 & 1157 & 804 & 859 & 1189 & 330 & $85.0 \%$ \\
\hline & c3 & 354 & 1164 & 810 & 855 & 1229 & 374 & $95.6 \%$ \\
\hline & $\mathrm{d} 3$ & 352 & 1159 & 807 & 861 & 1265 & 404 & $103.7 \%$ \\
\hline & e3 & 353 & 1241 & 888 & 868 & 1279 & 411 & $95.8 \%$ \\
\hline \multirow{5}{*}{9.6} & a4 & 353 & 1120 & 767 & 871 & 1195 & 324 & $87.5 \%$ \\
\hline & $b 4$ & 353 & 1230 & 877 & 857 & 1294 & 437 & $103.2 \%$ \\
\hline & $c 4$ & 353 & 1121 & 768 & 859 & 1340 & 481 & $129.7 \%$ \\
\hline & d4 & 353 & 1160 & 807 & 854 & 1266 & 412 & $105.7 \%$ \\
\hline & e4. & 353 & 1145 & 792 & 858 & 1249 & 391 & $.102 .2 \%$ \\
\hline \multirow{5}{*}{14.4} & 25 & 353 & 1030 & 677 & 864 & 1065 & 201 & $61.5 \%$ \\
\hline & b5 & 352 & 1076 & 724 & 857 & 1089 & 232 & $66.4 \%$ \\
\hline & c5 & 352 & 1109 & 757 & 858 & 1140 & 282 & $77.1 \%$ \\
\hline & d5 & 353 & 1097 & 744 & 856 & 1146 & 290 & $80.7 \%$ \\
\hline & es & 353 & 1061 & 708 & 883 & 980 & 97 & $28.4 \%$ \\
\hline \multirow{5}{*}{19.2} & a6 & 352 & 1148 & 796 & 880 & 1341 & 461 & $119.9 \%$ \\
\hline & $b 6$ & 352 & 1206 & 854 & 865 & 1216 & 351 & $85.1 \%$ \\
\hline & $\infty$ & 352 & 1136 & 784 & 875 & 1209 & 334 & $88.2 \%$ \\
\hline & d6 & 353 & 1120 & 767 & 874 & 1113 & 239 & $64.5 \%$ \\
\hline & 6 & 353 & 1137 & 784 & 871 & 1206 & 335 & $88.5 \%$ \\
\hline \multirow{5}{*}{24} & a7 & 352 & 1139 & 787 & 877 & 1117 & 240 & $63.2 \%$ \\
\hline & b7 & 353 & 1167 & 814 & 903 & 1162 & 259 & $65.9 \%$ \\
\hline & c7 & 353 & 1166 & 813 & 894 & 1146 & 252 & $64.2 \%$ \\
\hline & d7 & 351 & 1170 & 819 & 903 & 1163 & 260 & $65.7 \%$ \\
\hline & e7 & 353 & 1168 & 815 & 911 & 1176 & 265 & $67.3 \%$ \\
\hline & a8 & 354 & 1093 & 739 & 872 & 1047 & 175 & $49.0 \%$ \\
\hline & b8 & 354 & 1142 & 788 & 884 & 1126 & 242 & $63.6 \%$ \\
\hline 28.8 & c8 & 353 & 1148 & 795 & 880 & 1132 & 252 & $65.6 \%$ \\
\hline & d8 & 354 & 1142 & 788 & 852 & 1103 & 251 & $66.0 \%$ \\
\hline & es & 353 & 1135 & 782 & 898 & 1152 & 254 & $67.3 \%$ \\
\hline & 29 & 353 & 1199 & 846 & 907 & 1136 & 229 & $56.1 \%$ \\
\hline & 69 & 354 & 1193 & 839 & 917 & 1153 & 236 & $58.3 \%$ \\
\hline 33.6 & c9 & 353 & 1169 & 816 & 906 & 1169 & 263 & $66.7 \%$ \\
\hline & d9 & 354 & 1159 & 805 & 863 & 1108 & 245 & $63.0 \%$ \\
\hline & eq & 354 & 1167 & 813 & 849 & 1077 & 228 & $58.1 \%$ \\
\hline & 210 & 353 & 1168 & 815 & 865 & 941 & 76 & $19.3 \%$ \\
\hline & b10 & 353 & 1163 & 810 & 850 & 962 & 112 & $28.6 \%$ \\
\hline 57.6 & c10 & 351 & 1152 & 801 & 851 & 998 & 147 & $38.0 \%$ \\
\hline & d10 & 353 & 1162 & 809 & 856 & 1023 & 167 & $42.7 \%$ \\
\hline & elo & 353 & 1159 & 806 & 852 & 1025 & 173 & $44.4 \%$ \\
\hline & all & 353 & 1103 & 750 & 906 & 942 & 36 & $9.9 \%$ \\
\hline & b11 & 353 & 1144 & 791 & 860 & 930 & 70 & $18.3 \%$ \\
\hline 81.6 & cll & 353 & 1159 & 806 & 849 & 941 & 92 & $23.6 \%$ \\
\hline & d11 & 353 & 1141 & 788 & 845 & 956 & 111 & $29.2 \%$ \\
\hline & ell & 353 & 1136 & 783 & 854 & 972 & 118 & $31.2 \%$ \\
\hline & 212 & 353 & 1166 & 813 & 849 & 885 & 36 & $9.2 \%$ \\
\hline & b12 & 352 & 1157 & 805 & 890 & 939 & 49 & $12.6 \%$ \\
\hline 105.6 & c12 & 353 & 1170 & 817 & 878 & 935 & 57 & $14.4 \%$ \\
\hline & d12 & 353 & 1146 & 793 & 881 & 957 & 76 & $19.8 \%$ \\
\hline & el2 & 353 & 1148 & 795 & 893 & 997 & 104 & $27.1 \%$ \\
\hline
\end{tabular}




\begin{tabular}{|c|c|}
\hline $\begin{array}{l}\text { NRC FORM } 335 \\
\text { (2.89) } \\
\text { NRCM 1102, } \\
\text { 3201, } 3202, \\
\\
\text { BIBLIOG. NUCLEAR REGULATORY COMMISSION } \\
\text { (See instructions on the reverse) }\end{array}$ & $\begin{array}{l}\text { 1. REPORT NUMBER } \\
\text { (Assigned by NRC, Add Vol, Supp., Rev., and Addendum } \\
\text { Numbers, if any.) } \\
\text { NUREG/CR-6368 } \\
\text { SEA } 95-554-06-A: 9\end{array}$ \\
\hline \multirow{3}{*}{$\begin{array}{l}\text { 2. TITLE AND SUBTITLE } \\
\text { Experimental investigation of Sedimentation of LOCA-Generated Fibrous } \\
\text { Debris and Sludge in BWR Suppression Pools }\end{array}$} & DATE REPORT PUBLISHED \\
\hline & \begin{tabular}{c|c} 
MONTH & YEAR \\
December & 1995 \\
\end{tabular} \\
\hline & $\begin{array}{r}\text { 4. FIN OR GRANT NUMBER } \\
\text { W6459 }\end{array}$ \\
\hline $\begin{array}{l}\text { 5. AUTHOR(S) } \\
\text { F. J. Souto and D. V. Rao }\end{array}$ & $\begin{array}{l}\text { 6. TYPE OF REPORT } \\
\text { Technical }\end{array}$ \\
\hline & 7. PERIOD COVERED (Inclusive Dates) \\
\hline
\end{tabular}

Science and Engineering Associates, Inc.

6100 Uptown Blvd. NE

Albuquerque, NM 87110

9. SPONSORING ORGANIZATION - NAME AND ADDRESS (If NRC, type "Same as above"; ff contractor, provlde NRC Divislon, Offlce or Reglon, U.S. Nuclear Commission and malling address.)

Division of Engineering Technology

Office of Nuclear Regulatory Research

U.S. Nuclear Regulatory Commission

Washington, DC 20555-0001

10. SUPPLEMENTARY NOTES

M. L. Marsha11, Jr., A. W. Serkiz, NRC Project Managers

11. ABSTRACT (200 words or less)

Several tests were conducted in a 1:2.4 scale model of a Mark I suppression pool to investigate the behavior of fibrous insulation and sludge debris under LOCA conditions. NUKON ${ }^{\mathrm{TM}}$ shreds, manually cut and tore up in a leaf shredder, and iron oxide particles were used to simulate fibrous and sludge debris, respectively. The suppression pool model included four downcomers fitted with pistons to simulate the steam-water oscillations during chugging expected during a LOCA. The study was conducted to provide debris settling velocity data for the models used in the BLOCKAGE computer code, developed to estimate the ECCS pump head loss due to clogging of the strainers with LOCA generated debris. The tests showed that the debris, both fibrous and particulate, remains fully mixed during chugging; they also showed that, during chugging, the fibrous debris underwent fragmentation into smaller sizes, including individual fibers. Measured concentrations showed that fibrous debris settled slower than the sludge, and that the settling behavior of each material is independent of the presence of the other material. Finally, these tests showed that the assumption of considering uniform debris concentration during strainer calculations is reasonable. The tests did not consider the effects of the operation of the ECCS on the transport of debris in the suppression pool.

12. KEY WORDS/DESCRIPTORS (List word or phrases that will ass/st researchers in locating the report.)

Suppression Pool Phenomena

Debris Transport

BWR Suction Strainers

\begin{tabular}{|c|c|}
\hline \multicolumn{2}{|c|}{$\begin{array}{c}\text { 13. AVAILABILITY STATEMENT } \\
\text { Unlimited }\end{array}$} \\
\hline 14. & SECURITY CLASSIFICATION \\
\hline & $\begin{array}{l}\text { (This Page) } \\
\text { Unclassified }\end{array}$ \\
\hline & $\begin{array}{l}\text { (This Report) } \\
\text { Unclassified }\end{array}$ \\
\hline & IUMBER OF PAGES \\
\hline & \\
\hline
\end{tabular}

